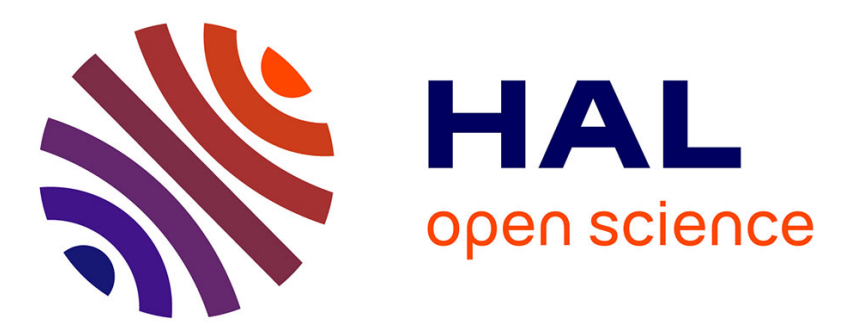

\title{
Recent Developments in the Meyer-Schuster Rearrangement
}

Frédéric Justaud, Ali Hachem, René Grée

\section{To cite this version:}

Frédéric Justaud, Ali Hachem, René Grée. Recent Developments in the Meyer-Schuster Rearrangement. European Journal of Organic Chemistry, 2021, 2021 (4), pp.514-542. 10.1002/ejoc.202001494 . hal-03269552

HAL Id: hal-03269552

\section{https://hal-univ-rennes1.archives-ouvertes.fr/hal-03269552}

Submitted on 29 Jun 2021

HAL is a multi-disciplinary open access archive for the deposit and dissemination of scientific research documents, whether they are published or not. The documents may come from teaching and research institutions in France or abroad, or from public or private research centers.
L'archive ouverte pluridisciplinaire HAL, est destinée au dépôt et à la diffusion de documents scientifiques de niveau recherche, publiés ou non, émanant des établissements d'enseignement et de recherche français ou étrangers, des laboratoires publics ou privés. 


\title{
Recent developments in the Meyer-Schuster rearrangement
}

\author{
Frédéric Justaud, ${ }^{[a]}$ Ali Hachem, ${ }^{[b]}$ and René Grée* ${ }^{* a]}$
}

Dedication: Most of this review article has been prepared during Covid 19 pandemy. Therefore, we dedicate it, -first to all persons who unfortunately died from this disease and, -second to all people (medical doctors and many others) who helped their congeners to survive to this pandemy.

[a] Dr René Grée, Univ Rennes, CNRS (Institut for Chemical Sciences in Rennes), UMR 6226, 35000 Rennes, France. E-mail: rene.gree@univ-rennes1.fr [b] Lebanese University, Faculty of Sciences (I), Laboratory for Medidinal Chemistry and Natural Products and PRASE-EDST, Hadath, Lebanon

Abstract: The Meyer-Schuster rearrangement is an efficient method to prepare $\alpha, \beta$-unsatured carbonyl compounds starting from propargylic alcohols and this review presents the remarkable progress made during the last decade in this reaction. New efficient catalytic systems have been discovered and many elegant applications have been reported for this rearrangement. To be noticed in particular are the new and efficient cascade processes affording a wide range of carboand heterocyclic molecules. Moreover, brilliant applications of this rearrangement have been described as well, in the total synthesis of complex natural products and their analogues. Finally, the first examples of aza-Meyer-Schuster rearrangements have been described also recently.

\section{Introduction}

The Meyer-Schuster rearrangement (MSR), which is the acid-mediated transformation of propargylic alcohols 1 into conjugated carbonyl derivatives 2 , has been discovered close to a century ago. ${ }^{[1]}$ The generally accepted mechanism involves the formation of carbenium ion intermediates 3-3', which are hydrolyzed to allenols 4 and the $\alpha, \beta$-unsaturated carbonyl derivatives $\mathbf{2}$ are obtained after prototropy (Scheme 1). On the other hand, trapping of allenols intermediates by electrophilic species $\mathrm{E}^{+}$afford the $\alpha$-substituted compounds 5. Both types of $\alpha, \beta$-unsaturated carbonyls 2 and $\mathbf{5}$ are obviously very useful intermediates for the preparation of all kind of organic targets, including complex natural products and their analogues. Therefore it is not surprising that the MSR has been intensively developed since its discovery. Two comprehensive reviews have been published to describe the progress of this reaction, ${ }^{[2]}$ with the most recent in 2009. ${ }^{[3]}$ Some other, more focused, excellent reviews have also been presented, such as one on "intercepted Meyer- Schuster". ${ }^{[4]}$ On the other hand gold catalysis, as well as transition metal-catalyzed reactions of propargylic derivatives, have been much studied during the last decade, and therefore the progress for MSR has also been included in corresponding review articles. ${ }^{[5,6]}$

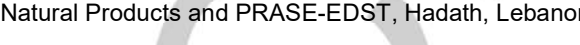


analogues published during the last 10 years. The final part will be dealing with the recent developments of the azaanalogue of MSR.

\section{New catalytic systems leading to $\alpha, \beta-$ unsaturated carbonyl derivatives via MSR.}

In this part, we will focus essentially on the methodological developments performed recently and starting from standard propargylic alcohols. The catalysts employed during cascade reactions starting by a MSR or in the total synthesis of natural products and their structural analogues will be presented respectively in parts 3 and 4 .

\subsection{Reactions affording type-2 enones with $\mathrm{H}$ in vicinal position}

\subsubsection{Brønsted acids}

Numerous MSR studies using all kind of Brønsted acids and affording type-2 derivatives have been already reported previously. ${ }^{[1,2]}$ A few more examples have been described during the last 10 years (Table 1). For the solution phase chemistry, examples involved p-toluenesulfonic acid at 30 $\mathrm{mol} \%$ in DCE at $60^{\circ} \mathrm{C},{ }^{[8]}$ as well as phosphorous acid at 50 wt $\%$ at $110^{\circ} \mathrm{C} .^{[9]} \mathrm{A}$ new series of active reagents are the highly electron deficient fluoroaromatics containing boronic acids. They performed MSR at $20 \mathrm{~mol} \%$ in toluene at temperatures ranging from r.t. to $50^{\circ} \mathrm{C}$ for a wide range of substrates. ${ }^{[10]}$ The hemiaminals $\mathbf{6}$, which are intermediates obtained by condensation of propargyl aldehydes with secondary amines, are an interesting case. For these molecules, the stereochemical outcome of MSR was depending mainly upon the nature of the acid: with benzoic acid, the $E$ isomers 8 were obtained while the use of $\mathrm{TsOH}$ gave mainly, or exclusively, the $Z$ isomer 7 of the enaminones (Scheme 2). ${ }^{[11 \mathrm{a}]}$
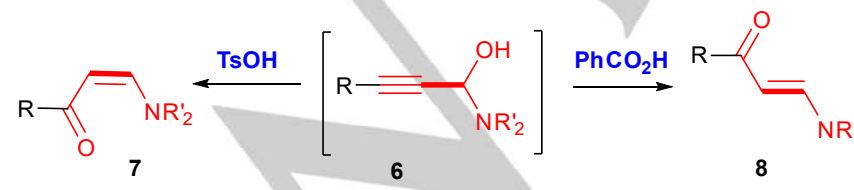

$\mathrm{R}=\mathrm{Ar}$, alkyl, cycloalkyl

Scheme 2. Stereocontrolled MSR in the case of hemiaminals.

Interestingly, a direct condensation of arylpropiolaldehydes with secondary amines, in ethanol and without acid catalysis, also gave the $Z$ enaminones. ${ }^{[11 b]}$

Supported acidic reagents have been also employed. For instance, heteropolyacids 9 proved to be useful since some stereocontrol was observed during MSR. While the acid $\mathrm{H}_{3}\left[\mathrm{PMo}_{12} \mathrm{O}_{40}\right] \cdot n \mathrm{H}_{2} \mathrm{O} 9 \mathrm{a}$ afforded essentially the E-stereoisomer, the corresponding silver derivative $\mathrm{Ag}_{3}\left[\mathrm{PMO}_{12} \mathrm{O}_{40}\right] \cdot n \mathrm{H}_{2} \mathrm{O}$ 9b gave mostly the Z-isomeric enones. ${ }^{[12]}$ On the other hand, $\mathrm{H} \beta$ zeolite was also able to perform MSR in water at $100^{\circ} \mathrm{C}$, affording three examples of cinnamaldehyde derivatives. ${ }^{[13]}$ Finally, in refluxing toluene and in the presence of acidic alumina, propargylic alcohols and 2-thionaphthol reacted together in a cascade process to give directly the thioacetal of the enal obtained after MSR. ${ }^{14]}$

\begin{tabular}{|c|c|c|c|}
\hline Entry & Acid & Solvent, $\mathrm{T}$ & Ref. \\
\hline 1 & p-TSA (30 mol\%) & $\mathrm{DCE}, 60^{\circ} \mathrm{C}$ & $\begin{array}{l}\text { [8], [11a], } \\
{[55],[76],} \\
{[77 a],[110]}\end{array}$ \\
\hline 2 & $\mathrm{MsOH}$ & & $\begin{array}{c}\text { [53], [54], } \\
\text { [56], [57], } \\
\text { [[68], [77a], } \\
{[110]}\end{array}$ \\
\hline 3 & TFA & & $\begin{array}{c}\text { [43], [71], } \\
\text { [88], [91], } \\
\text { [115] }\end{array}$ \\
\hline $\begin{array}{l}4 \\
5\end{array}$ & $\begin{array}{c}\mathrm{H}_{3} \mathrm{PO}_{2}(50 \mathrm{wt} \%) \\
\mathrm{Ar}_{F} \mathrm{~B}(\mathrm{OH})_{2} \\
(20 \mathrm{~mol} \%)\end{array}$ & $\begin{array}{c}110^{\circ} \mathrm{C} \\
\text { Toluene, } \\
\text { rt- } 50^{\circ} \mathrm{C}\end{array}$ & $\begin{array}{c}{[9]} \\
{[10]}\end{array}$ \\
\hline 6 & $\mathrm{H}_{3} \mathrm{PO}_{4} / \mathrm{DDQ}$ & & [131] \\
\hline 7 & $\begin{array}{c}\mathrm{PhCO}_{2} \mathrm{H} \\
(25 \mathrm{~mol} \%)\end{array}$ & Toluene, $80^{\circ} \mathrm{C}$ & [11a] \\
\hline 8 & $\begin{array}{c}\mathrm{H}_{3}\left[\mathrm{PMO}_{12} \mathrm{O}_{40}\right] \cdot n \mathrm{H}_{2} \mathrm{O} \\
9 \mathrm{a} \text { or } \\
\mathrm{Ag}_{3}\left[\mathrm{PMO} \mathbf{O}_{12} \mathrm{O}_{40}\right] \cdot n \mathrm{H}_{2} \mathrm{O} \\
\mathbf{9 b}(10 \mathrm{~mol} \%)\end{array}$ & $\begin{array}{c}\text { EtOAc, } 50^{\circ} \mathrm{C} \\
\text { or } \\
\text { Acetone, } 50^{\circ} \mathrm{C}\end{array}$ & [12] \\
\hline $\begin{array}{c}9 \\
10\end{array}$ & $\begin{array}{c}\mathrm{H} \beta \text { zeolite } \\
\text { Acidic alumina* }\end{array}$ & $\begin{array}{c}\mathrm{H}_{2} \mathrm{O}, 100^{\circ} \mathrm{C} \\
\text { Toluene, } \\
110^{\circ} \mathrm{C}\end{array}$ & $\begin{array}{c}{[13]} \\
{[14],[77 b]}\end{array}$ \\
\hline
\end{tabular}

*This reaction, performed in the presence of 2-thionaphthol, afforded directly the thioacetal after a cascade MSR-thioacetalization.

Table 1. Recent examples of MSRs mediated by Brønsted acids.

\subsubsection{Lewis acids}

Various Lewis acids have been used as well to perform the MSR during the last decade (Table 2). For instance, $\mathrm{FeCl}_{3}$ 10 has been employed with tertiary propargylic alcohols having a terminal alkyne unit, affording the desired enals in fair to good yields. ${ }^{[15]}$ On the other hand, $\mathrm{BF}_{3} . \mathrm{OEt}_{2} 11$ has been used with phenoxy propargylic alcohols to obtain, with a good stereoselectivity, the Z-conjugated esters. A mechanism involving an electrophilic borylation of an allene intermediate has been proposed to rationalize this stereoselectivity. ${ }^{[16]}$ The same catalyst has been also used 
starting from fluoroalkylated propargylic alcohols, leading to a series of $\beta$-fluoroalkyl- $\alpha, \beta$-enones in moderate to good yields and an excellent $E$-stereoselectivity. ${ }^{[17]}$ MSR was also effectively catalyzed by methyl triflate 12 in trifluoroethanol (TFE) to obtain a broad scope of conjugated $E$-enals and $E$-enones in fair to excellent yields. ${ }^{[18]}$

\begin{tabular}{|c|c|c|c|}
\hline Entry & Acid & Solvent, $\mathrm{T}\left({ }^{\circ} \mathrm{C}\right)$ & ref \\
\hline 1 & $\mathrm{FeCl}_{3} 10$ & & $\begin{array}{c}\text { [15], [21], [90], } \\
\text { [92] } \\
{[125]-[127],} \\
{[132]}\end{array}$ \\
\hline 2 & $\mathrm{BF}_{3} . \mathrm{Et}_{2} \mathrm{O} 11$ & & {$[16],[17],[114]$} \\
\hline$\overline{4}$ & MeOTf 12 & TFE, 70 & [18] \\
\hline 5 & $\mathrm{Sm}(\mathrm{OTf})_{3} 13$ & THF/MW & [19] \\
\hline 6 & $\begin{array}{l}\mathrm{Ph}_{3} \mathrm{PO}(2 \\
\text { equiv) } / \mathrm{Tf}_{2} \mathrm{O} \\
14 \text { ( } 1 \text { equiv) }\end{array}$ & DCM, 0-r.t. & [20] \\
\hline 7 & $\mathrm{Bi}(\mathrm{OTf})_{3} 15$ & DCE, 70 & [61], [63] \\
\hline 8 & $\mathrm{Ca}(\mathrm{OTf})_{2} 16$ & $\begin{array}{l}\text { i-BuOH, 90; } \\
\text { nBu }_{4} \text { NPF }_{6}, 100\end{array}$ & $\begin{array}{l}{[59],} \\
{[89]}\end{array}$ \\
\hline 9 & $\mathrm{Ca}(\mathrm{NTf})_{2} 17$ & & [66] \\
\hline 10 & CuCl 18a & DCM, 70 & {$[40],[70]$} \\
\hline 11 & Cul 18b & $\mathrm{DCM}, 50$ & [51] \\
\hline 12 & $\mathrm{Cu}(\mathrm{OTf})_{2}$ 18c & $\begin{array}{l}\text { Tol., 120; } \\
\text { DCM-EtOH, r.t. }\end{array}$ & [83], [119] \\
\hline 13 & $\mathrm{Sc}(\mathrm{OTf})_{2} 19$ & DCM-EtOH r.t. & [102], [118] \\
\hline 14 & $\mathrm{Fe}(\mathrm{OTf})_{3} 20$ & Dioxane, 100 & [21], [60] \\
\hline 15 & $\mathrm{Yb}(\mathrm{OTf})_{3} 21$ & MeCN, 80 & [128] \\
\hline 16 & $\mathrm{Zn}(\mathrm{OTf})_{2} 22$ & Tol., 100 & [64] \\
\hline 17 & $\mathrm{SnCl}_{2} 23$ & $\mathrm{tBuOH} / \mathrm{H}_{2} \mathrm{O}$ & [120] \\
\hline 18 & $\mathrm{PtCl}_{2} 24$ & Tol., 100 & [72] \\
\hline 19 & $\mathrm{HgCl}_{2} 25$ & Dioxane $/ \mathrm{H}_{2} \mathrm{O}$ & [107] \\
\hline 20 & $\mathrm{HgSO}_{4} 26$ & $\mathrm{THF}, 30$ & [101] \\
\hline 21 & $\mathrm{Pd}(\mathrm{OAc})_{2} 27$ & MeCN, 50 & [52] \\
\hline
\end{tabular}

Table 2. Recent examples of MSRs mediated by Lewis acids.

The potential use of lanthanide triflates for MSR has been confirmed recently and interestingly it was demonstrated that $\mathrm{N}$-fluorosuccinimide (NFSI) was an excellent activator for the catalytic activity of $\mathrm{Sm}(\mathrm{OTf})_{3} 13$. Under these conditions and using MW activation, excellent yields of a large number of transposed enals, enones and esters were obtained. ${ }^{[19]}$ Further, the Hendrickson's reagent 14 prepared by reaction of $\mathrm{Ph}_{3} \mathrm{PO}$ with $\mathrm{Tf}_{2} \mathrm{O}$ performed efficiently the MSR of terminal propargylic alcohols to conjugated enals. ${ }^{[20]}$ Finally, it is interesting to notice that $\alpha$-allenols are also suitable substrates for MSR-type reactions. Under catalysis with $\mathrm{Fe}$ (III) salts, or with triflic acid, they afforded the expected conjugated enones in fair to excellent yields. ${ }^{[21]}$

\subsubsection{Metal catalysts}

A variety of late/transition metal catalysts have been developed during the last decade. Representative examples are given in Table 3 and Figure 1. Gold complexes in particular have been extensively used.

\begin{tabular}{|c|c|c|c|}
\hline Entry & Catalyst & Solvent, $\mathrm{T}\left({ }^{\circ} \mathrm{C}\right)$ & ref. \\
\hline 1 & $\mathrm{AuCl}_{3}$ 28a & r.t. & {$[5],[81]$} \\
\hline 2 & $\mathrm{AuBr}_{3} 28 \mathrm{~b}$ & & [67a] \\
\hline 3 & $\mathrm{Ph}_{3} \mathrm{PAuNTf}_{2} 28 \mathrm{c}$ & & $\begin{array}{c}\text { [21]-[24], [41], } \\
\text { [99], [121] }\end{array}$ \\
\hline 4 & $\left(\mathrm{Ph}_{3} \mathrm{P}\right) \mathrm{AuCl} 28 \mathrm{~d}$ & & $\begin{array}{c}\text { [42], [80], [82], } \\
\text { [113], [122] }\end{array}$ \\
\hline 5 & $\begin{array}{l}{\left[\left(\mathrm{PPh}_{3}\right) \mathrm{AuNTf}_{2}\right]_{2 .} \text { Tol. }} \\
28 \mathrm{e}\end{array}$ & & $\begin{array}{c}{[67 \mathrm{a}],[73]} \\
{[121]}\end{array}$ \\
\hline 6 & $\begin{array}{l}\text { Me4-t-BuXPhosAuCl } \\
28 f, \text { AgOTf 29a } \\
\text { (5 mol\% each) }\end{array}$ & & [31] \\
\hline 7 & $\begin{array}{l}\text { (IPr)AuX with } X=\mathrm{OH} \\
\left(28 \mathrm{~g}_{1}\right), \mathrm{Cl}\left(28 \mathrm{~g}_{2}\right), \mathrm{NTf}_{2} \\
\left(28 \mathrm{~g}_{3}\right)\end{array}$ & & $\begin{array}{l}\text { [25], [58], } \\
\text { [103], [122] }\end{array}$ \\
\hline 8 & $\begin{array}{l}{\left[\{(\mathrm{IPr}) \mathrm{Au}\}_{2}(\mathrm{~m}-\right.} \\
\mathrm{OH})]\left[\mathrm{BF}_{4}\right] 28 \mathrm{~h}\end{array}$ & & $\begin{array}{c}\text { [26], [98], } \\
\text { [100], [103]- } \\
\text { [105], [122] }\end{array}$ \\
\hline 9 & {$[\mathrm{Au}(\mathrm{IPr})]_{2}\left[\mathrm{SO}_{4}\right] 28 \mathrm{i}$} & $\begin{array}{l}\mathrm{MeOH} / \mathrm{H}_{2} \mathrm{O} \\
60\end{array}$ & {$[27]$} \\
\hline 10 & TA-Au 28j & $\mathrm{MeOH}, 60$ & [28] \\
\hline 11 & TA-Au-Me 28k & $\mathrm{MeCN}, 50$ & [44] \\
\hline 12 & FTA-Au 28I & $\begin{array}{l}\mathrm{MeOH} / \mathrm{H}_{2} \mathrm{O} \\
(9 / 1), 40\end{array}$ & [29] \\
\hline 13 & TriaAuCl $28 \mathrm{~m}$ & $\begin{array}{l}\mathrm{MeOH} / \mathrm{H}_{2} \mathrm{O} \\
(9 / 1), 60\end{array}$ & [30] \\
\hline 14 & TA-Py-Au(III) 28n & $\mathrm{MeCN} / \mathrm{H}_{2} \mathrm{O}$ & {$[47]$} \\
\hline 15 & (Johnphos)ÁuCl 280 & & [32], [79] \\
\hline 16 & $\mathrm{LAuCN}, \mathrm{SbF}_{6} 28 \mathrm{p}$ & & [82], [124] \\
\hline 17 & AgOTf $29 a+28 d, 28 a$ & $\begin{array}{l}\text { Heptane or } \\
\text { THF, } 80\end{array}$ & [31a], [80] \\
\hline 18 & $\mathrm{AgSBF}_{6} 29 \mathrm{~b}$ & $\mathrm{MeNO}_{2}$, r.t. & [33] \\
\hline 19 & $\mathrm{AgBF}_{4} 29 \mathrm{c}+28 \mathrm{e}$ & Tol., 100 & [72] \\
\hline 20 & $A g(O A c) 29 d$ & Tol., 100 & [84] \\
\hline 21 & $\begin{array}{l}{\left[\mathrm{Ag}\left\{\mu^{2}-\mathrm{N}, \mathrm{S}-\right.\right.} \\
(\mathrm{PTA})=\mathrm{NP}(=\mathrm{S})(\mathrm{OEt}) 2\}] \\
x[\mathrm{SbF} 6] \times 29 \mathrm{e}\end{array}$ & $\begin{array}{l}\mathrm{H}_{2} \mathrm{O} / \mathrm{MW} / \\
\text { 160/air }\end{array}$ & [34] \\
\hline 22 & $\begin{array}{l}\operatorname{Re}(\mathrm{O}) \mathrm{Cl}_{3}\left(\mathrm{OPPh}_{3}\right) \cdot(\mathrm{SMe} \\
\text { 2) } 30 \mathrm{a}\end{array}$ & $\begin{array}{l}\text { EtOAc, } 70 ; \\
\text { Dioxane, r.t. }\end{array}$ & [63], [95], [96] \\
\hline 23 & $\begin{array}{l}\operatorname{Re}(\mathrm{CO})_{3} \mathrm{Ph}_{2} \mathrm{PCH}_{2} \mathrm{P}\{] \mathrm{N} \\
\left.\mathrm{P}(] \mathrm{S})(\mathrm{OPh})_{2}\right\} \mathrm{Ph}_{2}, \mathrm{SbF}_{6} \\
30 \mathrm{~b}\end{array}$ & THF/MW/80 & [35] \\
\hline 24 & $\mathrm{nBu}_{4} \cdot \mathrm{ReO}_{4} 30 \mathrm{c}$ & DCM, r.t. & [38] \\
\hline 25 & $\mathrm{Ph}_{3} \mathrm{SiOReO}_{3}$ 30d & $\mathrm{Et}_{2} \mathrm{O}$, r.t. & [38] \\
\hline 26 & $\begin{array}{l}{\left[\mathrm{Ru}\left(3-2-\mathrm{C}_{3} \mathrm{H}_{4} \mathrm{Me}\right)(\mathrm{CO})\right.} \\
(\mathrm{dppf})]\left[\mathrm{SbF}_{6}\right] 31\end{array}$ & sealed tube & [93a] \\
\hline 27 & $\begin{array}{l}{\left[\mathrm{IrCp}^{*}(\mathrm{NCMe})_{2}\left(\mathrm{PPh}_{2} \mathrm{Me}\right.\right.} \\
)][\mathrm{PF}]_{2} 32\end{array}$ & DCM, r.t. & [36] \\
\hline & $\begin{array}{l}\mathrm{MoO}_{2}(\mathrm{acac})_{2} 33 / \\
\mathrm{AuCl}(\mathrm{PPh} 3) 28 \mathrm{~d} / \\
\text { AgOTf 29a }\end{array}$ & Tol., r.t. & $\begin{array}{l}\text { [108], [109], } \\
{[112],[117]}\end{array}$ \\
\hline 28 & {$\left[\mathrm{VO}\left(\mathrm{OSiPh}_{3}\right)\right] 34 \mathrm{a}$} & & $\begin{array}{c}{[39],[75],} \\
{[106],[109]} \\
{[111]}\end{array}$ \\
\hline 29 & {$\left[\mathrm{~V}(\mathrm{O}) \mathrm{Cl}(\mathrm{OEt})_{2}\right] 34 \mathrm{~b}$} & Tol./MW/80 & {$[37]$} \\
\hline 30 & $\mathrm{VOCl}_{3} 34 \mathrm{c}$ & DCM, r.t. & [48] \\
\hline 31 & $\mathrm{VO}(\mathrm{acac})_{2} 34 \mathrm{~d}$ & Tol., 80 & [94] \\
\hline
\end{tabular}

Table 3. Recent examples of MSRs mediated by metal catalysts.

The simple complex $\mathrm{Ph}_{3} \mathrm{PAuNTf} \mathrm{H}_{2}$ 28c, with methanol or boric acids, was able to induce MSR from various propargylic alcohols. ${ }^{[22]} \mathrm{MSR}$ occured as well in the presence of various protic additives, but for those having $\mathrm{pK}$ around 7-9 such as $p$-nitrophenol and with not to sterically hindered propargylic alcohols, the addition of water becomes possible to give the aldol-type equivalent. ${ }^{[23]}$ It has also been used in the case of 
a cyclopropyl propargylic internal alcohol to prepare the corresponding enone. ${ }^{[24]}$ The NHC-derived gold catalysts proved to be very powerful catalysts. Starting from Nolan's key intermediate $\mathbf{2 8} \mathbf{g}_{1},{ }^{[25]}$ several useful catalysts have been described such as the di-gold species $28 \mathrm{~h}$ which can be used for MSR at low catalyst loadings ( 0.1 to $0.5 \mathrm{~mol} \%$ ) without any additive such as acids or other metals. ${ }^{[26]}$ Another possibility was to prepare gold complexes from mineral acids such as nitric, phosphoric or sulfuric acid. These species, and particularly the last one (a di-gold complex sulfate) $28 \mathbf{i}$ proved to be very efficient as well to perform MSR. ${ }^{[27]}$

The cheaper triazole-gold catalyst $\mathbf{2 8} \mathbf{j},{ }^{[28]}$ as well as the corresponding furan-triazole derivative (FTA-Au) 28I, ${ }^{[29]}$ also performed very well the MSR reaction at low catalyst loadings. Further, the easily available triazole acetyl gold complex 28m (at $1 \mathrm{~mol} \%$ ) gave the enones in good yields and with an excellent $E$ stereselectivity. ${ }^{[30]}$

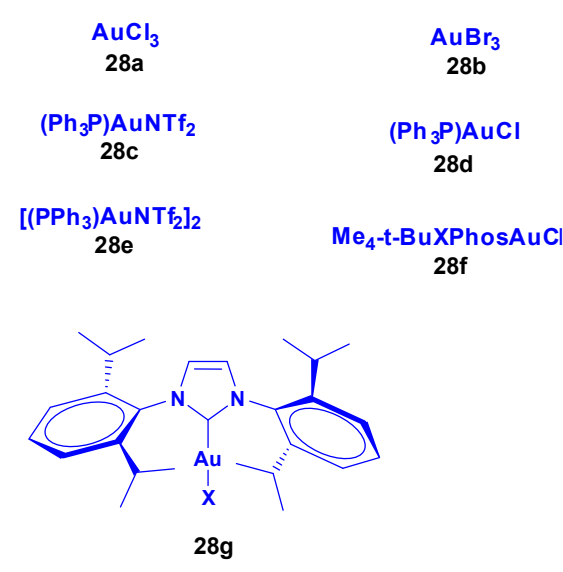

(IPr)AuX with $X=\mathrm{OH}(28 \mathrm{~g} 1), \mathrm{Cl}(28 \mathrm{~g} 2), \mathrm{NTf}_{2}(28 \mathrm{~g} 3)$

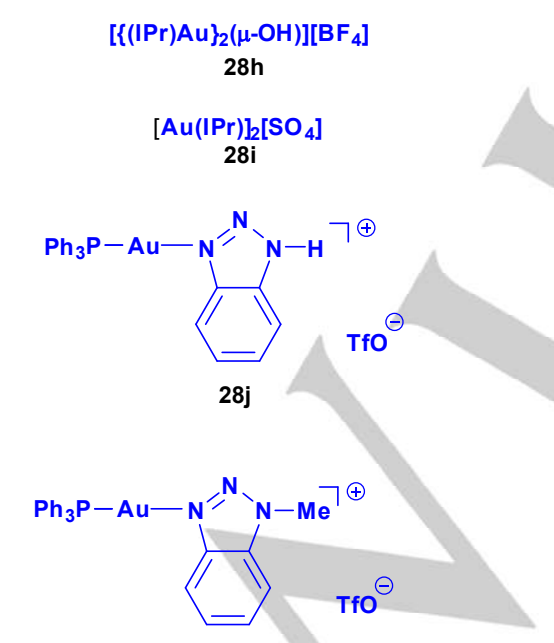

28k

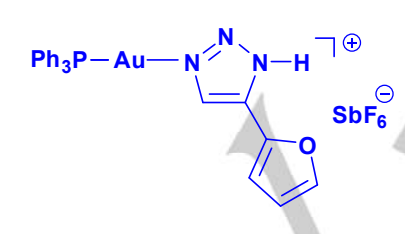

281

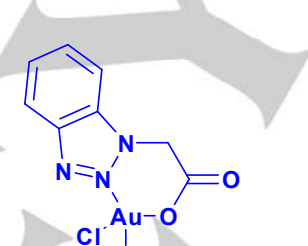

$\mathrm{Cl}$
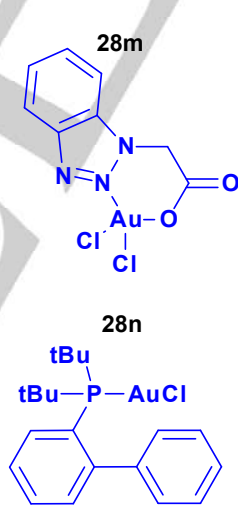

280

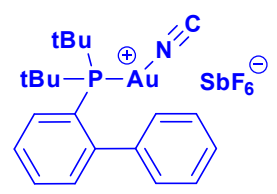

$28 p$
$\operatorname{AgOTf}(29 a), \operatorname{AgSBF}_{6}(29 b)$, $\mathrm{AgBF}_{4}(29 \mathrm{c}), \mathrm{Ag}(\mathrm{OAc})(29 \mathrm{~d})$

$\left[\mathrm{Ag}\left\{\mu^{2}-\mathrm{N}, \mathrm{S}-(\mathrm{PTA})=\mathrm{NP}(=\mathrm{S})(\mathrm{OEt})_{2}\right\}\right] \times\left[\mathrm{SbF}_{6}\right] \mathrm{x}$ with PTA $=1,3,5$-triaza-7-phosphaadamantane 29 e

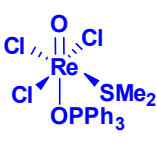

$30 \mathrm{a}$

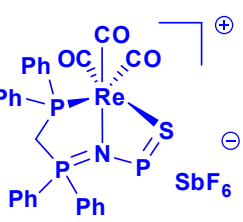

$30 \mathrm{~b}$

$\begin{array}{cc}\mathrm{nBu}_{4} \cdot \mathrm{ReO}_{4} & \mathrm{Ph}_{3} \mathrm{SiOReO}_{3} \\ 30 \mathrm{c} & 30 \mathrm{~d}\end{array}$

$\left[R u\left(\eta 3-2-C_{3} H_{4} M e\right)(C O)(d p p f)\right]\left[S_{3 b F}\right]$

31

$\left[\operatorname{IrCp}^{*}\left(\mathrm{NCMe}_{k}\left(\mathrm{PPh}_{2} \mathrm{Me}\right)\right]\left[\mathrm{PF}_{6}\right]_{2}\right.$

$$
\mathrm{MoO}_{2}(\mathrm{acac})_{2}
$$

33

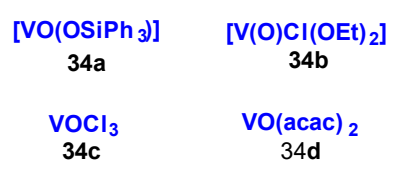

Figure 1. Representative examples of catalysts used recently, for instance in cascade reactions starting with MSR (Part 3) and/or MSR used in the total syntheses of natural products and analogues (Part 4).

\section{Accepted nananuscript}


The combination of gold with silver catalysts is particularly efficient and excellent examples will be described in the application of MSR to the total synthesis (part 4). A peculiar case was the use of an appropriate combination of $28 \mathrm{f}$ with AgOTf (29a) catalysts for the stereocontrolled synthesis of conjugated enamides through a tandem reaction (Scheme 3 ). Reaction of primary amides on propargylic aldehydes gave intermediate hemiaminals $\mathbf{3 5}$ which were submitted immediately to MSR to produce the targets $36^{[31 \mathrm{a}]}$ The stereoselectivity of the reaction ( $E$ versus $Z$ ) can be controlled by the choice of the solvent and/or by addition of catalytic amounts of acids. This approach has been successfully extended to corresponding sulfonamides. ${ }^{[31 \mathrm{~b}]}$

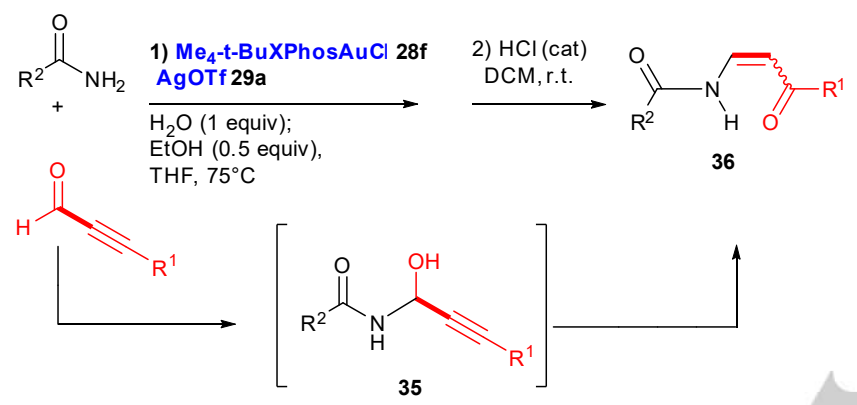

Scheme 3. Use of MSR for the stereoselective synthesis of enamides.

A combination of a gold catalyst $\mathbf{2 8 0}$ with copper triflate was also efficient to perform MSR. ${ }^{[32]}$ Further, several silver salts alone, and $\mathrm{AgSBF}_{6}(\mathbf{2 9 b})$ was the best, also performed well MSR starting from tertiary propargylic alcohols. ${ }^{[33]}$

New (iminophosphorane) $\mathrm{Ag}(\mathrm{I})$ coordination polymers 29e proved to be efficient catalyst precursors for MSR and such systems could be recycled several times with only little loss in activity. ${ }^{[34]}$ Further, iminophosphorane-phosphines are good ligands for rhenium complexes, such as $\mathbf{3 0 b}$, which afforded MSR for terminal propargylic alcohols into conjugated enals. ${ }^{[35]}$

The iridium complex $\mathbf{3 2}$, at $5 \mathrm{~mol} \%$ in dichloromethane at room temperature, gave a small library of conjugated enals. ${ }^{[36]}$ On the other hand, the readily available complex $\left[\mathrm{V}(\mathrm{O}) \mathrm{Cl}(\mathrm{OEt})_{2}\right] 3 \mathbf{3 4 b}$, in toluene at $80^{\circ} \mathrm{C}$ and under microwave irradiation, also gave MSR products in good yields. ${ }^{[37]}$

The MSR could be employed also for a novel preparation of useful $\alpha, \beta$-unsaturated acylsilanes $\mathbf{3 8}$, as indicated in Scheme 4 . This reaction involved rhenium-oxo complexes, such as $\mathbf{3 0}$ or $\mathbf{3 0 d}$, with or without acids such as p-TSA. ${ }^{[38]}$

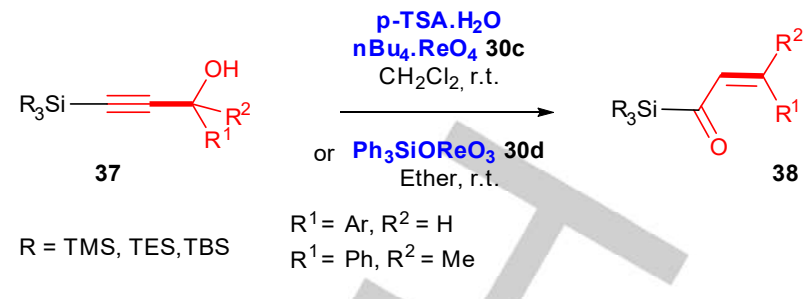

Scheme 4. MSR used for a new preparation of $\alpha, \beta$-unsaturated acylsilanes.

\subsection{Reactions affording type-5 enones with various $E$ atoms/groups in vicinal position}

The major intermediates in MSR, the allenols, could be trapped under appropriate conditions by other electrophilic species than a proton and this will ultimately afford new $\mathrm{C}-\mathrm{C}$ bond formation, as well as new C-halogen or C-heteroatom bonds. Similarly, the intermediates involved in the different metal- or transition metalmediated MSRs could be trapped by various species to afford new $\alpha, \beta$-substituted enones 5. All these transformations will obviously require a fine tuning of the properties of the catalytic system in charge of the MSR, relative to the reagents/catalysts in charge of creating the new $\mathrm{C}-\mathrm{C}$ or $\mathrm{C}-\mathrm{Z}$ bond. Corresponding results will be presented in this part and we will first consider the formation of $\mathrm{C}-\mathrm{C}$ bond during MSR.

\subsection{1- allyl-substituted $\alpha$-enones}

A remarkable example was reported by B. M. Trost's group in $2011 .{ }^{[39]}$ They developed a cross-coupling reaction of a vanadiummediated MSR with a Pd-catalyzed allylation process (Scheme 5).

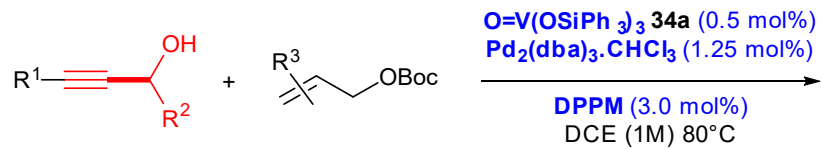

$$
\begin{aligned}
& \begin{array}{ll}
\mathrm{R}^{3} & \begin{array}{l}
\mathrm{R}^{1}=\text { alkyl, cycloalkyl, OEt, } \mathrm{N}(\mathrm{Bn}) \mathrm{Ts} \\
\mathrm{R}^{2}=\mathrm{H}, \text { alkyl, Ar }
\end{array}
\end{array}
\end{aligned}
$$

Scheme 5. Combination of MSR with a Pd-mediated allylation to afford $\alpha$-allylated $\alpha, \beta$-unsaturated ketones.

Extensive studies have been performed regarding the nature of the two catalysts, as well as the phosphine ligands, the solvents and the reaction conditions, in order to limit the competitive processes such as the classical MSR. Using 34a for the vanadium-mediated MSR and under optimized conditions, the desired transformation occured with a remarkable broad scope for

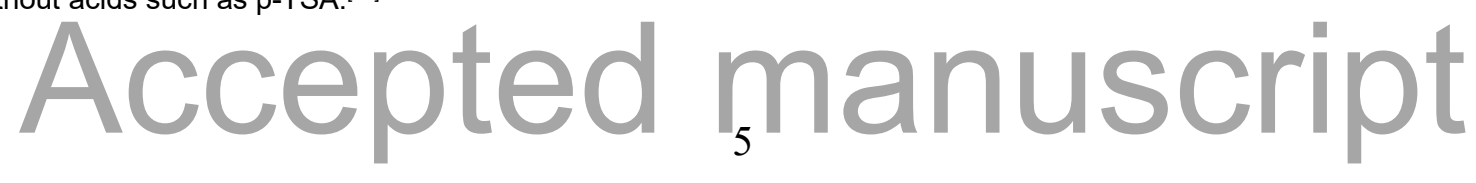


alcohols 39 , affording enones as well as unsaturated esters and amides 40 . It has been employed to prepare modified steroids.

\subsection{2- aryl-substituted $\alpha$-enones}

Three examples of arylative MSRs have been described to date. In a first case, the arylation has been performed using diaryliodonium salts and copper catalysts (Scheme 6). ${ }^{[40]}$ Starting from propargylic alcohols, the successful coupling was obtained using diphenyl iodonium triflate $\mathbf{4 1}$ and $\mathrm{CuCl}$ 18a as catalyst in the presence of an hindered base. Various types of propargylic alcohols could be used, as well as several iodonium salts 41 , giving the desired enones $\mathbf{4 2}$ in good yields. This could be extended to oestrone derivatives, as well as to the preparation of biologically relevant 3,4-diarylpyrazoles.
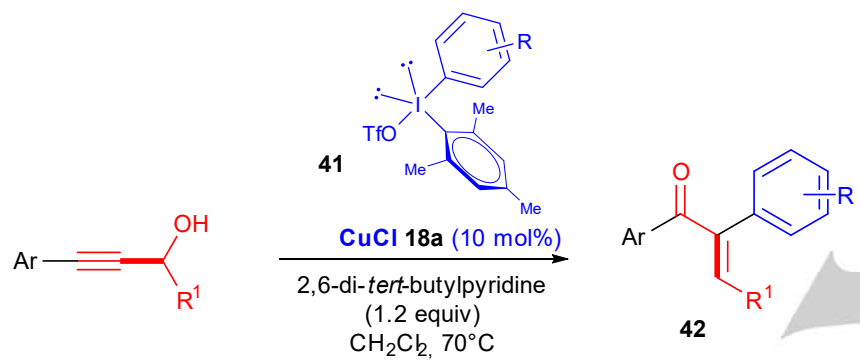

Scheme 6. Arylative MSR using iodonium salts.

A second method used a gold-ruthenium-photoredox $(28 c+43)$ co-catalyzed reaction to prepare the target molecules. In that case, diazonium salts were employed as reactive species to introduce the aromatic groups (Scheme 7). ${ }^{[41]}$ This cascade reaction provided a large variety of target molecules $\mathbf{4 5}$ in fair to good yields. It has been performed, as well, starting from an alkynyl hydroperoxide.

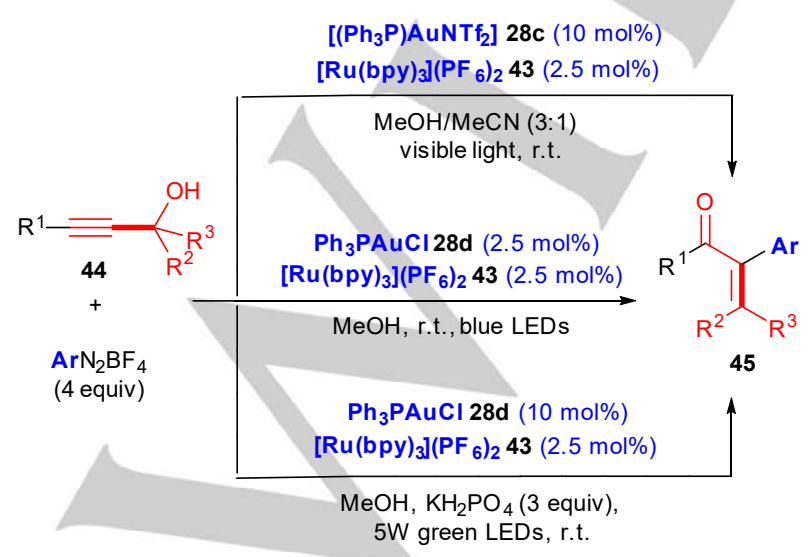

Scheme 7. Domino MSR-arylation reaction of propargylic alcohols.
More recently, two groups have reported a similar method, using now $\mathrm{Ph}_{3} \mathrm{PAuCl} \mathbf{2 8 d}$ at lower loading as catalyst and blue ${ }^{[42 \mathrm{a}]}$ or green $^{[42 b]}$ LEDs. Another group has described a method using a new, stable, Au/Ru heterobimetallic catalyst with a [2.2] paracyclophane backbone. ${ }^{[42 c]}$ Further, examples involving intramolecular Friedel-Crafts reactions will be reported in the part 3.

A special case was the introduction of an arylsulfido moiety vicinal to the carbonyl group toward the compound 46. This was performed by reaction of various types of propargylic alcohols (including primary ones) with a range of aryl sulfoxides in excess and in the presence of triflic acid (0.2 equiv) in nitromethane (Scheme 8). ${ }^{[43]}$

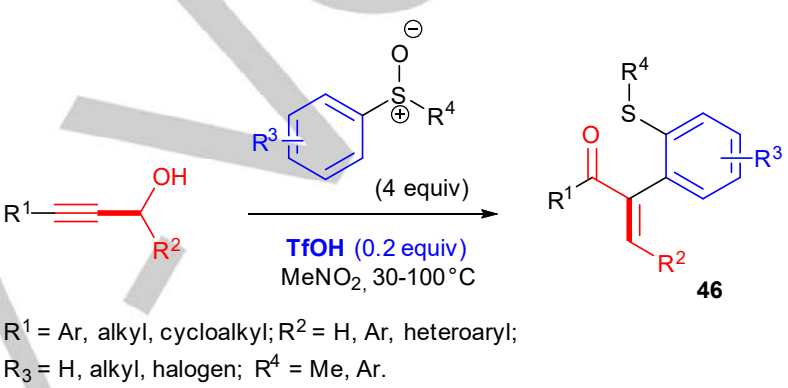

Scheme 8. MSR used for the preparation of $\alpha$-arylsulfido enones.

\subsection{3- alkynyl-substituted $\alpha$-enones}

Very recently, a gold-catalyzed alkynylative MSR has been reported (Scheme 9). ${ }^{[44]}$ It involved reaction of propargylic alcohols with ethynylbenziodoxolones in the presence of gold catalysts. After optimization studies, the catalyst $\mathbf{2 8 k}$ proved to give the best results and a wide range of target molecules $\mathbf{4 8}$ could be obtained in good to excellent yields.
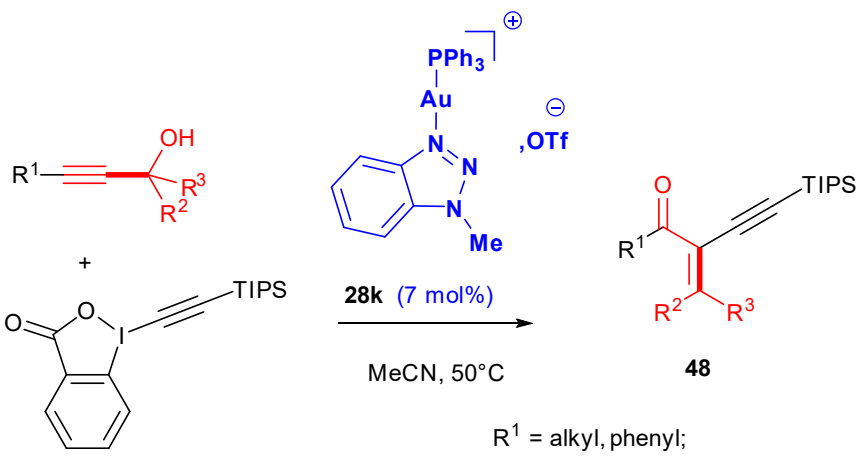

$$
\begin{aligned}
& \mathrm{R}^{1}=\text { alkyl, phenyl; } \\
\mathrm{R}^{2}, \mathrm{R}^{3}= & \mathrm{H}, \text { alkyl, Ar, heteroaromatic }
\end{aligned}
$$

Scheme 9. Gold-catalyzed alkynylative MSR.

\subsection{4- Halogeno-substituted $\alpha$-enones}

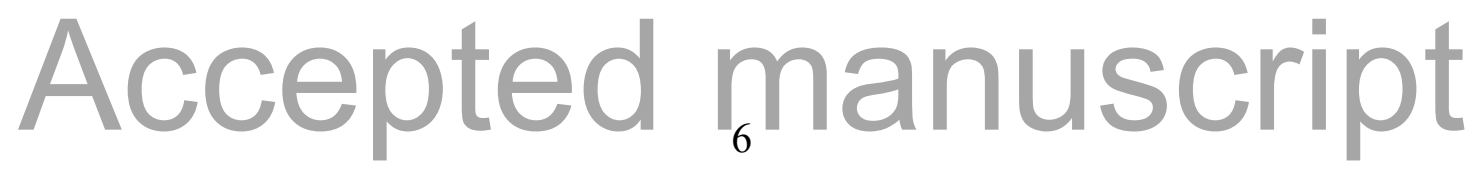




\begin{tabular}{|c|c|c|c|c|c|c|c|}
\hline Entry & $\mathrm{R}^{1}$ & $\mathrm{R}^{2}$ & $\mathrm{R}^{3}$ & Halogenation reagent/ $\mathbf{X}$ & Catalyst & solvent & Ref. \\
\hline 1 & OEt/OPh & $\begin{array}{l}\text { H, alkyl, } \\
\text { cycloalkyl, Ar }\end{array}$ & $\mathrm{H}$, alkyl, $\mathrm{Ar}$ & $\mathrm{I}_{2}$ or $\mathrm{NIS}($ 2equiv)/I & no & $\begin{array}{l}\text { Toluene/(OEt), } \\
\mathrm{CH}_{2} \mathrm{Cl}_{2} /(\mathrm{OPh})\end{array}$ & {$[445]$} \\
\hline 2 & $\mathrm{Ar}$ & $\mathrm{Ar}$ & $\mathrm{Ar}, \mathrm{H}, \mathrm{Me}$ & $\mathbf{I}_{2}$ (2equiv)/ I & no & THF & {$[46]$} \\
\hline 3 & $\mathrm{Bu}, \mathrm{Ph}$ & $\mathrm{Ar}$ & $\mathrm{H}, \mathrm{Me}$ & $\mathrm{NXS} / \mathrm{I}, \mathrm{Br}$, and TCICA/Cl & TA-Py-Au(III) 28n & $\mathrm{MeCN} / \mathrm{H}_{2} \mathrm{O}$ & {$[47]$} \\
\hline 4 & $\operatorname{Ar}$ & $\operatorname{Ar}$ & $\mathrm{Ar}, n-\mathrm{Pr}$ & NIS/ I & $\mathrm{AgSBF}_{6} 29 \mathrm{~b}$ & $\mathrm{MeNO}_{2}$ & [33] \\
\hline 5 & Alkyl & $\mathrm{Ar}$ & $\mathrm{H}$ & $\mathrm{NXS} / \mathrm{I}, \mathrm{Cl}$ & $\mathrm{VOCl}_{3} 34 \mathrm{c}$ & $\mathrm{CH}_{2} \mathrm{Cl}_{2}$ & [48] \\
\hline
\end{tabular}

Table 4. Examples of MSRs used for the preparation of $\alpha$-halogeno enones.

Next, the formation of C-halogen bond during MSR will be considered. Several methods have been developed for the preparation of $\alpha$-halogeno enones $\mathbf{4 9}$, as indicated in Scheme 10 and Table 4.

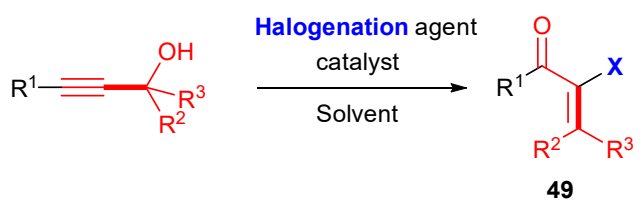

$\mathbf{X}=\mathrm{I}, \mathrm{Br}, \mathrm{Cl}$

Scheme 10. MSR used for the preparation of $\alpha$-halogeno enones.

The halogen atoms have been introduced by using $\mathrm{N}$-halogeno succinimides or by iodine. Some reactions have been performed using only halogenation reagents (entries 1 and 2), ${ }^{[45,46]}$ while in other cases gold catalyst $\mathbf{2 8 n}$ (entry 3$)^{[47]}$ or silver catalyst $\mathbf{2 9 b}$ (entry 4$)^{[33]}$ have been employed. Trapping of the intermediate allenol by the electrophilic halogenation agent was a possible mechanism for these transformations. In the last example (entry $5), \mathrm{VOCl}_{3} 34 \mathrm{c}$ was used as a reagent in excess. ${ }^{[48]}$ In that case, the reaction proceeded likely via a propargyl vanadyl ester which was transposed into an allenolate ester, with a final addition of the halogen atom. When $34 \mathrm{c}$ and NIS were used, 1:2 mixtures of the chloro- and iodo-enones were obtained, indicating a possible competition between external and internal delivery of the halogens.

Finally, it is interesting to notice that, to the best of our knowledge, few examples have been reported to date of the use of MSR for the preparation of $\alpha$-fluoro enones. Such derivatives were obtained earlier as minor by-products in a gold and Selectfluor ${ }^{\circledR}$ mediated C-C coupling reaction. ${ }^{49 a]}$ On the other hand, starting from propargylic acetates and using $\mathrm{NHC}$ carbenes with the same fluorinating agent, the target enones were isolated in good to excellent yields. ${ }^{[49 b]}$ In the same way, to the best of our knowledge, there is no example of introduction of silicon- or tin-substituted groups in $\alpha$-position of enones using MSR.
Another possibility to prepare $\alpha$-halo enones has been reported starting from propargylic acetates 50 (Scheme 11). ${ }^{[50 a]}$

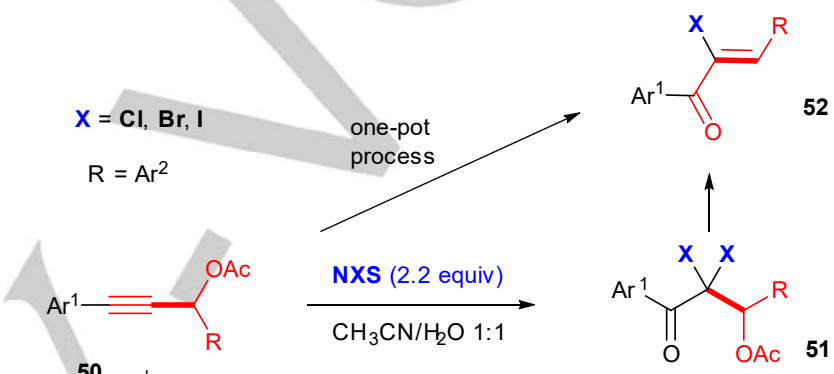

50

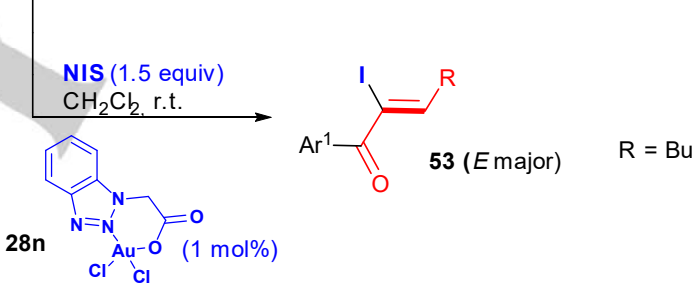

Scheme 11. Preparation of $\alpha$-halogeno-enones from propargylic acetates.

Reaction with $\mathrm{N}$-halogenosuccinimides gave the gem-dihalogeno ketones 51, which could be isolated. On further heating under the reaction conditions, or by reaction with an hindered base like diisopropylethylamine, the $\alpha$-halogeno enones $\mathbf{5 2}$ were obtained. These products could be prepared as well in a one-pot process. Then, corresponding iodo derivatives were used in classical Sonogashira-type reactions. Alternatively, triazole acetyl gold (III) catalyst 28n, already used for the classical MSR, gave the iodo $\alpha$-enones $\mathbf{5 3}$ when the reaction was performed in the presence of $\mathrm{NIS} .{ }^{[30]}$ It hast to be noticed that type-51 dihalo alcohols have been obtained also by dihalohydration of propargylic alcohols using, or not, gold catalysts. However for these transformations a mechanism has been proposed, which does not involve MSR. ${ }^{[50 b]}$

\section{Accepted manuscript}




\subsection{5- $\mathrm{CF}_{3}$-substituted $\alpha$-enones}

Introduction of $\mathrm{a} \mathrm{CF}_{3}$ group vicinal to the enone appeared also as an attractive challenge, taking into account the number of possible biologically important relevant targets. Therefore a cascade reaction involving first the MSR, and then a copper-catalyzed trifluoromethylation, was successfully demonstrated as indicated in Scheme 12. ${ }^{[51]}$ To introduce a $\mathrm{CF}_{3}$ group the authors used Togni's reagent $\mathbf{5 5}$ and a careful screening of the reaction conditions indicated that Cul was the best copper catalyst. Further, the reaction was performed in the presence of pyruvic acid. Under these optimized conditions and starting from tertiary propargylic alcohols $54\left(R^{1}\right.$ and $R^{2}$ different from $H$ ), the desired products 56 were obtained in fair to good yields. In the case of secondary alcohols (54 with $R^{1}=H$ ), slightly different reaction conditions were developed with the use of Cul at $15 \mathrm{~mol} \%$ and without additive. Under these conditions the desired enones were obtained in fair yields and with a good $E: Z$ stereoselectivity. Representative examples of corresponding enones could be transformed into isoxazoles such as $\mathbf{5 7}$ by reaction with hydroxylamine and a one-pot procedure was also established for the preparation of these heterocycles.

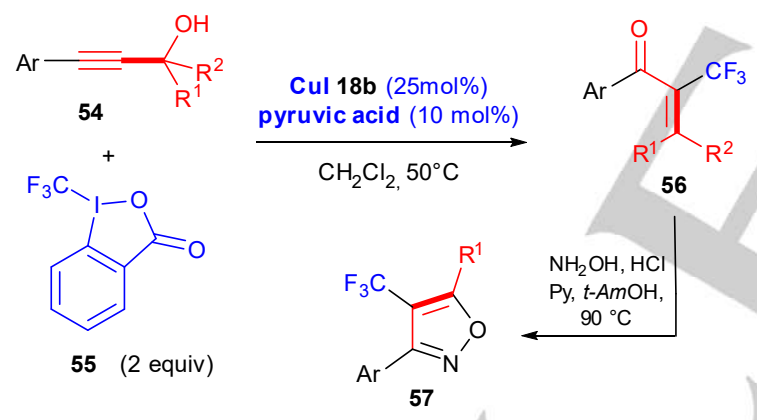

Scheme 12. MSR used for the preparation of $\alpha-\mathrm{CF}_{3}$ enones. 2.2.6- $\alpha$-nitro enones

The use of the MSR for a direct introduction of a nitro group in position vicinal to the carbonyl of the enones was also successfully performed (Scheme 13). ${ }^{[52]}$

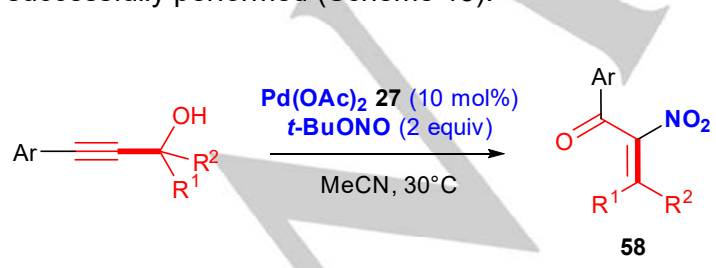

Scheme 13. MSR used for the preparation of $\alpha$-nitro enones.
The MSR was induced by palladium catalysis, while the nitro group was introduced by using tertio-butyl nitrite. The choice of palladium acetate 27 in acetonitrile provided the optimized reaction conditions. Starting from various types of tertiary propargylic alcohols, the desired nitro enones $\mathbf{5 8}$ were obtained in good yields.

\subsection{7- Reactions starting from Z-enoates propargylic}

alcohols

The (Z)-enoate propargylic alcohols are a special and very attractive class of substrates for the MSR since they offer specific reactivities, as indicated in Scheme 14 . Due to the $Z$ geometry of the starting alcohols 59, the acidic conditions induced the formation of the cyclic oxonium ions $\mathbf{6 0}$. From these intermediates several process can occur, depending on the reaction conditions and especially the nature of the acid used. When the counteranion of this acid was nucleophilic enough, the final products were the $\alpha$-substituted derivatives $61\left(X=\mathrm{Cl}\right.$, OMs, OTs). If $X^{-}$was a too weak nucleophile, the intermediate $\mathbf{6 0}$ reacted with water to afford the vicinal dicarbonyl derivatives $62 .{ }^{[53]}$ On the other hand when the reaction mixture contained some nucleophilic species compatible with the reaction conditions such as electron rich arenes, latter nucleophiles can trap the intermediates $\mathbf{6 0}$ to give the $\alpha$-aryl substituted derivatives $63 .{ }^{[54]}$

Further, with aromatic substituents in proper position such as 64, an intramolecular Friedel-Crafts process can occur to afford the dihydronaphtalene derivatives 65 . In that case, the $\alpha$-aryl enone became included in a cycle. ${ }^{[55]}$ On the other hand, the trapping of the intermediate ion $\mathbf{6 0}$ with a 1,3 bisnucleophile such as a naphthol 66 afforded the naphtofurans 67 . This approach could be used for the synthesis of benzofurans as well. ${ }^{[56]}$
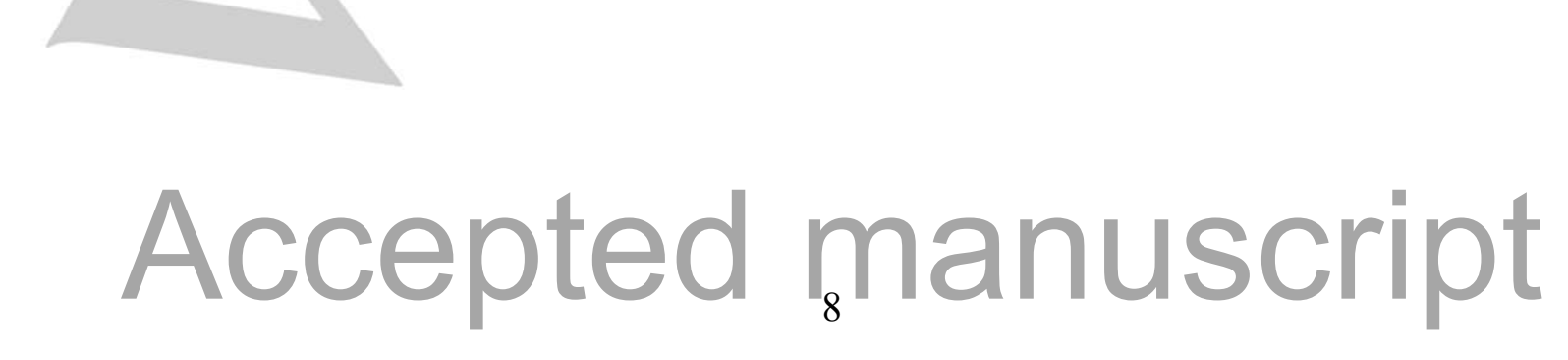


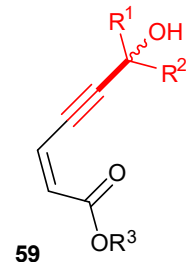

59

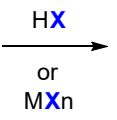

$\mathrm{MXn}$

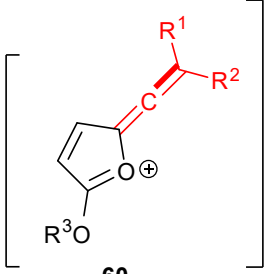

60

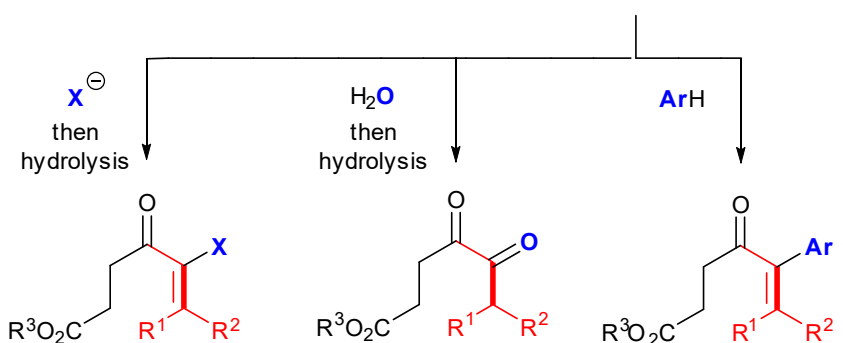

61

62<smiles>[R][Y]1ccc2c(c1)C(C(=O)CCC(=O)OCC)=C([R])CC=2</smiles>

59

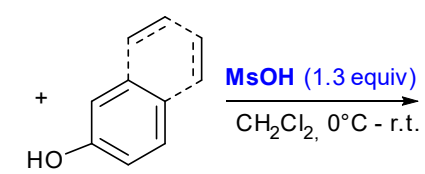
66

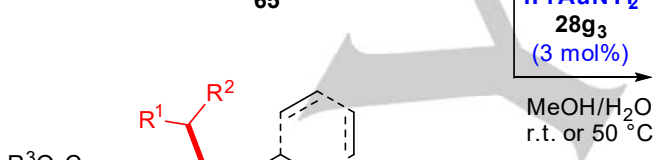

$\mathrm{R}^{1}, \mathrm{R}^{2}=$ alkyl, aryl

\section{Cascade reactions starting by a Meyer Schuster Rearrangement.}

\subsection{MSRs followed by intermolecular 1,4 additions}

The MSRs afford $\alpha, \beta$-unsaturated carbonyl derivatives, therefore it is not surprising that cascade reactions involving MSR followed by 1,4 additions have been developed during the last decade. We will present first the intermolecular additions leading to new $\mathrm{C}-\mathrm{C}$ bond formations, and then the addition of nucleophiles with heteroatoms yielding new $\mathrm{Nu}-\mathrm{C}$ bonds.

In the area of $\mathrm{C}-\mathrm{C}$ bond formation, this cascade approach has been used for the preparation of $\beta$-disubstituted ketones as indicated in Scheme 16.
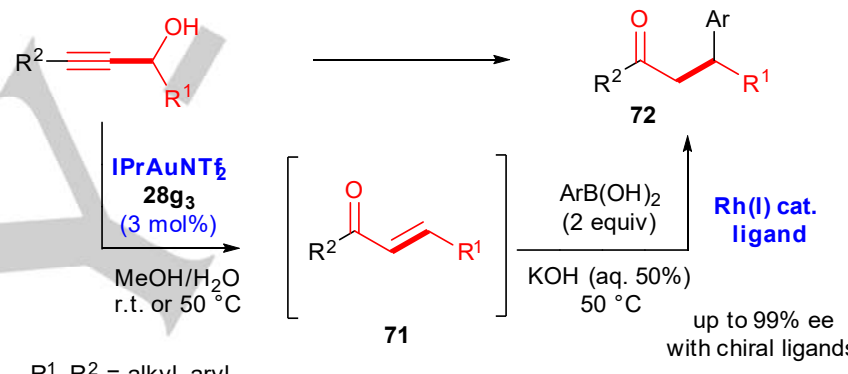

Scheme 14. MSRs starting from (Z)-enoate propargylic alcohols.

Finally, it was also possible to start from similar enals $\mathbf{6 8}$, offering a new pathway to prepare, through intermediate 69 , interesting acylfurans $\mathbf{7 0}$ related to some sesquiterpene-type natural products (Scheme 15). ${ }^{[57]}$

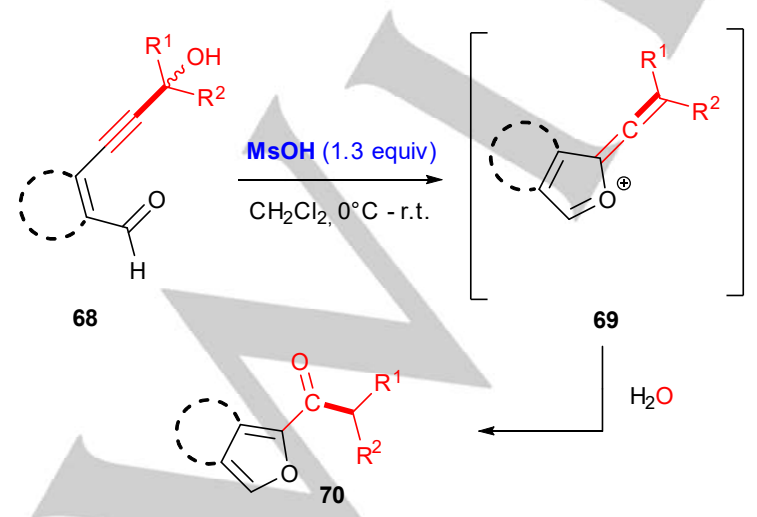

Scheme 15. MSRs starting from (Z)-enal propargylic alcohols.

Scheme 16. One-pot cascade MSR-conjugate addition.

A combined gold-rhodium catalysis proved to be very successful in that case. The $\mathrm{Au}(\mathrm{l})$ catalysed MSR afforded the intermediate enones 71 used immediately in a Rh-catalyzed boronic acid 1,4addition to access the desired ketones $\mathbf{7 2}$ in a one-pot process. Under optimized conditions, this transformation had a large scope. Furthermore, it proved to be suitable for asymmetric catalysis by appropriate choice of the chiral ligands on rhodium to avoid any competition with the gold catalyst used for the MSR. By using Hayashi's diene ligand, high ee's (up to 99\%) could be obtained for this 1,4 -addition step. ${ }^{[58]}$

Excellent results have been obtained also in the oxindole family as indicated in Scheme 17. ${ }^{[59]}$ Starting from propargyl alcohols 73, the MSR was best performed using a mixture of calcium triflate 16 and tetrabutyl ammonium salt to afford the enones 74 which were isolated in fair to excellent yields. These derivatives reacted with 2-methylquinolines, in an anti-Michael mode, to give the

\section{Accepted ņanuscript}


adducts $75 \mathbf{a}$, and a one-pot procedure was also established to obtain such compounds. In an interesting extension, the enamino esters, obtained in situ by condensation of aniline with ethylacetoacetate, reacted with the enones $\mathbf{7 4}$ to give the addition products $\mathbf{7 5 b}$. This step was followed immediately by a cyclization to afford the pyrroles 76. Here also a one-pot, three components (propargyl alcohols, $\beta$-keto-esters and anilines), synthesis was demonstrated
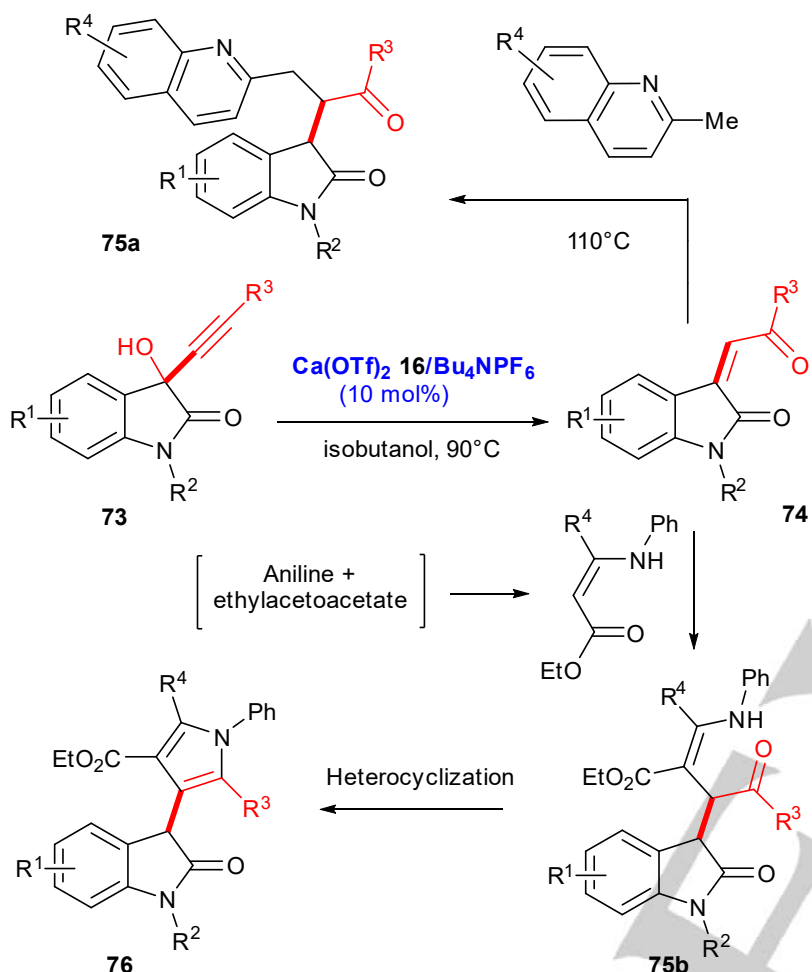

74

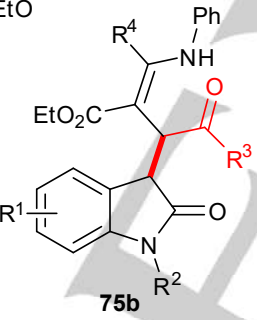

Scheme 17. Cascade MSR-C-C bond formation in the oxindole series.

The addition of heteroatomic nucleophilic species has been considered as well. Michael addition of nitrogen nucleophiles was not an obvious process, taking into account the acidic reaction conditions usually employed for MSR. However, it was successfully performed by using tosylamines (Scheme 18). In that case, $\mathrm{Fe}(\mathrm{OTf})_{3} 20$ proved to be the catalyst of choice and addition of tosylamines occurred smoothly to give the target molecules $\mathbf{7 7}$. This transformation did not occur with tertiarty propargylic alcohols. Finally, this method was employed for the preparation of the drug Fluoxetine, in racemic form. ${ }^{[60]}$

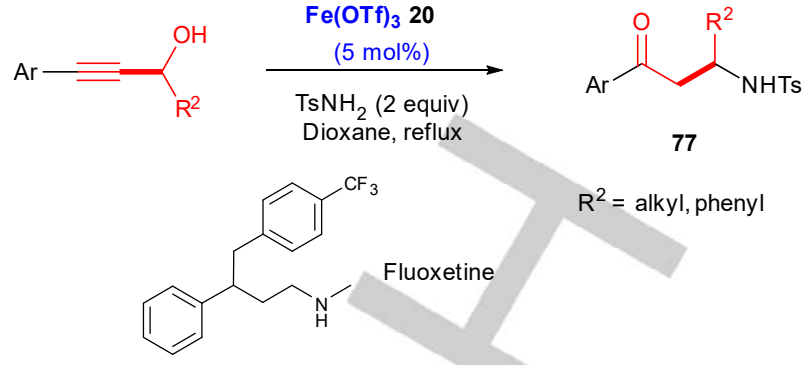

Scheme 18 . Synthesis of $\beta$-amino ketones by a cascade MS hydroamination process.

Oxygen-based nucleophiles also performed 1,4-additions after MSR (Scheme 19). Propargylic alcohols reacted with $\mathrm{Bi}(\mathrm{OTf})_{3} 15$ at $5 \mathrm{~mol} \%$ to give the intermediate enones, which were trapped by various types of alcohols, affording the ethers 78 . This reaction worked best with propargylic alcohols bearing electron rich $\mathrm{Ar}$ groups. Sterically hindered alcohols and phenols did not react under these conditions. Small amounts of by-products, such as enones resulting from $\mathrm{ROH}$ elimination, were also obtained in few cases. Further, with propargylic alcohols having an appropriate carbamate in ortho substituent on the Ar aromatic group, an intramolecular addition occurred, affording a dihydroquinolone derivative, as described later. ${ }^{[61]}$

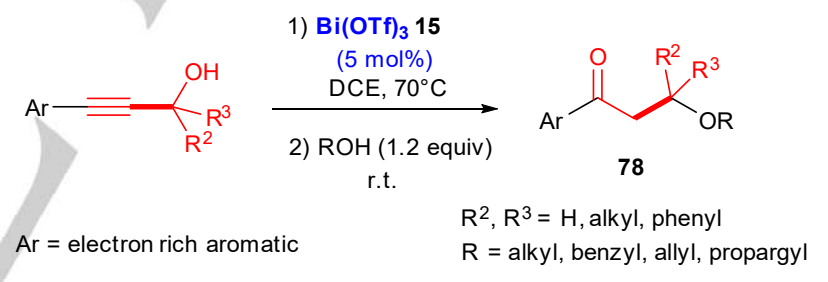

Scheme 19. One-pot cascade MSR-alcohol addition.

Thiols have been employed to obtain $\beta$-sulfanyl ketones as indicated in Scheme 20. A first example was reported using the $\operatorname{Re}(\mathrm{V})$ oxo complex $30 \mathrm{a}$ to perform the MSR, followed by addition of various types of thiols, affording the desired ketones $\mathbf{7 9}$ in good to excellent yields. ${ }^{[62]}$ In a second example, $\mathrm{Bi}(\mathrm{OTf})_{3} 15$ was used as the catalyst for the MSR reaction, followed by the thia-Michael addition to afford adducts $\mathbf{8 0}$. ${ }^{[63]}$ 


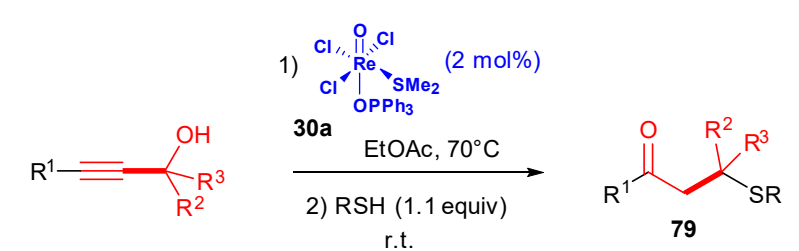

$\mathrm{R}^{1}, \mathrm{R}^{2}, \mathrm{R}^{3}=$ alkyl, Ar; $\mathrm{R}=$ alkyl, benzyl, Ar $\quad \mathrm{R}=\mathrm{Ar}$, alkyl, benzyl
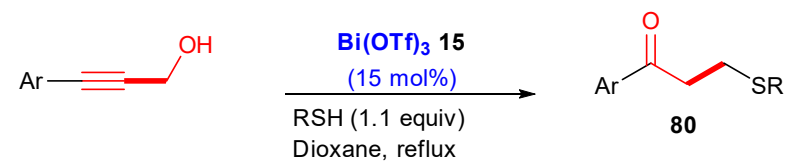

Scheme 20. One-pot cascade MSR-thia Michael addition.

Similar approaches have been exploited for the introduction of phosphorus nucleophiles (Scheme 21).

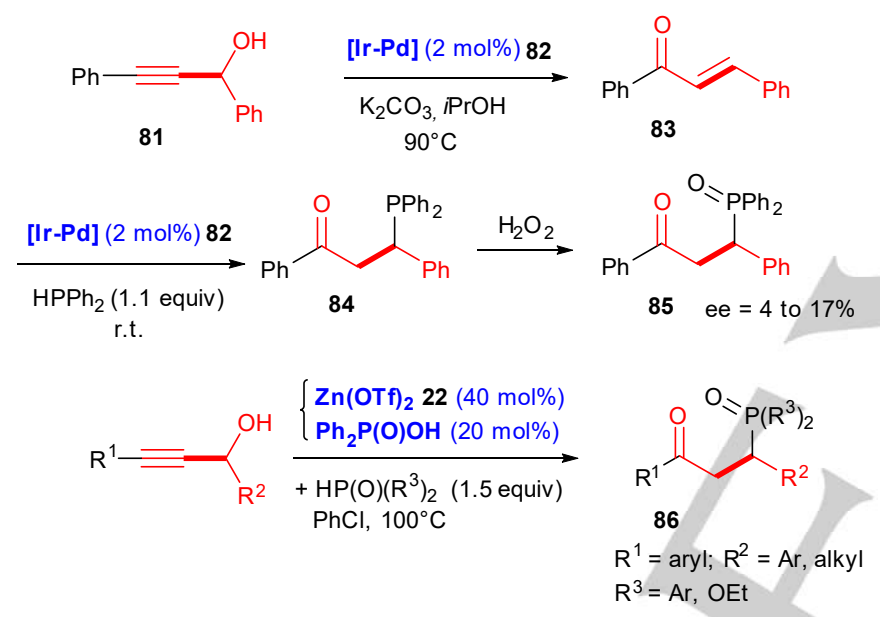

Scheme 21. MSR followed by phosphine addition.

First, starting from the diphenyl propargylic alcohol 81, and using several heterodimetallic Iridium-Palladium complexes $\mathbf{8 2}$, it was possible to perform the MSR, followed by the addition of diphenyl phosphine to get $\mathbf{8 4}$. This compound was transformed into the more stable oxide 85. Extension to asymmetric catalysis was explored, but only low ee's were obtained. ${ }^{[64]}$ More recently, a reaction catalyzed by zinc triflate $\mathbf{2 2}$ has been developed. Screening of potential additives established than addition of $\mathrm{Ph}_{2} \mathrm{P}(\mathrm{O}) \mathrm{OH}$ to the zinc catalyst proved to be very fruitful and under those conditions, a wide range of $y$-ketophosphine oxides 86 were obtained in fair to good yields. ${ }^{[65]}$

\subsection{MSR followed by intramolecular 1,4-additions}

We will consider first the $\mathrm{C}-\mathrm{C}$ bond formation in the context of the elegant studies by Gandon's group (Scheme 22). ${ }^{[66]}$ Starting from $\beta$-keto esters tethered to remote propargylic alcohols 87 , the MSR was performed by gallium and calcium catalysts. This was the first report of the use of such metals in the MSR. The calcium bistriflamide 17 proved to be better in that case and therefore it was employed in the next experiments. Five products could be obtained, depending mainly upon the reaction conditions. First, the combination of calcium bis-triflamide and potassium hexafluorophosphate in dichloromethane delivered smoothly the desired enones 88 resulting from MSR (pathway A). ${ }^{[66 a, 66 b]}$ Addition of molecular sieves to ensure completely anhydrous conditions afforded the cyclic ether derivatives $\mathbf{8 9}$. In the absence of water, the MSR was not observed and trapping of the allenyl carbenium anion by the carbonyl oxygen built a O-C bond during the cyclization (Cond. D).

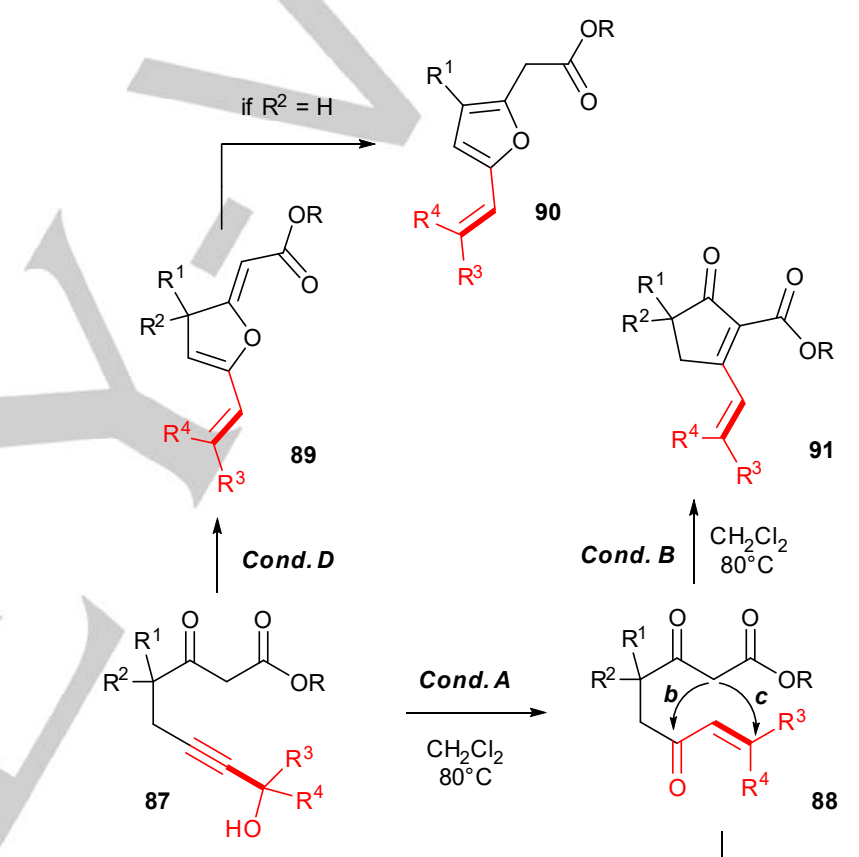

Cond. A: $\mathrm{Ca}\left(\mathrm{NTf}_{2}\right)_{2} 17$ (5 mol\%), $\mathrm{KPF}_{6}(5 \mathrm{~mol} \%)$ Cond. B: $(R, R)$-TUC (20 mol\%)

Cond. C: $\mathrm{Ca}\left(\mathrm{NTf}_{2}\right)_{2} 17(5 \mathrm{~mol} \%), \mathrm{KPF}_{6}(5 \mathrm{~mol} \%)$ i-PrOH (5 equiv)

Cond. D: $\mathrm{Ca}\left(\mathrm{NTf}_{2}\right)_{2} 17$ (10 $\left.\mathrm{mol} \%\right) \mathrm{KPF}_{6}(10 \mathrm{~mol} \%)$,

$(R, R)$-TUC

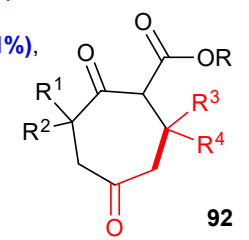

Scheme 22. Ca (II) MSRs followed by intramolecular cyclizations.

Further, when $\mathrm{R}^{2}$ was hydrogen, an aromatization process could occur to yield the furans $\mathbf{9 0}$. Such derivatives are interesting models for natural cembranolides for instance. ${ }^{[66 c]}$ On the other hand, reaction of enones 88 with $(R, R)$-TUC, the Takemoto's catalyst, gave the intramolecular aldol condensation yielding the electrophilic cyclopentenones 91 (Cond. B). ${ }^{[66 c]}$ Finally, when the reaction of propargylic alcohols with the catalysts was performed 
in the presence of isopropanol, the seven-membered cyclic systems 92 were obtained through intermediate 88 (pathway C). ${ }^{[66 a]}$ Extensive mechanistic and computational studies have been performed to rationalize these selectivites. ${ }^{[66 b]}$

Next, we will consider the $\mathrm{N}-\mathrm{C}$ bond formation in the intramolecular processes after the MSR. The 2-substituted piperidine is a scaffold found in many alkaloids such as coniine, sedamine and pelletierine for instance. It was easily accessible by using a MSR starting from propargylic alcohols 93. ${ }^{[67 a]}$ Reaction with the gold(I) complex 28e, at $1 \mathrm{~mol} \%$ with 1 equivalent of methanol, afforded the desired piperidines 94 in fair to good yields (Scheme 23). The cascade process occurred already at room temperature. On the other hand, (hard) gold (III) catalysts, such as $\mathrm{AuBr}_{3} \mathbf{2 8 b}$, induced a different reaction pathway affording alkynylpiperidines 94 ' by intramolecular substitution.

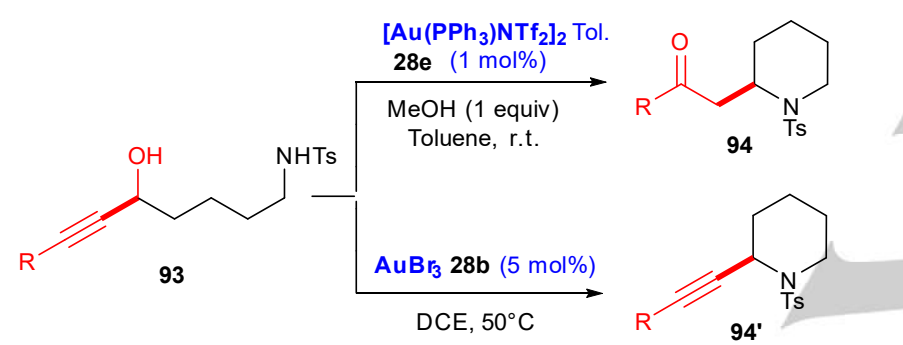

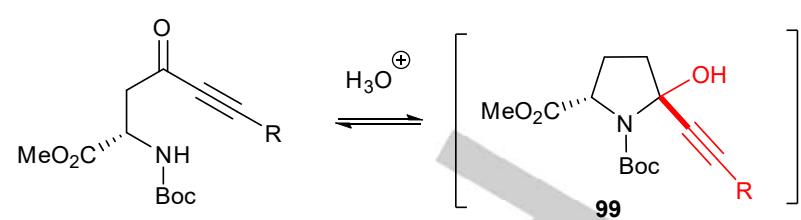

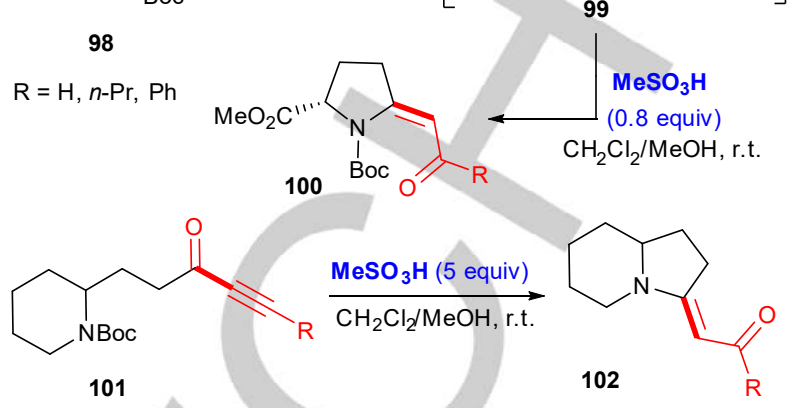

101

2) $2 \times$ ArNCO

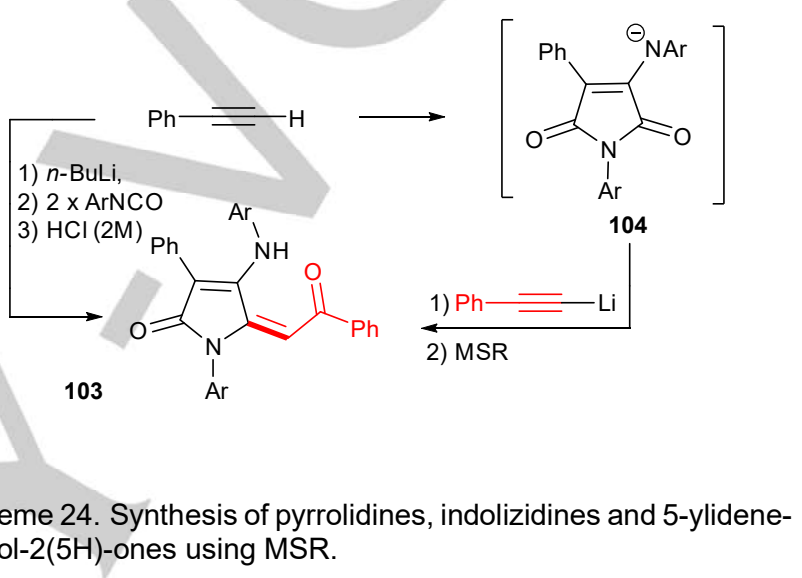

3) $\mathrm{HCl}(2 \mathrm{M}) \mathrm{Ar}$
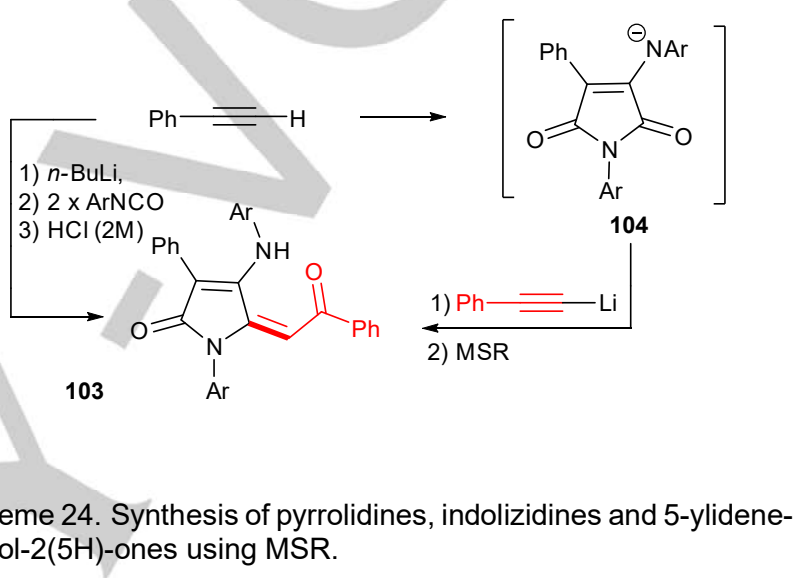

104 pyrrol-2(5H)-ones using MSR.
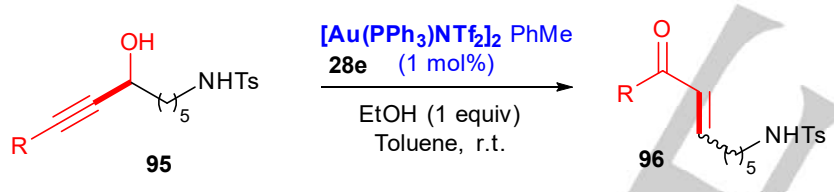

$\mathrm{R}=$ alkyl, $\mathrm{Ar}$<smiles>[R]C(=O)CC1CCCCCN1[As]</smiles>

$\mathrm{AuBr}_{3} 28 \mathrm{~b}$

(1 $\mathrm{mol} \%)$

Toluene, $60^{\circ} \mathrm{C}$

97
Scheme 23. MSR followed by intramolecular aza-Michael for the synthesis of piperidines and azepanes.

The situation was slightly different for the synthesis of the azepanes 97 , starting from alcohols 95 . With the soft gold (I) catalyst 28e, the first step occurred smoothly to give the enones 96 as a mixture of $E$ and $Z$ isomers but the second step required the use of a hard gold (III) catalyst $\mathbf{2 8 b}$. Under these conditions, the aza-Michael addition products, the azepanes 97 could be obtained in moderate to good yields. A one-pot procedure was developed for these syntheses. ${ }^{[67 \mathrm{~b}]}$

MSR has been used also for the synthesis of pyrrolidines as indicated in Scheme 24. ${ }^{[68 a]}$ The optically pure $\gamma$-amino-enones 98 reacted with methanesulfonic acid in a mixture of dichloromethane and methanol to give the exoxyclic vinylogous amides 100 in very high ee's. This reaction was not successful with gold catalysts. Control experiments indicated that it was going first through aminal intermediate 99 which afforded final products through the MSR. In a similar manner, the piperidinoynones 101 gave the indolizidines 102. ${ }^{[68 \mathrm{~b}]}$

The reaction of phenylacetylene anion with isocyanates usually affords pyrrolopyrroles derivatives. ${ }^{[69]}$ However, when the reaction was quenched with dilute $\mathrm{HCl}, 5$-ylidenepyrrol-2(5H)-ones 103 were obtained, likely through 104 and involving a MSR in the last step.

The MSR was used also for the preparation of different dihydroquinolones. A first series involved the use of $\mathrm{Bi}(\mathrm{OTf})_{3} 15$ as a catalyst, as described earlier in the intermolecular mode. ${ }^{[61]}$ Another catalytic system employed iodonium salts as indicated in Scheme 25. ${ }^{[70]}$ The reaction of carbamates 105 with phenyliodonium triflate at $10 \mathrm{~mol} \%$ gave the desired heterocycles 106. Then, by using a copper-mediated arylative condensation process in the presence of ditertiobutyl pyridine (DTBP) the intermediates 107 were obtained. By reaction of these compounds with $\mathrm{BF}_{3}$. $\mathrm{OEt}_{2} 11$, the aza-Michael addition occurred to deliver the targets 108. A one-pot procedure was also demonstrated for this synthesis. 
<smiles>[R]C([R])(O)C#Cc1ccccc1NC(=O)OCC</smiles>

105

$\mathrm{Ph}_{2}$ IOTf (1.2 equiv)

CuCl 18a (0.1 equiv)

DTBP (1.2 equiv) DCE, $80^{\circ} \mathrm{C}$<smiles>[R]C(C)=C(CC)C(=O)c1ccccc1NC(=O)OCC</smiles>

107<smiles>O=PNC1=C(C#CCO)C=C[R]C=C1</smiles>

109
$\mathrm{BF}_{3} \cdot \mathrm{Et}_{2} \mathrm{O}$ (1 equiv)

11

\section{$\underset{\mathrm{DCE}, 80^{\circ} \mathrm{C}}{\stackrel{\mathrm{Ph}_{2} \text { IOTf }(0.1 \text { equiv })}{\longrightarrow}}$}
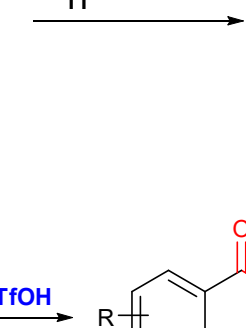<smiles>[R]C1([R])CC(=O)c2ccccc2N1</smiles>

$106 \mathrm{CO}_{2} \mathrm{Et}$

$\mathrm{R}^{1}, \mathrm{R}^{2}=\mathrm{H}$, alkyl, phenyl<smiles>[R]C1([R])C(c2ccccc2)C(=O)c2ccccc2N1C(=O)OCC</smiles>

108

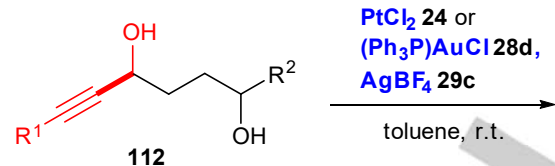

112

$$
\mathrm{R}^{1}=\mathrm{Me} \text {, phenyl }
$$

$\mathrm{R}^{2}=\mathrm{Bn}, i-\mathrm{Pr}$

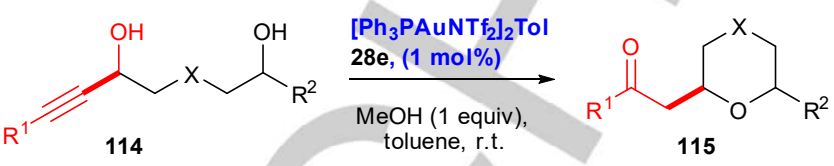

$\mathrm{R}^{1}=$ alkyl, $\mathrm{Ar} ; \mathrm{R}^{2}=\mathrm{H}, \mathrm{Me}$

$X=\mathrm{CH}_{2}, \mathrm{O}, \mathrm{NBoc}$

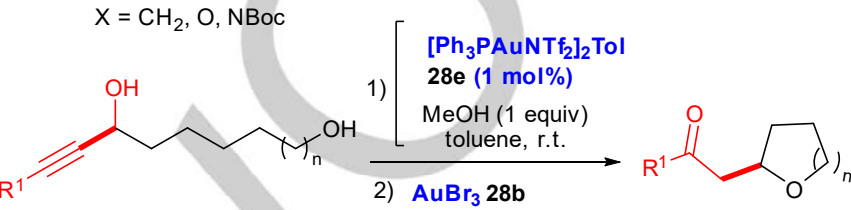

116<smiles>[R]C(=O)CC1CCC([R])O1</smiles><smiles>C[R]1ccc2c(c1)C(=O)CCN2[TlH]</smiles>

$\mathrm{R}^{1}=$ alkyl, phenyl; $\mathrm{n}=1,3$
117
Scheme 25. Synthesis of dihydroquinolones using MSR

For the tertiary propargylic alcohols (105 with $\mathrm{R}^{1}$ and $\mathrm{R}^{2}$ different from $H$ ), a different process occurred to give indenones via an intramolecular Friedel-Crafts reaction.

It has been successfully extended to the preparation of dihydroquinolones starting from primary propargylic alcohols 109 and using triflic acid, to afford first $\mathbf{1 1 0}$ and then the deprotected target 111 in up to $85 \%$ yields. ${ }^{[71]}$

Intramolecular C-O bond formation has been also developed after MSR (Scheme 26). It was first demonstrated that hex-5-yne-1,4-diols 112 gave 2,5 disubstituted tetrahydrofurans 113, as diastereoisomeric mixtures, through a cascade sequence of MSR followed by oxaMichael addition. $\mathrm{PtCl}_{2} 24$ was employed first, but better results were obtained with a $\left(\mathrm{Ph}_{3} \mathrm{P}\right) \mathrm{AuCl} 28 \mathrm{~d} / \mathrm{AgBF}_{4} 29 \mathrm{c}$ combination to give tetrahydrofurans $113 .{ }^{[72]}$
More recent studies established the use of both gold (I) complex 28e and methanol toward 6-membered cyclic ethers such as $\mathbf{1 1 5}$. For compounds 117, the combination of gold (I) and gold (III) complexes $(\mathbf{2 8 e}+\mathbf{2 8 b})$ was required to obtain excellent results in the case of 5- and 7-membered cycles. This was explained by the fact that, like mentioned previously for piperidines and azepanes, the first (soft) gold (I) catalyst induced the MSR while the second hard and/or oxophilic, gold (III) derivative catalyzed the oxaMichael step. ${ }^{[73]}$

\subsection{MSR followed by various types of carbo-and/or heterocyclization processes.}

We will first consider the preparation of sulfenyl indenones. Starting from propargylic alcohols 118, the MSR gave the intermediate allenols which were trapped by sulfur centered radicals $R^{3} S$. Then a cascade intramolecular trapping, followed by dehydrogenative aromatization, gave the target molecules 119 (Scheme 27).

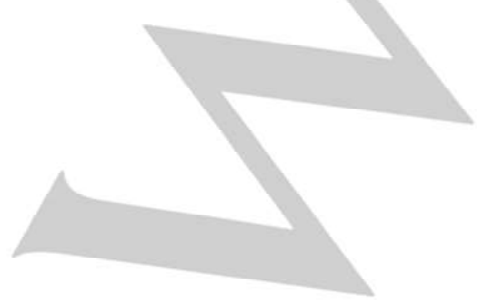




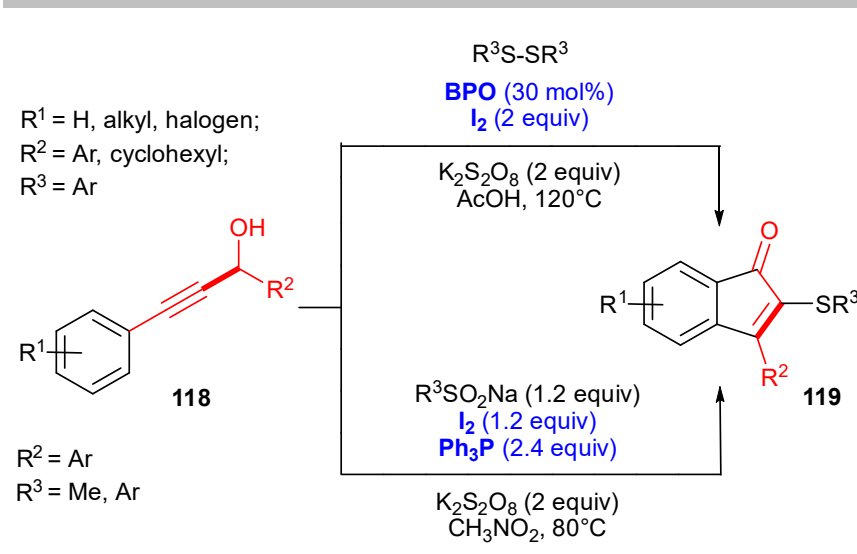

Scheme 27. Synthesis of 2-sulfenylindenones via MSR followed by cyclization and aromatization.

Two types of reaction conditions have been used. In the first, disulfides were employed as reagents together with a combination of benzoyl peroxide (BPO), iodine and potassium persulfate. ${ }^{[74]}$ In the second process, arylsulfinates were used in combination with iodine, triphenyl phosphine and potassium persulfate. ${ }^{[75]}$ In both cases good to excellent yields in sulfenylindenones have been obtained.

Another application was dealing with the synthesis of 3-alkoxy or 3-sulfamido indanones 122 and 123 via a cascade MSR intramolecular cyclization (Scheme 28). In the presence of paratoluene sulfonic acid, the propargylic alcohols $\mathbf{1 2 0}$ having an aldehyde in ortho position underwent the MSR and the intermediate allenol reacted intramolecularly with the vicinal aldehyde to get the intermediate 3-hydroxy indanone 121. Then reactions with various types of alcohols, or sulfamides, afforded the target molecules 122 and 123 , respectively in fair to good yields. ${ }^{[76]}$

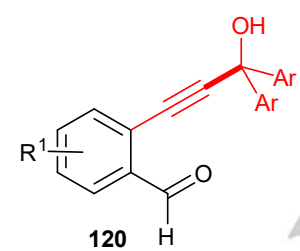
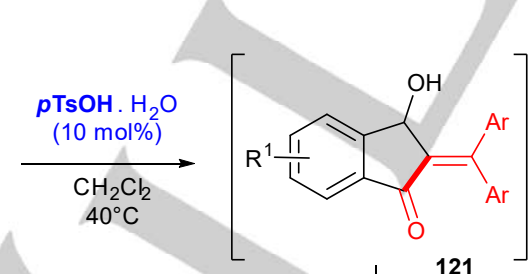

120

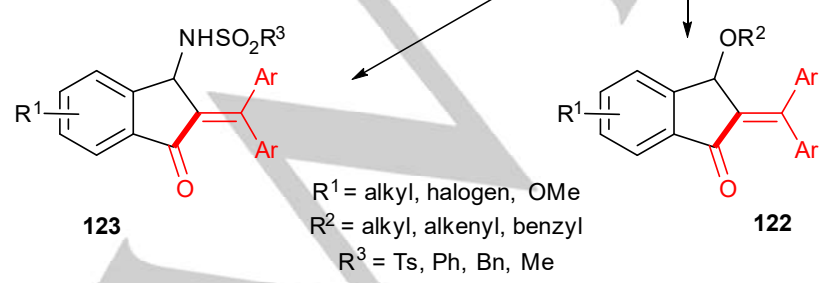

Scheme 28. Synthesis of 3-alkoxy- or 3-sulfamido indanones via MSR followed by cyclization and substitution.
The MSR has been used to prepare naphthols and photochromic naphtopyrans as indicated in Scheme 29. [77a, 77b]<smiles>CC#CC(O)(Br)c1ccccc1Br</smiles>

124

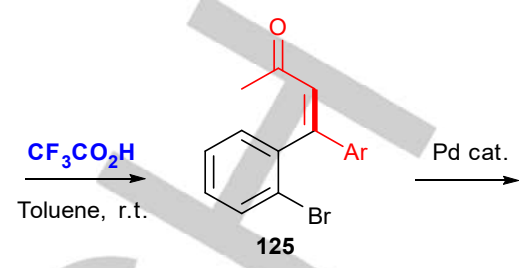

$\mathrm{Ar}=\mathrm{Ph}, 4-\mathrm{OMePh}$<smiles>Oc1cc(I)c2ccccc2c1</smiles>

126

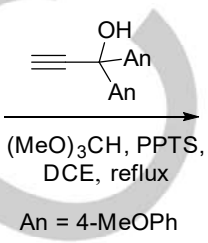

$\mathrm{An}=4-\mathrm{MeOPh}$

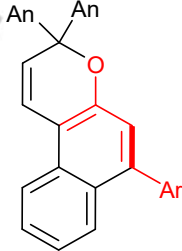

127
Scheme 29. Synthesis of 4-aryl-2-naphtol derivatives via MSR followed by cyclization and aromatization.

In the presence of trifluoroacetic acid, the MSR performed from the easily available propargylic alcohols 124 gave the enones 125 as the $Z$ isomers. Then palladium-mediated $\alpha$-arylations gave the 4-aryl naphthols 126 which were smoothly transformed into the desired naphtopyrans 127.

New syntheses of benzo[b]fluorenones also involved the MSR as a key step (Scheme 30).

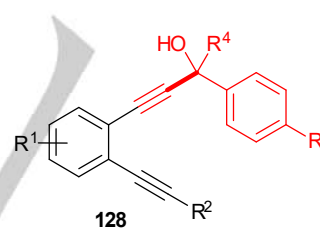
$\mathrm{R}^{2}=t$-Bu, c-propyl, Arl $\mathrm{R}^{3}, \mathrm{R}^{4}=\mathrm{H}, \mathrm{Me}$, OMe, halogen<smiles>[R]C=Cc1cc[R1]([H])cc1C#CC([R])(O)c1ccc([R]O[Na])cc1</smiles>

131
$\mathrm{R}^{1}=\mathrm{H}, \mathrm{Me}, \mathrm{F}, \mathrm{OMe}, \mathrm{OCF}_{3}$<smiles>[R]C#Cc1ccccc1C(O)=CC(=O)c1ccc([R])cc1</smiles>
129<smiles>[Mg]=[V]</smiles><smiles>[Y]c1ccc2c([R])c3c4cc[R1]([H])ccc=4c(=O)c3c([R])c2c1</smiles>

Scheme 30. Synthesis of benzofluorenones using MSR

Starting from diynes 128 , the MSR induced by traces of water and/or acids, gave the allenols 129 as intermediates. The reaction was performed in the presence of DDQ, and an oxidation occurred, followed by a cycloisomerization to yield the target molecules 130 in fair to good yields. Some derivatives with thienyl groups were also prepared. ${ }^{[78 a]} \mathrm{A}$ little later, the same group established that a similar process was possible starting from

\section{Accepted manuscript}


alkene derivatives 131. In that case, two equivalents of DDQ were used. ${ }^{[78 b]}$

Another interesting example was a gold-silver catalyzed MSR-expansion cascade to obtain $\alpha$-hydroxy- $\alpha$-vinyl cyclopentanones 133 starting from cyclobutyl alkyne 1,4diols 132 (Scheme 31). ${ }^{[79]}$

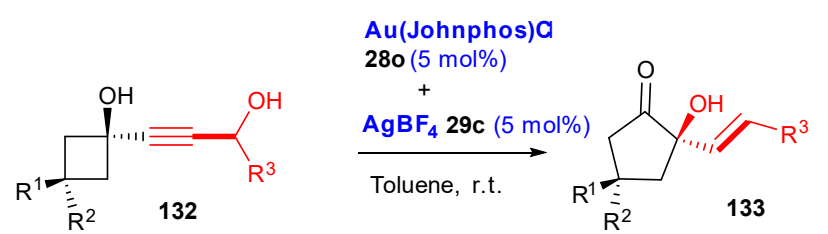

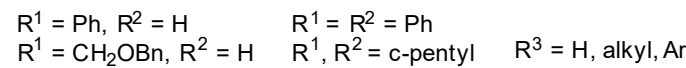

Scheme 31. Synthesis of cyclopentanones by a MSR-1,2 shift cascade.

In this process, the gold/silver $(\mathbf{2 8 0}+\mathbf{2 9 c})$-mediated MSR was followed immediately by a 1,2 shift to deliver the cyclopentanones. To support this mechanism, extensive studies have been performed using optically active starting materials, as well as labelling experiments. After adjustment of the ligands on the catalysts it could be extended to one example of oxetanone and one azetidinone.

Pyrroles and indoles have also been prepared by using MSR (Scheme 32). In the first case, the cyclobutanol derivatives with the appended propargylic side chains 134 reacted, in the presence of a primary amine, with the combination of gold and silver catalysts $(\mathbf{2 8 d}+\mathbf{2 9 a})$ to afford the cyclopenta[b]pyrroles 136. This reaction was proposed to occur first via the MSR, followed by a gold-mediated 1,2-migration of the cyclobutyl to a cyclopentyl group to give the dione 135 . Then, a classical PaalKnorr synthesis gave the pyrroles $136 .{ }^{[80]}$ In a different approach, the rearrangement of $\beta$-lactams 137 with a propargylic alcohols in position 4, gave the pyrroles 138 likely through MSR followed by an aminocyclization-dehydration process. The same process was employed with dimeric forms of 137 to give bis pyrrole derivatives. ${ }^{[81]}$ More recently, a synthesis of 6-hydroxyindoles 141 has been reported by condensation of alkynylcyclohexadiones 139 with amines in the presence of $\mathrm{AuCl}_{3} \mathbf{2 8 a}$, or better with catalyst 28p. ${ }^{[82]}$ During MSR, the amines add to cationic intermediate to give allenylamines which tautomerized to the conjugated imines 140. Final intramolecular Michael additions and aromatizations gave the targets 141 .

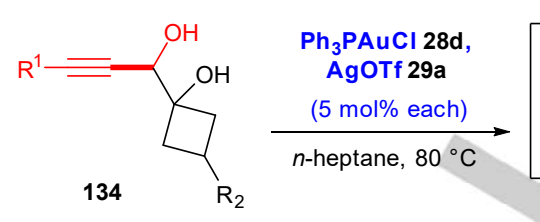<smiles>[R19]CCCCCCCC([R])CC1CC([R1])CC1=O</smiles>

$\mathrm{R}^{1}=t-\mathrm{Bu}, \mathrm{Ar}$ $\mathrm{R}^{2}=\mathrm{H}, \mathrm{Ph}$

$\mathrm{R}^{3}=\mathrm{H}$, alkyl, c-propyl, propargyl, Ar<smiles>[R]c1cc2c(n1[R])CC([R])C2</smiles>

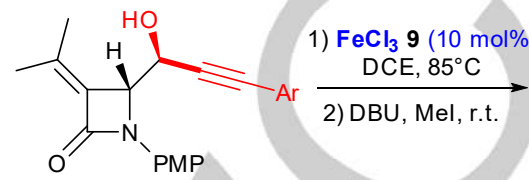

137

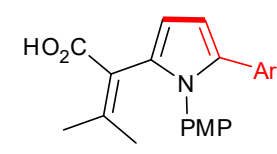

138
$\mathrm{PMP}=4-\mathrm{OMe}-\mathrm{C}_{6} \mathrm{H}_{4}$

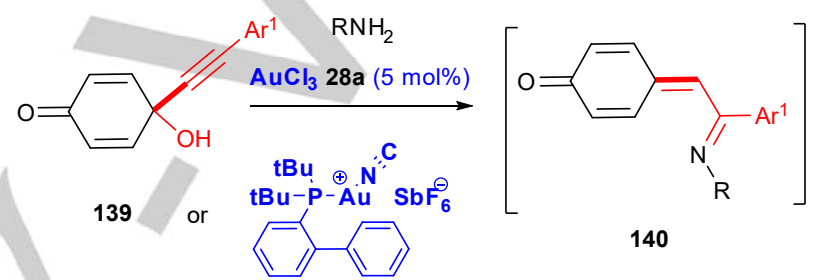

28p $(2.5 \mathrm{~mol} \%)$

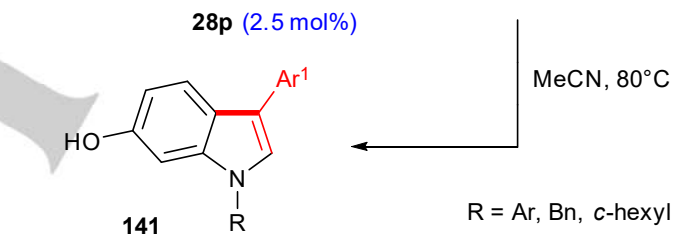

Scheme 32. Synthesis of pyrroles and indoles using MSR.

For the preparation of carbazoles, the condensation of propargylic alcohols 142 with Z-2-styryl-1H-indoles 143 was employed and the MSR was performed by copper triflate 18c (Scheme 33). Addition of indoles was followed by two consecutive intramolecular cyclization processes and a final oxidation step to yield the heteroaromatic targets 144 . It has been extended to a series of other propargylic alcohols bearing mostly aryl/heteroaryl substituents. ${ }^{\left[{ }^{[3]}\right]}$ The same group has also proposed a synthesis of quinolines by reaction of similar propargylic alcohols 145 with benzo[d]isoxazoles $146 .{ }^{[84]}$ The MSR was performed by a combination of copper triflate and silver acetate. The intermediate allenol arising through MSR was trapped by the benzoxazole activated by the Lewis acids. Then again cyclization, followed by re-aromatization, afforded the targets 147 . 


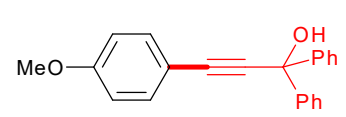

142<smiles>[R]c1ccc(/C=C\c2c[nH]c3ccc([R])cc23)cc1</smiles>

143 ( 1.3 equiv)

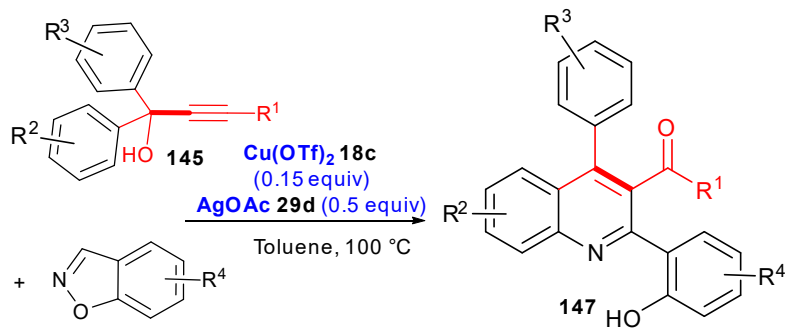

146 ( 3 equiv)

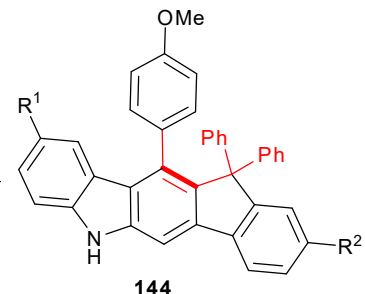

$\mathrm{R}^{1}=\mathrm{H}, \mathrm{Me}, \mathrm{OMe}$, halogen $\mathrm{R}^{2}=\mathrm{H}, \mathrm{Br}, \mathrm{F}$

$\mathrm{R}^{1}=\mathrm{H}$, alkyl, cyclopropyl, Ar, heteroaryl $\mathrm{R}^{2}, \mathrm{R}^{3}=\mathrm{H}, \mathrm{Me}, \mathrm{OMe}, \mathrm{F}$ $\mathrm{R}^{4}=\mathrm{H}, \mathrm{OMe}, \mathrm{Br}$
Scheme 33. Synthesis of carbazoles and quinolones using MSR.

By using appropriately designed diynes 148 , it was possible to prepare also tetrahydrobenzo[f]isoquinolines 149 through a cascade reaction (Scheme 34). ${ }^{[85]}$

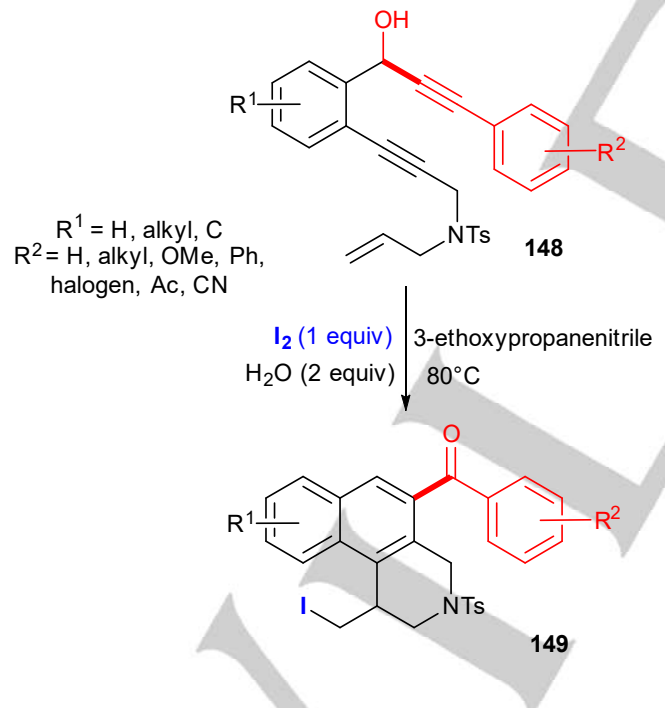

Scheme 34. Synthesis of isoquinolines using MSR.

The MSR was promoted by iodine and using 3ethoxypropanenitrile as the best, somewhat unusual solvent. The allenol was trapped intramolecularly by the second alkyne, activated by iodine. A second intramolecular trapping occurred on the terminal double bond to give, after re-aromatization, the target molecules 149 in fair to excellent yields.
Reaction of secondary propargylic alcohols 150 with aromatic azide 151 gave the quinolines 152 , while starting from tertiary alcohols 153 the same reaction afforded the quinolinium salts 154 (Scheme 35). On the other hand, using the other azides 155 , under the same reaction conditions with alcohols 156, the complex salts 157 were obtained. A tentative mechanism was proposed to explain these results. In a first step, the propargylallenyl cation intermediate in MSR reacted in a Friedel-Crafts reaction with the aromatic azide. Then Schmidt reactions, followed by aryl shifts, gave final compounds 152 or 154 . For the complex salts 157 involvement of a second Friedel-Crafts reaction was considered. ${ }^{[86]}$

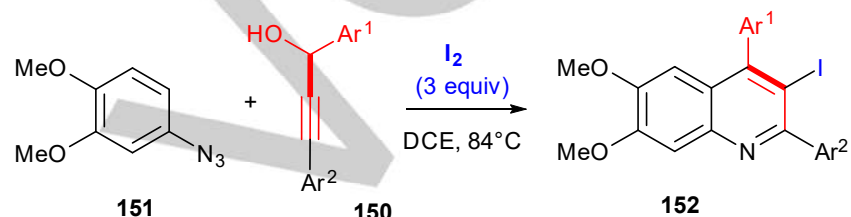<smiles></smiles>

154

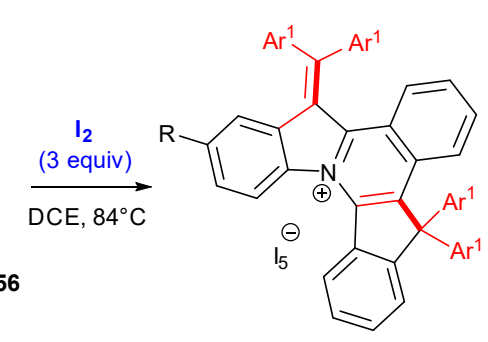

157

Scheme 35. Synthesis of iodine-containing quinolines and quinolinium salts using MSR.

A synthesis of spiro derivatives 159 has been described starting from propargylic alcohols 158 and using concentrated sulfuric acid in dichloroethane (Scheme 36 ). This process involved MSR followed by hydrolysis of the nitrile to an amide. After intramolecular formation of a cyclic imide, a Friedel-Crafts reaction occurred on the vicinal aromatic group to give 159. It has been demonstrated also that an electrophilic substitution can be performed with $\mathrm{N}$-iodo-succinimide to replace the indenyl $\mathbf{H}$ near the spirocyclic system by iodine. Then Suzuki coupling reactions were performed to introduce new aromatic groups in this position. ${ }^{[87]}$

\section{Accepted n్nanuscript}




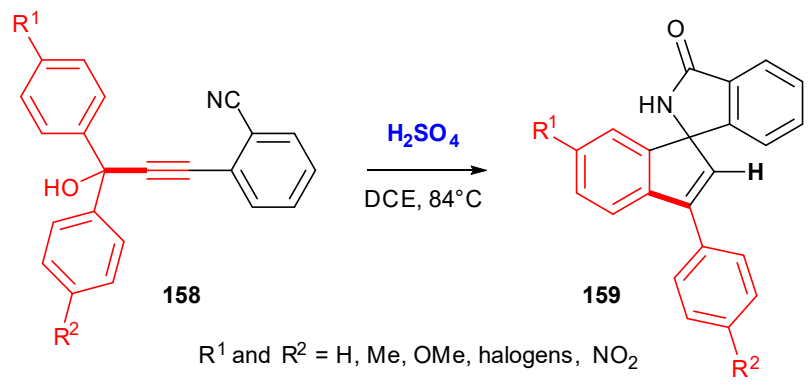

Scheme 36. Synthesis of spirobicyclic systems using MSR.

In the oxygenated series, a cascade annulation was performed starting from isatin-derived propargylic alcohols 160 to yield 3chlorobenzofurans 161 (Scheme 37).<smiles>[R][R]c1ccc2c(c1)N([R1])C(=O)C2c1oc2ccc([R3])cc2c1Cl</smiles>

160 $\mathrm{R}^{1}=$ alkyl, $\mathrm{Bn} ; \mathrm{R}^{2}=\mathrm{H}, \mathrm{Me}$, halogen, $\mathrm{OMe}, \mathrm{CF}_{3} ;$<smiles>[R]C#CC1(O)C(=O)N([R17])c2ccc([R])cc21</smiles><smiles>[R]c1ccc2c(c1)C(c1oc3ccc4ccccc4c3c1[R])C(=O)N2[R1]</smiles>

$\mathrm{R}^{1}=\mathrm{H}, \mathrm{Me} ; \mathrm{R}^{2}=\mathrm{H}, \mathrm{Me}$, halogen; $\mathrm{R}^{3}=n-\mathrm{Bu}, \mathrm{Ph}$

Scheme 37. Synthesis of 3-chlorobenzofurans and oxindolylnaphtofurans using MSR.

By reaction with $\mathrm{TMSCl}$ in trifluoroethanol, the MSR occurred to give the carbenium ions which were trapped by $\mathrm{Cl}^{-}$. So, in this process TMSCl was both promoter and source of $\mathrm{Cl}^{-}$. Next in the sequence an intramolecular addition by the phenolic oxygen gave the benzofurans. ${ }^{[88]} \mathrm{A}$ second example was dealing with oxindolylnaphtofurans $163 .{ }^{[89]}$ After optimization of the reaction conditions, calcium triflate (16 at $5 \mathrm{~mol} \%$ ) in the presence of an ammonium salt (at $10 \mathrm{~mol} \%$ ) gave the best results. The propargylic alcohols 162 gave the MSR and the intermediate carbenium ion was trapped by the naphthol on the position remote to the indole. Then, an intramolecular 5-exo dig cyclization followed by a prototropy afforded the target molecules 163 .
Dihydrobenzofurans and dihydroindoles were prepared as well starting from propargylic alcohols appropriately linked to aromatic groups 164 (Scheme 38). The MSR was better performed with $\mathrm{FeCl}_{3} 10$ in dioxane and in the presence of calcium hydride to ensure more anhydrous conditions. ${ }^{[90]}$ After MSR, an intramolecular Friedel-Crafts reaction occurred from the intermediate carbenium ions to afford the targets 165 .
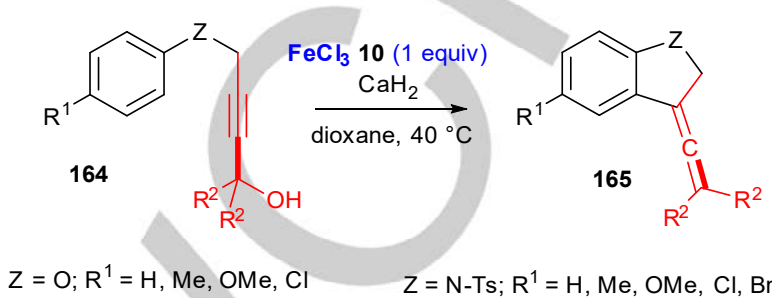
$\mathrm{R}^{2}=\mathrm{Ar} \quad \mathrm{R}^{2}=\mathrm{Ar}$

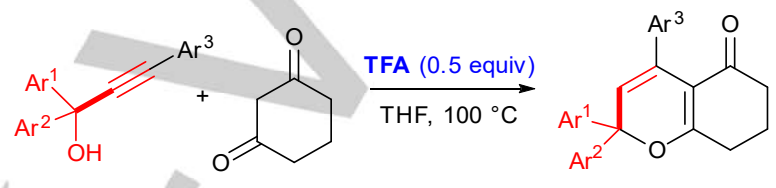

166

167

Scheme 38. Synthesis of dihydrobenzofurans, dihydroindoles and chromenones using MSR.

On the other hand, chromenones 167 have been synthetized by reaction of cyclohexanedione with propargylic alcohols 166 in the presence of trifluoroacetic acid in THF. ${ }^{[91]}$ During MSR the intermediate carbenium ions were trapped by the enol form of cyclohexanedione and, after prototropic shifts, a second cyclization afforded the targets. Extensions have been performed with various propargylic derivatives, with substituted cyclohexanediones and with cyclopentanediones.

Benzothiophenes $\mathbf{1 7 0}$ were obtained starting from trifluoromethylated propargylic alcohols 168 (Scheme 39). ${ }^{[92]}$

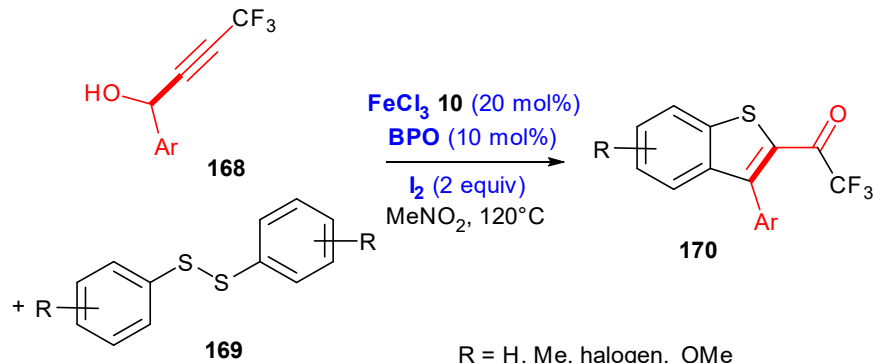

Scheme 39. Synthesis of benzothiophenes using MSR.

The MSR was best performed using $\mathrm{FeCl}_{3} 10$ and the intermediate allenols were trapped with the $\mathrm{PhS}^{*}$ radical generated in situ from disulphide 169 by the couple BPO/lodine. 
Intramolecular cyclization, followed by aromatization gave the targets molecules. This reaction could be extended to the selenium analogue of $\mathbf{1 7 0}$.

\subsection{Miscellaneous one-pot reactions starting with MSRs.}

The MSR affording enals or enones, therefore many applications are possible, the key issue being that the reaction conditions for the second step after MSR should be compatible with MSR catalysts. Apart from those already described in this review, several other one-pot transformations have been also demonstrated.

Two examples are dealing the synthesis of dienes of use in the area of dyes (Scheme 40). ${ }^{[93]}$

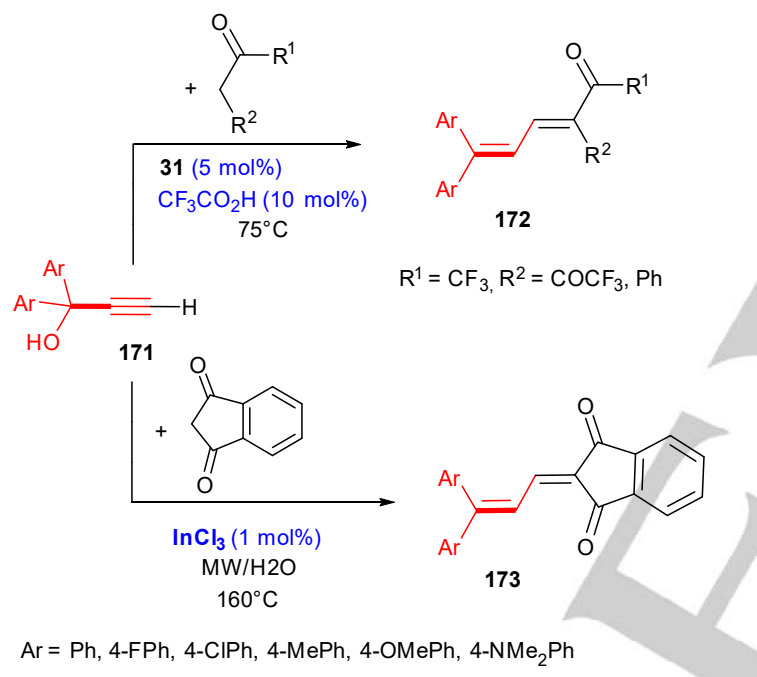

Scheme 40. MSRs plus aldol reaction for the synthesis of pushpull dienes.

In line with previous work from the same authors, the MSR of diaryl propargylic alcohols 171 with the $16 \mathrm{e}^{-}$ruthenium complex 31 gave the corresponding enals, which reacted immediately with the fluorinated $\beta$-dicarbonyl reagents to give the desired dienes 172. In a similar way, but under microwave-assisted conditions and with $\mathrm{InCl}_{3}$ as the catalyst, the aldol reaction with indane-1,3-dione gave the push-pull conjugated derivatives 173.

In a different area, MSR proved to be extremely fruitful for the preparation of [3]-dendralene derivatives (Scheme 41). ${ }^{[94]}$

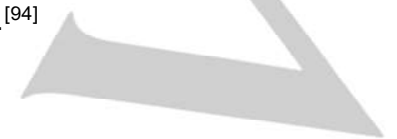

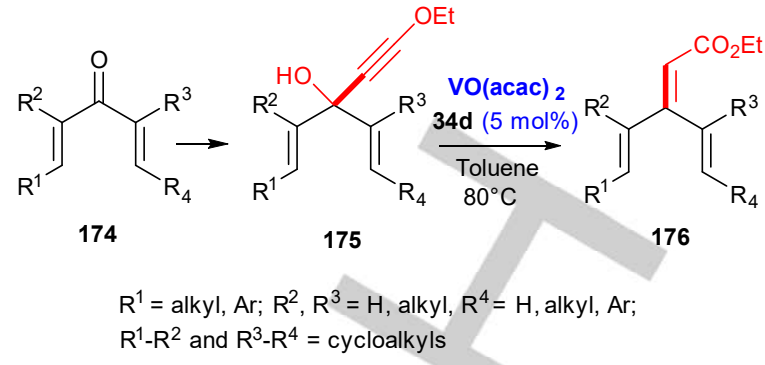

Scheme 41. MSRs for the synthesis of [3]-dendralene derivatives.

Olefination procedures starting from cross-conjugateddienone 174 to get the target molecules 176 were not successful. On the contrary, after careful screening of the catalysts, the MSR of propargylic alcohols 175 mediated by $\mathrm{VO}(\text { aca })_{2} 34 \mathrm{~d}$ gave 176 . In this case gold catalysts, with or without additives, afforded unreliable results. Further, latter catalysts also gave competitive reactions affording alkylidene cyclopentenes through Nazarovtype cyclizations.

Other applications were one-pot consecutive MSR-Diels-Alder transformations as indicated in Scheme 42. The oxo- $\mathrm{Re}^{\mathrm{V}}$ catalyst 30a was able to induce both the MSR and catalyze the D-A reaction giving the adducts $\mathbf{1 7 7}$ in fair to good yields with a high endo selectivity. ${ }^{[95]}$ A very recent example of domino MSRintramolecular D-A reaction, mediated by oxovanadates and used for the preparation of odorants, will be described in Part 4.
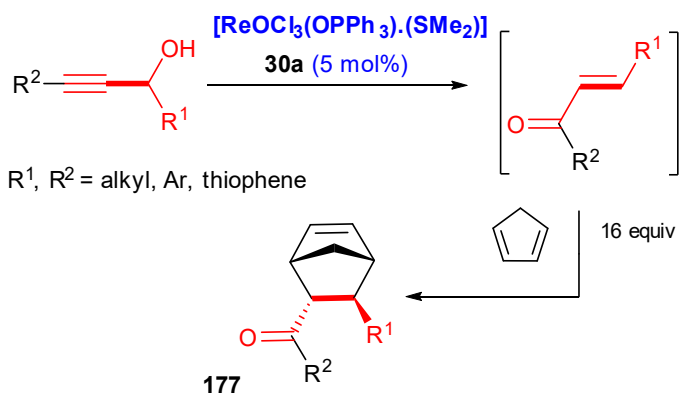

Scheme 42. Consecutive MSR-Diels Alder reactions.

Another example of a consecutive process was the MSR followed by enantioselective reduction to afford optically active allylic alcohols 181 (Scheme 43). ${ }^{[96]}$ The same Re-oxo complex 30a was used to perform the MSR starting from propargylic alcohols 178. Next, extensive screenings established that the hydrosilylation step was best performed using phenyldimethylsilane in the presence of chiral ligands such as $180 \mathrm{a}$, or better $180 \mathrm{~b}$, to give

\section{Accepted manuscript}


the allylic alcohols 181 in moderate to good yields with good to excellent ee's (49-92 \%).

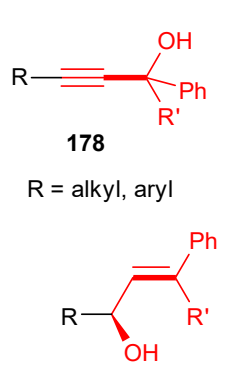

181

$\mathrm{R}=\mathrm{alkyl}$, aryl
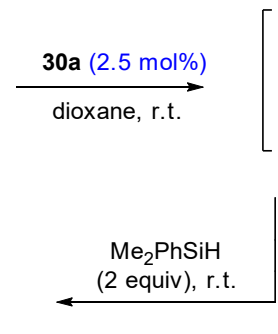

180a: $\mathrm{Ar}=\mathrm{H}$

180b: $\mathrm{Ar}=3,5 \mathrm{diCl}-4 \mathrm{OMe}$

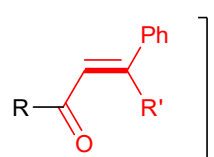

179
Scheme 43. Consecutive MSR asymmetric hydrosilylation reactions.

For the synthesis of 5-chloropyrazoles 185 , of potential interest in crop protection, a cascade MSR-von Auwers rearrangement was developed starting from propargylic alcohols 182 (Scheme 44). ${ }^{[97]}$ After MSR to 183, the migration of the $\mathrm{CCl}_{3}$ group occurred with rearomatization to deliver the ketones 184 and two extra steps gave the target molecules 185 .

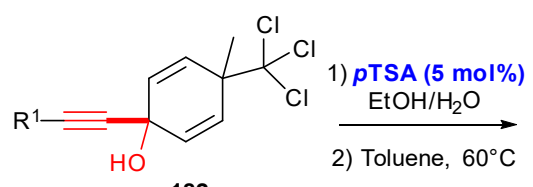

182<smiles>[R]C(=O)C(c1ccc(C)cc1)C(Cl)(Cl)Cl</smiles>

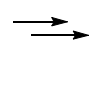

184 $\mathrm{R}^{1}=\mathrm{Ar}$, cyclopropyl; $\mathrm{R}^{2}=\mathrm{H}, \mathrm{Me}, \mathrm{Bn}$

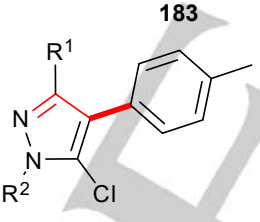

Scheme 44. Consecutive MSR-von Auwers rearrangement.

\section{Use of Meyer Schuster rearrangement in the total synthesis of natural products and analogues}

The MSR is clearly a powerful method to introduce enone-type structures in organic molecules. Therefore, it is not surprising that it has found excellent applications in the total synthesis of natura products and/or derivatives thereof.

An example was described in a short preparation of the prostaglandin $\mathrm{PGF}_{2 \alpha}$ (Scheme 45). Addition of the 1-heptyne on the Corey lactone 186 afforded the propargylic alcohol 187 which was subjected to MSR using the NHC-gold catalyst $\mathbf{2 8 h}$ at $2 \mathrm{~mol} \%$ affording the target $E$-enone 188 in $86 \%$ yield. This route was an alternative to the usual Horner-Wadworth-Emmons strategy starting from 186. The preparation of the prostaglandin $\mathrm{PGF}_{2 \alpha}$ was completed in three classical reactions. ${ }^{[98]}$

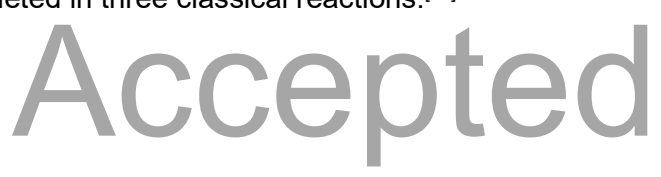

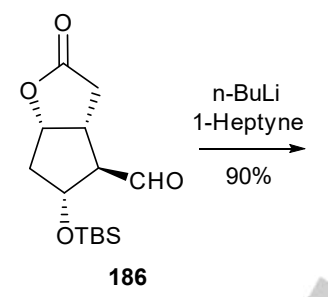
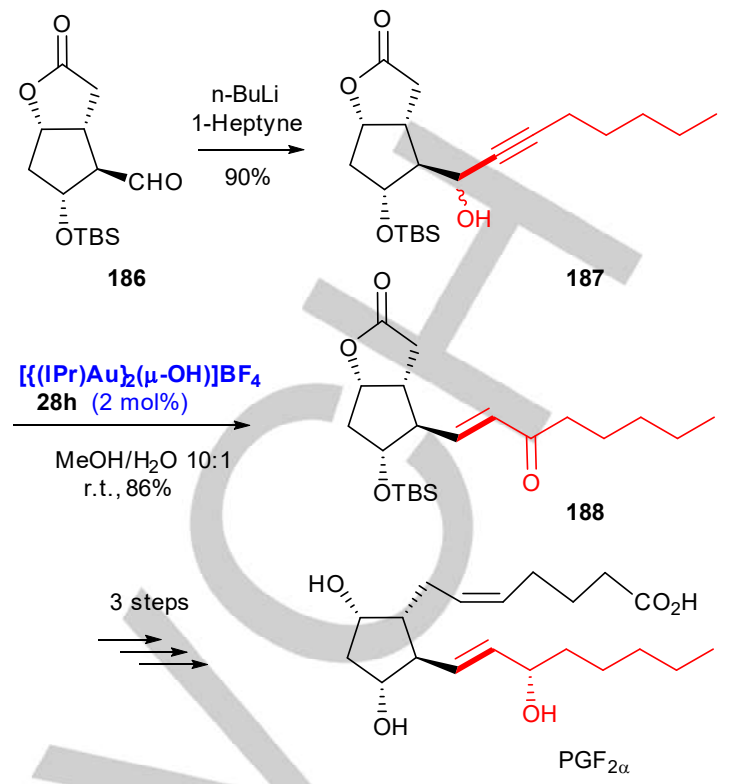

Scheme 45. Synthesis of prostaglandin $\mathrm{PGF}_{2 \square}$ using MSR.

Then, this approach was extended to two important antiglaucoma drugs, Latanoprost and Bitamoprost (Scheme 46). ${ }^{[99]}$ The intermediate 189 , obtained in the same way from Corey lactone, was submitted to MSR with the gold catalyst $28 \mathrm{c}$ at very low loading $(0.7 \mathrm{~mol} \%)$, affording in excellent yield and with complete stereoselectivity the E-enone 190. From this key intermediate, the two target molecules were obtained through literature procedures.
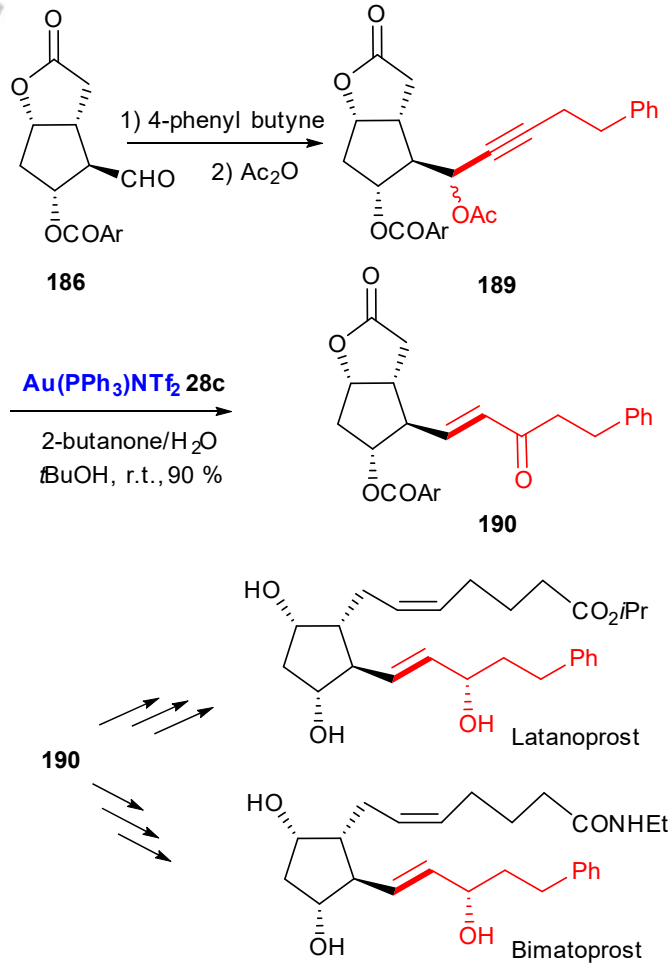

Scheme 46. Synthesis of Latanoprost and Bimatoprost through MSR. 
A similar strategy was followed for the synthesis of one of the important metabolites of $\alpha$-linoleic acid, called phytoprostanes (Scheme 47). ${ }^{[100]}$ The reaction of cyclopentylaldehyde 191 with the lithium salt of 1-butyne gave the propargylic alcohol 192 in $96 \%$ yield. By reaction with the gold catalyst $28 \mathrm{~h}$ (at $6 \mathrm{~mol} \%$ ) in a methanol-water mixture, the desired enone 193 was obtained in $76 \%$ yield as a pure $E$ isomer. Further steps allowed the preparation of the desired $16-\mathrm{L}_{1}$-PhytoP.<smiles>O=CC1=C(Br)CCC1O[AsH3-]</smiles>

191

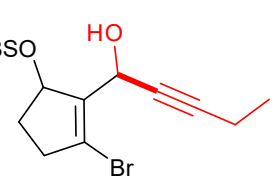

192

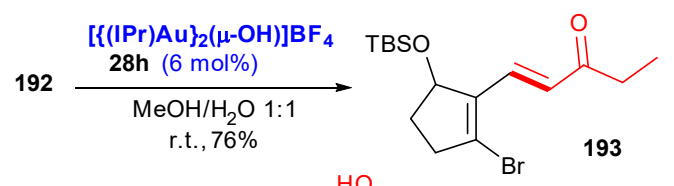

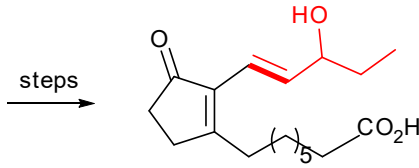

16-L1-PhytoP
Scheme 47. Synthesis of phytoprostanes using MSR.

One application has been reported also in the field of steroids (Scheme 48). ${ }^{[101]}$
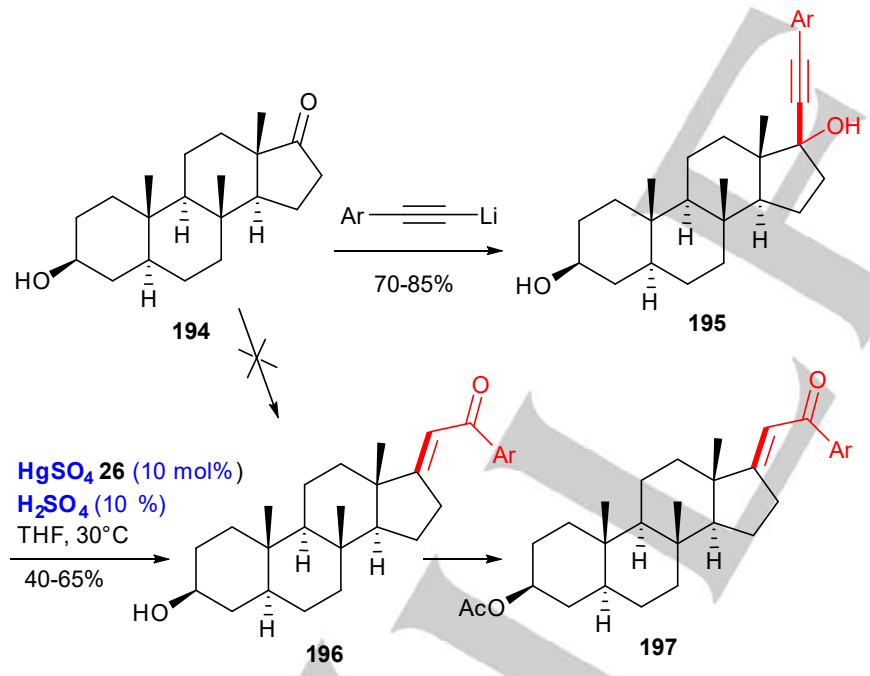

Scheme 48. Synthesis of steroid derivatives using MSR.

The authors designed some androstane derivatives 197 for screenings in cancer area. The classical olefination procedures starting from epiandrosterone 194 did not allow the synthesis of the desired enones 196 and therefore an MSR was considered. Addition of the lithio derivatives of alkynes gave in excellent yields the propargylic alcohols 195. Then, screening experiments demonstrated that the best conditions for MSR were a combination of mercury salt $\mathbf{2 6}$ and sulfuric acid in THF, affording the desired enones 196 in fair to good yields. Finally, a classical acetylation process gave the target acetates 197. Both series of molecules submitted to in vitro cytotoxicity studies demonstrated moderate activity against a panel of four human cancer cell lines. The synthesis of compound 201, which is the sex pheromone of the Longtailed Mealybug Pseudococcus longispinus, has been performed using as a key step a MSR (Scheme 49). ${ }^{[102]}$ Addition of the lithium derivative of ethoxyacetylene on the ketone 198 gave the alcohol 199. This was followed immediately by a MSR, mediated by scandium triflate 19 , affording the conjugated ester 200 as a $1: 1$ mixture of the $E$ and $Z$ isomers and in $71 \%$ overall yield for the two steps. Interestingly in that case, the classical Wittig or Horner-Wadworth-Emmons reactions starting from ketone 198 were also unsuccessful. Further five steps, including a Claisen rearrangement, allowed the preparation of the target pheromone 201.

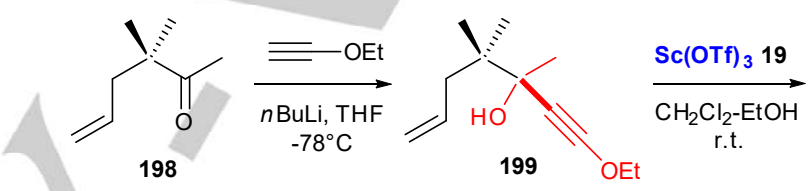<smiles>[Z17]CC(=O)OCC</smiles><smiles>CC(=O)OCCC1(C)C=CCC1(C)C</smiles>

201

Scheme 49. Synthesis of an insect sex pheromone using MSR.

The synthesis of $\alpha$-ionone $\mathbf{2 0 3}$ is also a good example of the use of MSR (Scheme 50). ${ }^{[103]}$ Starting from easily accessible propargylic acetate 202, various reaction conditions were tried, but the NHC-carbene gold catalyst $28 \mathrm{~h}$ proved to be the best reagent. In a butanone-water mixture, it gave the target ionone 203 in 70\% yield. Several other gold catalysts were tried, but they gave lower yields. On the other hand, Brønsted acids alone did not show any conversion and the starting material was recovered. This approach has been used subsequently for the preparation of flavor components of iris oils. ${ }^{[104]}$ The benzoate 205 could be prepared in $63 \%$ yield from the sensitive aldehyde 204. Starting from this intermediate, the MSR mediated by the same gold catalyst $\mathbf{2 8 h}$ afforded in $68 \%$ overall yield $\mathbf{2 0 6}$ as a mixture of the desired (-)-(2S,6R)-cis- $\alpha$-irone 206(E) and its Z-isomer. These two isomers could be separated by chromatography and the $Z$ derivative could be isomerized with iodine in dichloromethane back to the targeted $E$ compound. Here again, all trials using classical olefination procedures starting from aldehyde 204 proceeded either with low yields and/or with extensive epimerization/racemization.

$$
\text { Accepted } x_{00} \text { anuscript }
$$




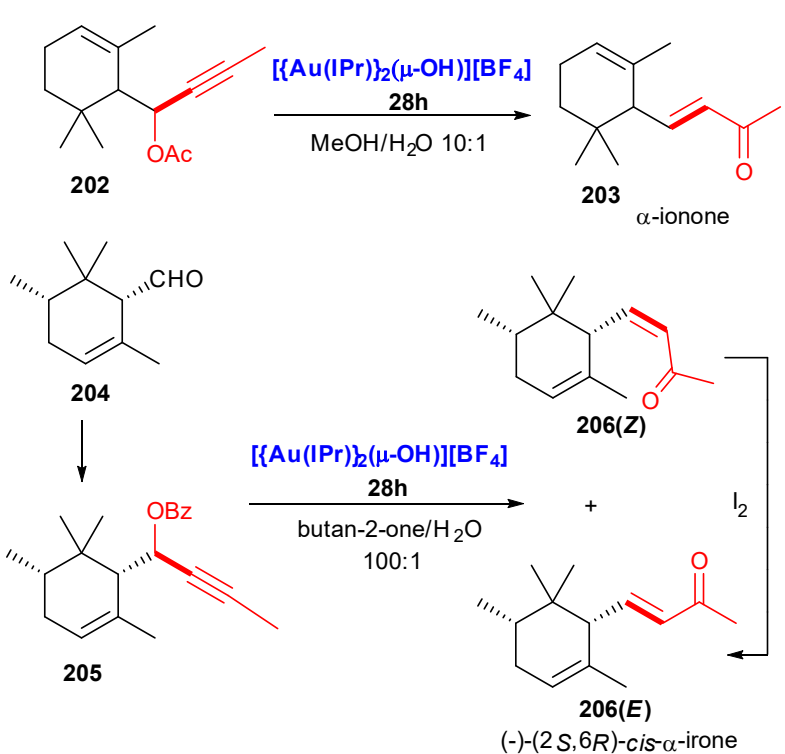

207a $: \begin{aligned} & \mathrm{R}=\mathrm{H} \\ & \text { 207b }: \mathrm{R}=\mathrm{Me}\end{aligned}$
$\begin{gathered}(S)-\gamma \text {-ionone } \\ (2 S, 6 R)-\gamma \text {-irone } 208 \mathrm{a}: \mathrm{R}=\mathrm{H}(55 \%) \\ \mathbf{2 0 8 b}: \mathrm{R}=\mathrm{Me}(65 \%)\end{gathered}$ olfactory tests. Mechanistic studies suggested first MSR affording allenyl vanadate intermediates which gave the final products $\mathbf{2 1 0}$ through IMDA reactions.

MSR has been used towards bicyclic terpene aldehydes but the results were strongly depending upon the reaction conditions and acids used (Scheme 52). The reaction of 2-ethynylisocamphanol 211 with formic acid led to a complex mixture where the desired enals 212 were obtained as a mixture of $E$ and $Z$ isomers together with the enone 213. On the other hand, 2ethynylisoborneol 214 reacted with $\mathrm{HCl}$ in the presence of $\mathrm{HgCl}_{2}$ 26 to give the enal 215 in fair yield. ${ }^{[107]}$
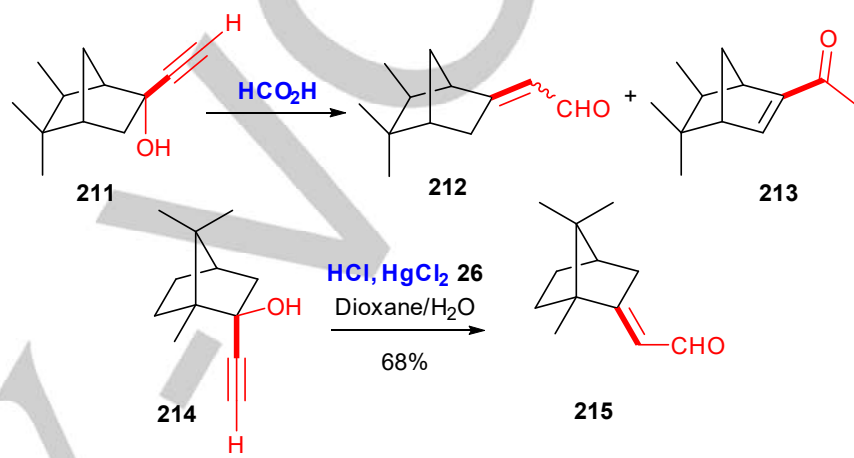

Scheme 50. Synthesis of $\alpha$-ionone 203, (-)-(2S,6R)-cis- $\alpha$-irone 206(E) and $(2 S, 6 R)-\gamma$-irone 208b.

Scheme 52. Synthesis of terpene aldehydes.

The (S)- $\gamma$-ionone 208a and the (2S,6R)-cis- $\gamma$-ionone 208b, which bear exocyclic double bonds, are very challenging molecules. In that case, the dual gold-silver catalyst $[\mathrm{Au}(\mathrm{IPr}) \mathrm{Cl}] \mathbf{2 8} \mathbf{g}_{2} / \mathrm{AbSbF}_{6}$ $\mathbf{2 9 b}$, proved to be efficient and, further, was able to suppress the competitive oxy-Cope rearrangement. Therefore, the target molecules were obtained in fair yields from acetates 207. ${ }^{[105]}$

Starting from hydroxyenynes 209, a new domino MSRintramolecular Diels-Alder (IMDA) sequence was employed to prepare odorants 210 (Scheme 51). ${ }^{[106]}$

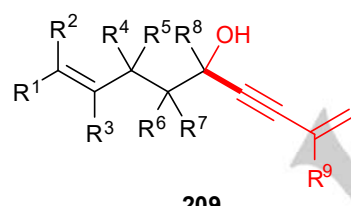

209

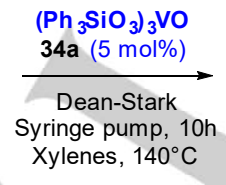

Xylenes, $140^{\circ} \mathrm{C}$

$R^{1}$ to $R^{9}=H$, alkyl,cycloalkyl, benzofuran, indole

Scheme 51. Synthesis of perfume components through a cascade MSR-IMDA.

After careful optimization, the process worked efficiently by using the oxovanadium catalyst $\mathbf{3 4 a}$, under high dilution conditions with syringe pump. It was occurring with a good range of substrates affording new hydrindanes which have been submitted to
Starting from alcohol 216, the MSR has been successfully used in the last step of the synthesis of the bioactive sesquiterpene lactone anthecotulide $217,{ }^{[108]}$ as well as the two syn- and antihydroxy anthecotulides (Scheme 53). ${ }^{[109 a]}$ Remarkably in all these cases, the combination of the three catalysts $33 / 28 d / 29 a$ as described earlier by Akai, ${ }^{[109 b]}$ which was employed with success here, did not act on the sensitive $\alpha$-methylene- $\gamma$-butyrolactone and/or the allylic alcohols groups.

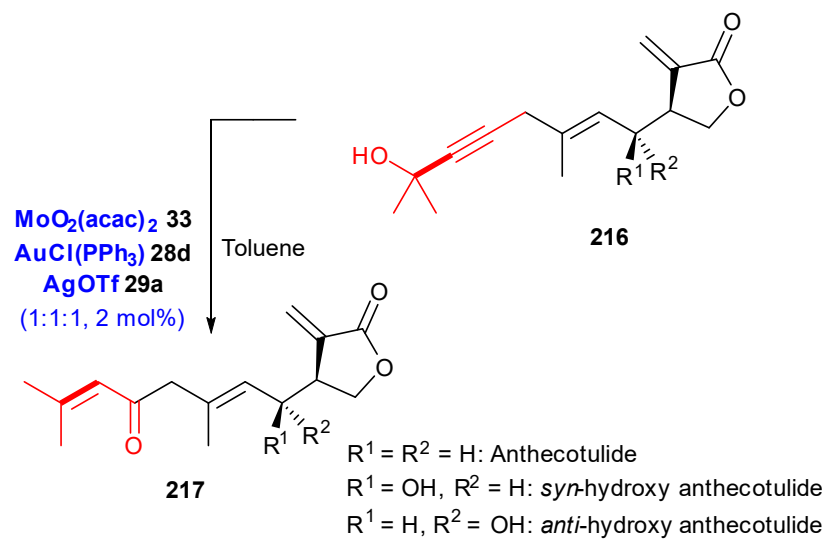

Scheme 53. Final step in the synthesis of the anthecotulides.

The total synthesis of callicarpenal, completed recently, involved also a MSR as a key step (Scheme 54). ${ }^{[110]}$

\section{Accepted manuscript}


<smiles>CC(C)=C1CC[C@@H](C)CC1=O</smiles><smiles>C=C(C)[C@]1(C)CC[C@@H](C)[C@](C)(CC(C)C)C1=O</smiles>

(R)-(+)-Pulegone

218
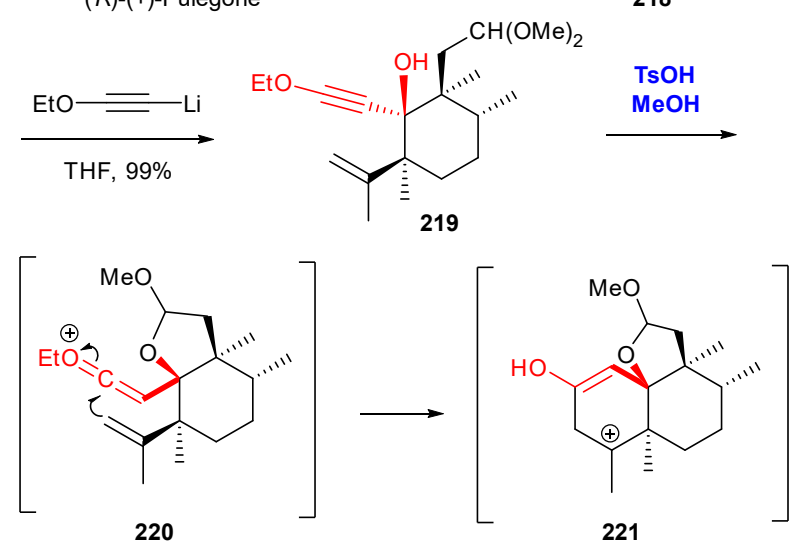<smiles>COC1C[C@]2(C)[C@@H](C)CC[C@]3(C)C(C)=CC(=O)C[C@@]32O1</smiles><smiles>CC[C@]1(C)C2=CC(=O)C=C(C)[C@@]2(C)CC[C@@H]1C</smiles>

223<smiles>CC1=CCC[C@H]2[C@@H](C)[C@H](C)CC[C@]12C</smiles>

(-)-Callicarpenal callicarpenal.

The authors started from $(R)-(+)$-pugelone and through a multistep sequence obtained the ketone 218. Then, addition of the ethoxyacetylene anion gave the propargylic alcohol 219. After screening different conditions for MSR, the authors found that use of $\mathrm{TsOH}$ in anhydrous methanol gave the best results affording a mixture of 222 (36\%) and 223 (46\%). This first isomer could be recycled also to 223 in two steps. The reaction was supposed to occur through the trapping of oxonium ion in $\mathbf{2 2 0}$ by the double bond to give the cation $\mathbf{2 2 1}$ which, after proton departure, gave 222 and 223. Starting from this intermediate 223, the authors completed in six steps the total synthesis of their target molecule. During synthetic studies towards sesquiterpenes with the dunniane skeleton, the MSR proved to be fruitful (Scheme 55). ${ }^{[111]}$ The advanced cyclobutane intermediate 224 reacted with ethynyl magnesium chloride to give the propargylic alcohols 225 in excellent yield. Then, MSR reaction performed with tris(triphenylsilyl)vanadate $34 \mathrm{a}$ in toluene at $120^{\circ} \mathrm{C}$, and under microwave irradiation, gave the enal $\mathbf{2 2 6}$ which was used directly

for the next steps including the synthesis of a dienamine followed by a Diels-Alder reaction. Ultimately, they obtained 227 with the desired carbon skeleton but they could not introduce the conjugated double bond required for the final target, dunniane $\mathbf{2 2 8}$.

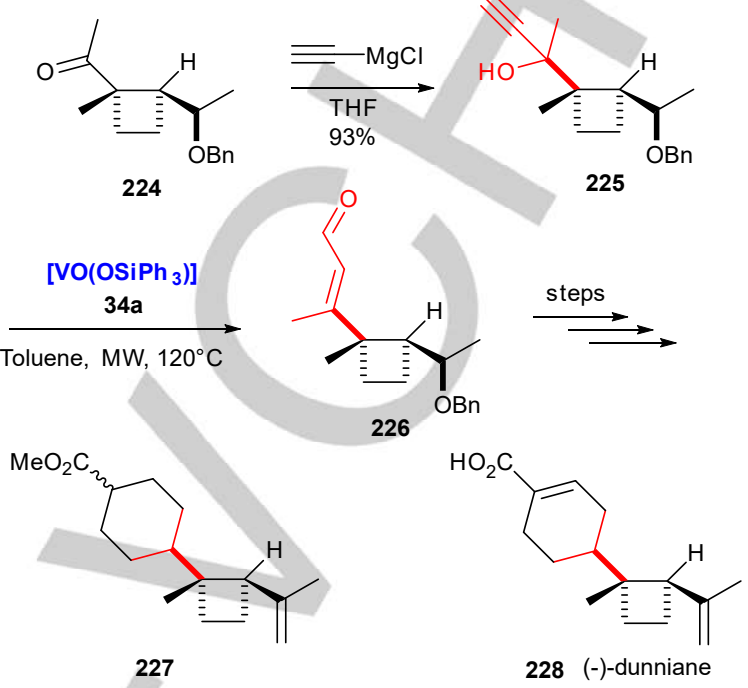

Scheme 55. Key steps involving MSR toward the synthesis of terpenes with a dunniane skeleton.

Platencin is a recently discovered molecule belonging to a new type of antibiotics. In order to prepare key intermediates towards the synthesis of this molecule, the bicyclic derivative 229 was reacted with propynyl Grignard to give the alcohol 230 in $87 \%$ yield and as a 1.5:1 diastereoisomeric mixture (Scheme 56). ${ }^{[112]}$ The combined gold/silver/molybdene-catalyzed (at $2 \mathrm{~mol} \%$ ) MSR proved to be extremely efficient, affording the enones 231 in a 1:1.7 ratio in favour of the $Z$ isomer. Latter derivative was transformed by chemo- and diastereoselective hydrogenation followed by cyclization, into $\mathbf{2 3 2}$ which has the [2.2.2] core of the target antibiotic.

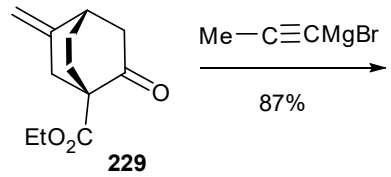<smiles>C=C1CC2CC(C#CC)(CC1OCC)C2(O)CCO</smiles>

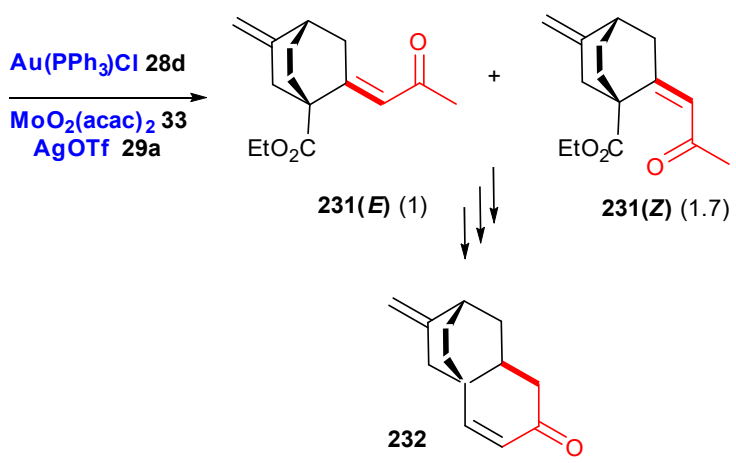

Scheme 56. MSR for the synthesis of the bicyclic core of Platencin.

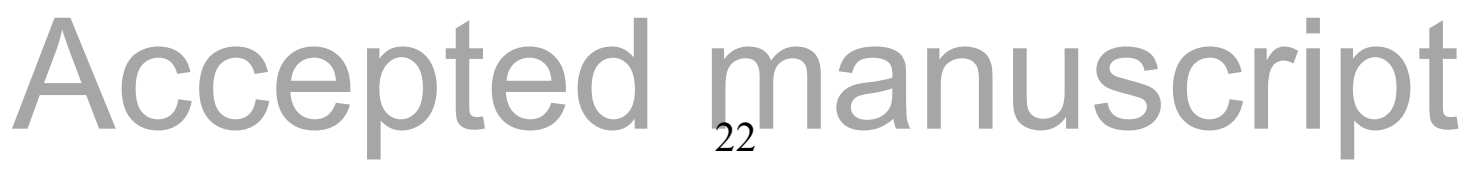


Recently chemists have prepared the reported structure of Stresgenin B, which is an inhibitor of the expression of the heat shock protein. ${ }^{[113]}$ Starting from $D$-Ribose, they could obtain through a ten steps sequence the intermediate 233. Addition of the ethoxyacetylene anion, in the presence of $\mathrm{CeCl}_{3}$, gave in $59 \%$ yield the propargylic alcohol 234 (Scheme 57). The MSR with a combination of gold and silver catalysts afforded the target molecule $\mathbf{2 3 5}$, albeit with a poor diastereoselectivity. In that case also, except a cerium-mediated Peterson reaction, all classical olefination procedures starting from the enone $\mathbf{2 3 3}$ to the target 235 were unsuccessful. The structure of this molecule was confirmed by X-Ray analysis but its NMR data were not matching with those of the natural product, therefore the structure of latter derivative has to be revised.

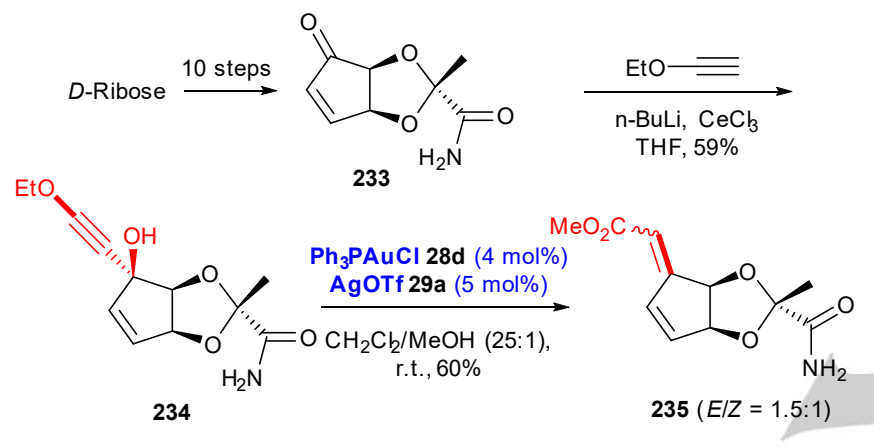

Scheme 57 . Synthesis of structure attributed to Stresnegin B.

In the field of alkaloids, the MSR has been employed for the preparation of pyrrolidines which are structurally related to polyhydroxylated derivatives, known in particular as glycosidases inhibitors (Scheme 58). ${ }^{[114]}$ Addition of TMS acetylene anion on enantiopure imide $\mathbf{2 3 6}$ gave, after desilylation, the propargylic alcohol 237 as a 6:4 mixture of diastereoisomers. MSR was successfully performed using $\mathrm{BF}_{3} . \mathrm{OEt}_{2} 11$ in dichloromethane affording 238 as a pure $E$-isomer in excellent yield.
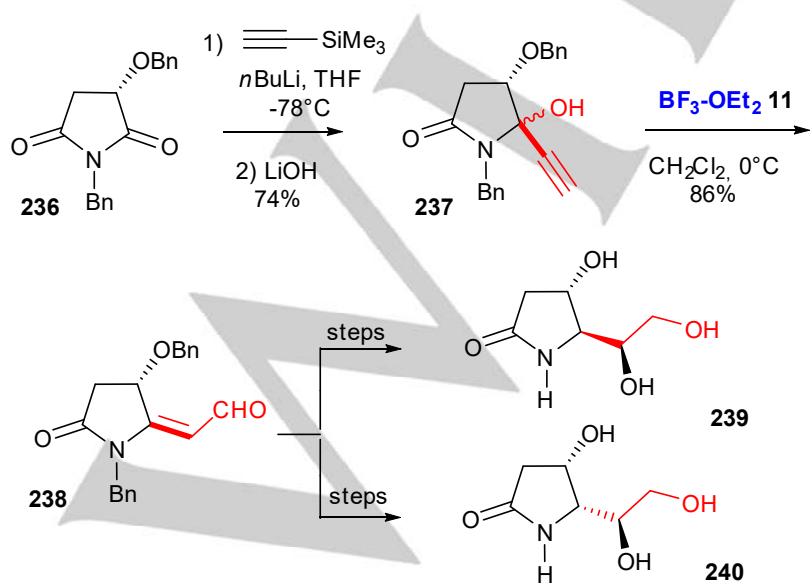

Scheme 58. Synthesis of trihydroxylated pyrrolines using MSR.
From this intermediate the targeted aza-sugars 239 and 240 could be obtained in 5-6 steps.

Another application of MSR in alkaloid chemistry is indicated in Scheme 59. Starting from propargylic alcohol 241, the MSR mediated by trifluoroacetic acid at $-20^{\circ} \mathrm{C}$ afforded, directly in $90 \%$ yield and $70 \%$ ee, the enone 242 (Fuligocandin A), with the required stereochemistry probably due to intramolecular hydrogen bonding. Next, an aldol condensation with an indole aldehyde gave the second target, Fuligocandin $B{ }^{[15]}$

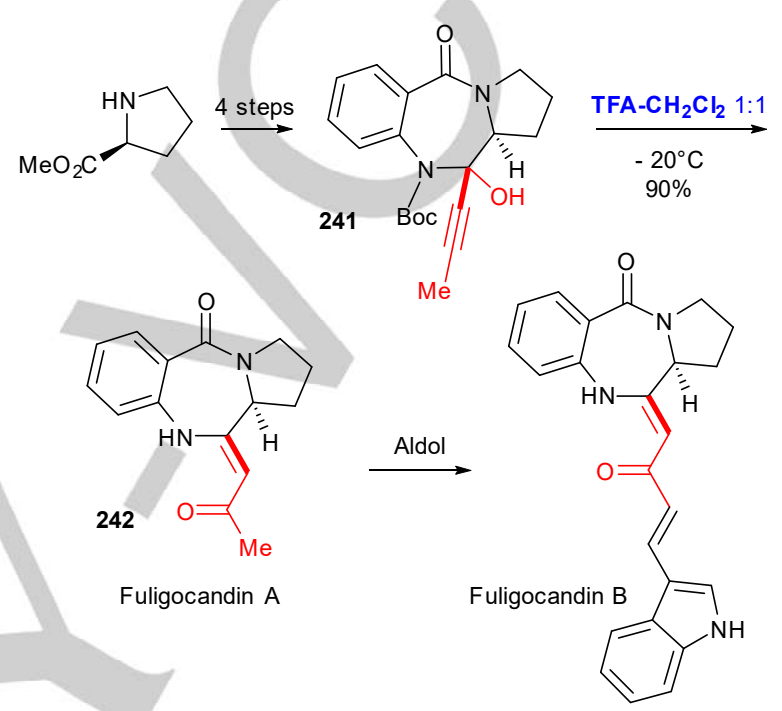

Scheme 59 .Synthesis of Fulinogandins A and B using MSR.

Another application related to the alkaloid field involved indoles as indicated in Scheme $60 .{ }^{[116]}$ The compond 243, obtained by Sonogashira-type reaction starting from 6-iodoindole, was submitted to MSR using para-toluene sulfonic acid in ethanol, affording enone 244 in $75 \%$ yield. Then a Sml 2 -mediated reductive [3+2] cycloaddition, followed by water elimination, gave the cyclopentene $\mathbf{2 4 5}$ in moderate yield.

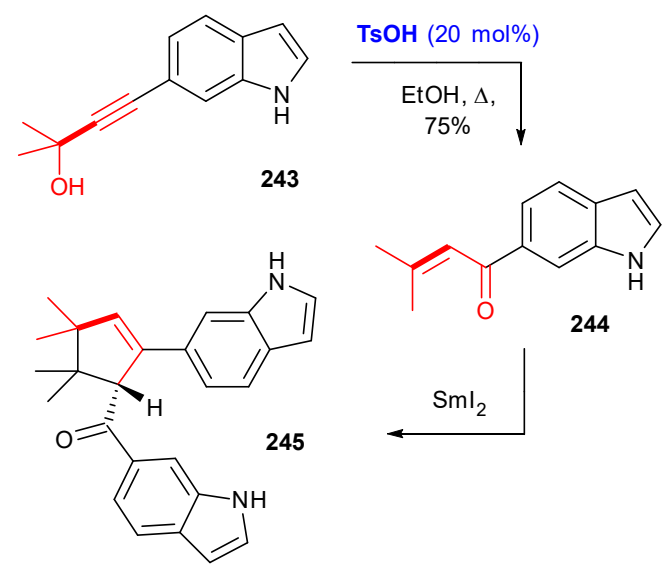

Scheme 60 Synthesis of Indoles using MSR.

\section{Accepted manuscript}


The MSR is also found in a study toward the preparation of the cyclopenta[f]indole core of another alkaloid, raputindole $A$ (Scheme 61). ${ }^{[17]}$ Reaction of the Grignard reagents 246 with the ketone $\mathbf{2 4 7}$ gave in fair to good yields the propargylic alcohols 248 Acid-mediated MSR was avoided due to the presence of the acid sensitive $N$-Boc group. However, reactions using the combination of three $\mathrm{Mo} / \mathrm{Au} / \mathrm{Ag}$ catalysts proved to be very efficient. At $1 \mathrm{~mol} \%$, it afforded the desired enone $249 \mathrm{a}(\mathrm{R}=\mathrm{H})$ in $86 \%$ yield and as a 2:1 mixture of $E$ and $Z$ isomers. In the case of $249 b$ and $249 c, 10$ mol\% and $12 \mathrm{~mol} \%$ of catalysts were required to give $249 \mathrm{~b}$ and 249c in $56 \%$ and $90 \%$ yields respectively and as $2: 1$ mixture of $E$ and $Z$ isomers. The result of $249 c$ was particularly remarkable since it demonstrated that the MSR can be performed even in the presence of a triflate substituent. However all trials to induce acid catalyzed cyclizations starting from these intermediates 249 toward the desired alkaloid were unsuccessful. Therefore, alternative strategies have to be developed towards the target molecule Raputindole A.
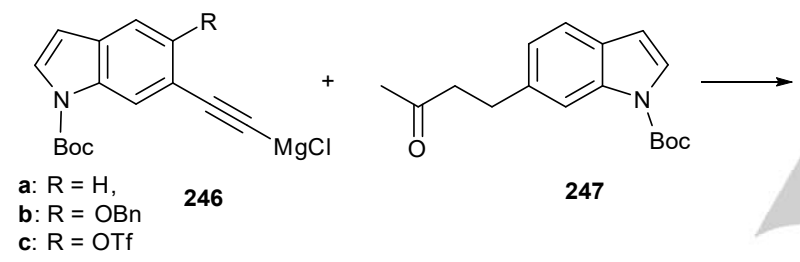

c: $R=O T f$

247

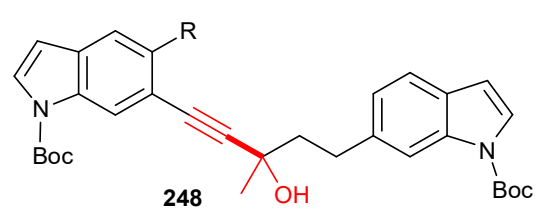

$\mathrm{MoO}_{2}(\mathrm{acac})_{2} 33$ I $\mathrm{Au}\left(\mathrm{PPh}_{3}\right) \mathrm{Cl} 28 \mathrm{~d} /$ AgOTf 29a (1-12 mol\%)

Toluene, rt<smiles>[R]c1cc2ccn(C(=O)OC(C)(C)C)c2cc1C(=O)C=C(C)CCc1ccc2ccn(C(C)(C)C)c2c1</smiles>

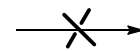
249<smiles>[R6]OC(C)C</smiles>

Scheme 61 . Use of MSR toward the synthesis of Raputindole A.

During the development of a new approach to the [7-5-5] tricyclic core of some Daphniphyllum alkaloids, a MSR was successfully used (Scheme 62). ${ }^{[118]}$ Reaction of Grignard from ethoxyacetylene on the ketone 250 gave the alcohol 251. The MSR was efficiently performed, in that case by using $\mathrm{Sc}(\mathrm{OTf})_{3} 19$, giving the desired conjugated ester $\mathbf{2 5 2}$ as a single stereoisomer and in excellent yield. From this intermediate, the authors could prepare $\mathbf{2 5 3}$, the tricyclic core of these complex alkaloids.
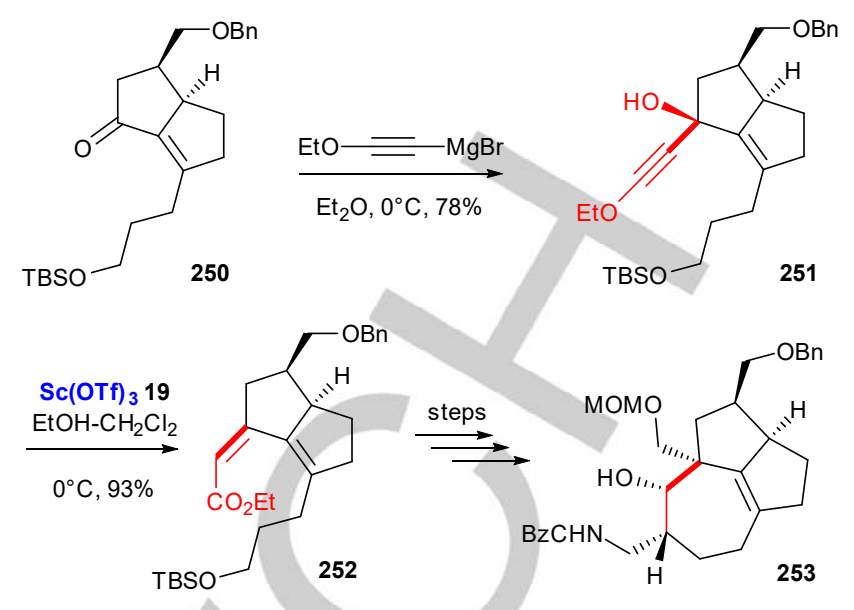

Scheme 62. Use of MSR towards the preparation of the tricyclic core of Daphniphyllum alkaloids.

Another interesting application of the MSR was found in the total synthesis of the alkaloids Lundurine A and B (Scheme 63). ${ }^{[119]}$<smiles>C#[13C][13C](=O)c1ccc2c(c1)C(O)(C#COCC)C1(CCC3(CC1)OCCO3)N2C(=O)c1ccc(OC)cc1</smiles>

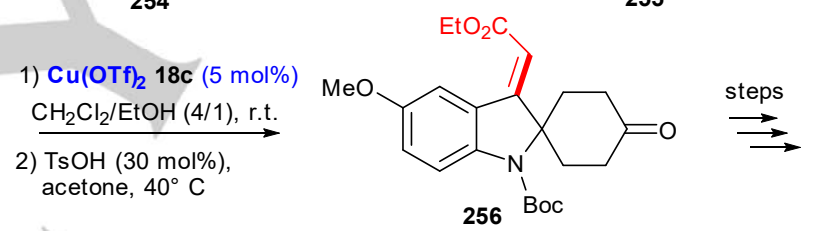<smiles>CCOC(=O)C=C1c2cc(OC)ccc2N(C(C)=O)C12C=CC(=O)CC2</smiles>
257<smiles>COc1ccc2c(c1)[C@@]13CCN4C(=O)C=CC4(CC[C@]21C)C3</smiles>

Lundurine A

Scheme 63. Use of MSR during the total synthesis of the alkaloids Lundurine $A$ and $B$.

Starting from the spiro intermediate $\mathbf{2 5 4}$, the protection as cyclic ketal, followed by addition of the anion of ethoxy acetylene afforded the propargylic alcohol 255. Then a copper (II)-mediated MSR, followed by a deprotection step, afforded smoothly the $\alpha, \beta-$ unsaturated ester 256. Introduction of the double bond and change of the protecting group gave the intermediate 257 ready for another key step, where the intramolecular cyclopropanation was performed using $\mathrm{Sml}_{2}$ in $t-\mathrm{BuOH}$ to give 258. From this

$$
\text { Accepted manuscript }
$$


derivative, the total synthesis of the complex targets Lundurin $A$ and Lundurin B (same without CO group) was successfully achieved.

A recent application was considered towards the preparation of plakinidine alkaloids (Scheme 64). ${ }^{[120]}$ One of the key steps involved a cascade MSR-aza-Michael addition. The authors started with model studies involving propargylic alcohol 259. They screened various types of conditions involving Brønsted and Lewis acids, as well as gold or platinum-based catalysts, and finally selected $\mathrm{SnCl}_{2} 23$ which gave the best results. The MSR to 260 was followed immediately by the intramolecular Michael addition to give $\mathbf{2 6 1}$ in $66 \%$ yield. A very interesting point here is the fact that the MSR occurred in the presence of the primary amino group. Then, on the way to the natural products, they could prepare a fully decorated tetracyclic core structure but unfortunately it proved to be impossible to graft the appropriate propargylic alcohol required for the crucial MS-aza Michael step.<smiles>Nc1ccccc1C#CCCOCCO</smiles>

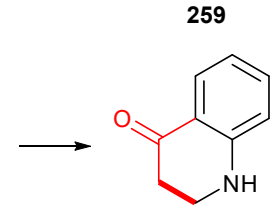

261

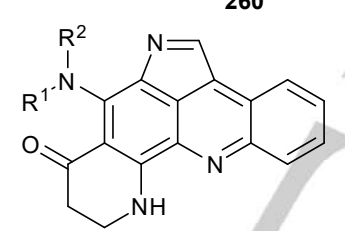

planikidine $A: \mathrm{R}^{1}=\mathrm{Me}, \mathrm{R}^{2}=\mathrm{H}$ planikidine $B: R^{1}=R^{2}=M e$ planikidine $D: R^{1}=R^{2}=H$
Scheme 64 . Use of MSR in model studies toward plakinidines.

Remarkable applications of MSR have been developed also in the area of complex macrolides, in particular towards enigmazole $A$ (Schemes 65 and 66).

In a first series of experiments, the propargylic acetate $\mathbf{2 6 3}$ was obtained from 262 through molybdenum complex-catalysed ring closing alkyne metathesis (RCAM). After oxidative cleavage of $\mathrm{PMB}$ with $\mathrm{DDQ}$, the corresponding alcohol was reacted with $\mathrm{Ph}_{3} \mathrm{AuNTf}_{2}$ (28c at $5 \mathrm{~mol} \%$ ) in dichloromethane. It afforded, in $95 \%$ yield, the tetrahydropyran 265 through a MSR, leading to 264 and followed by intramolecular hydroalkoxylation, while both steps were likely mediated by the gold catalyst $\mathbf{2 8 c}$. The saponification of enol acetate gave the ketone $\mathbf{2 6 6}$, as a simplified model for the target enigmazole A. ${ }^{[121]}$

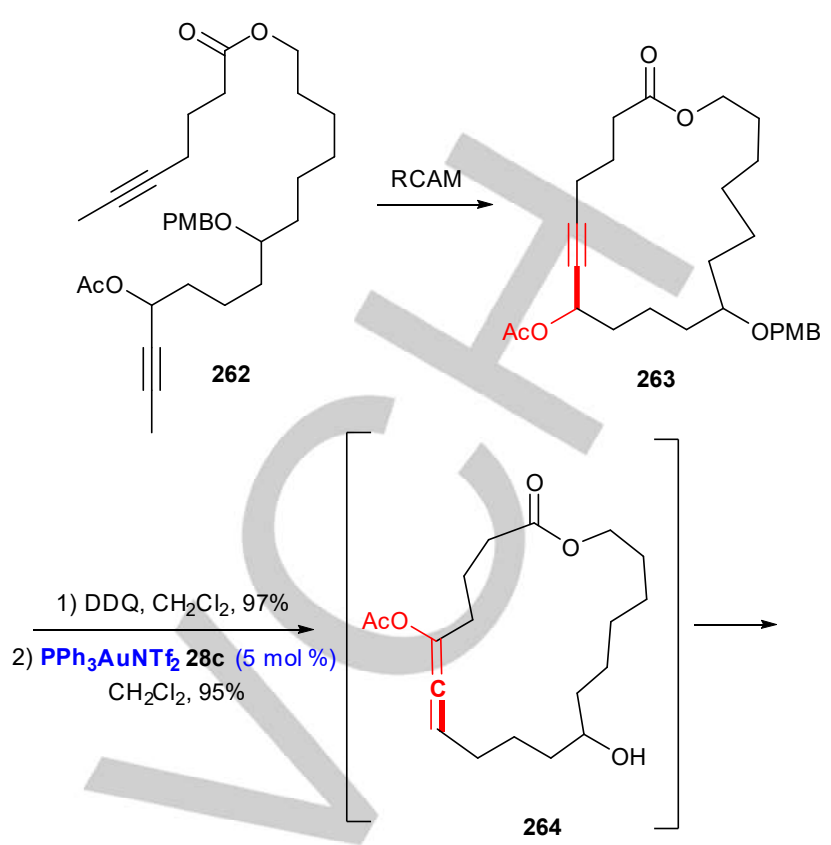

264

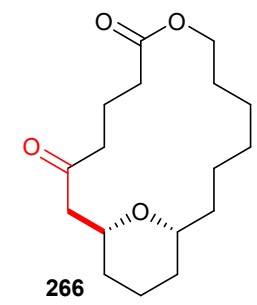

265

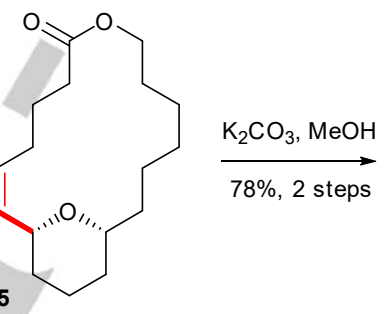

Scheme 65. Use of MSR towards an approach to complex macrolides.

The total synthesis of this macrolide was completed more recently, and also using a MSR in a crucial step (Scheme 66). After extensive optimization studies, the authors found that the propargylic benzoate 267 reacted with the combination of gold and silver catalysts $\left(\mathbf{2 8} \mathbf{g}_{2}+\mathbf{2 9 b}\right)$, in $\mathrm{THF} / \mathrm{H}_{2} \mathrm{O}$ mixture and under microwave irradiation, to give the desired enone 268 in $82 \%$ yield. Other gold and platinum complexes proved to be ineffective in this case. From this intermediate 268, the total synthesis of the enigmazole $A$ could be successfully completed. ${ }^{[122]}$ This example is particularly remarkable to demonstrate the potential of the MSR: in spite of the complexity of the molecule $\mathbf{2 6 7}$ and the high number of chiral stereocenters, it proved to be possible to find an appropriate catalyst to perform efficiently this reaction on the way to the targeted macrolide. 


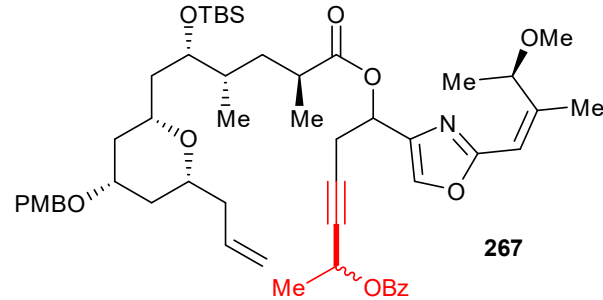

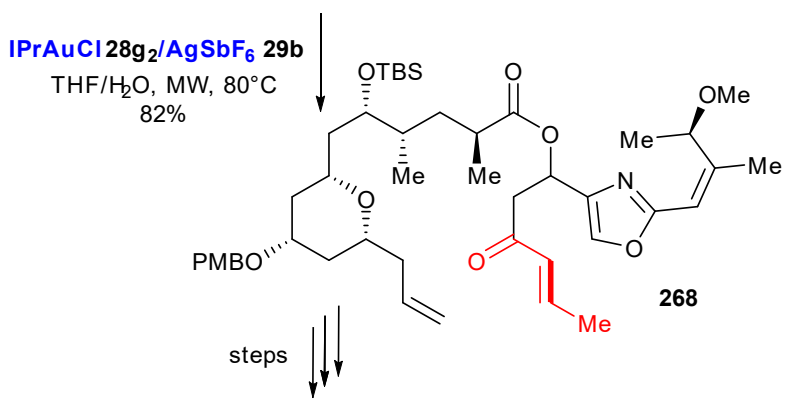

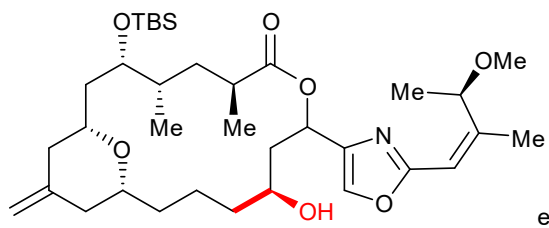

enigmazole $\mathrm{A}$

Scheme 66 . Use of MSR during the total synthesis of enigmazole A.

In the same area of complex macrolides bearing tetrahydropyran units, a domino MSR-hetero-Michael addition process has been developed to prepare cis-disubstituted tetrahydropyrans (Scheme 67). ${ }^{[123]}$ The alkyne diols 269 were submitted to various $\mathrm{Au}(\mathrm{I})$ and $\mathrm{Pt}$ (II) catalysts but the gold catalyst $\left[\mathrm{Ph}_{3} \mathrm{PAu}\right] \mathrm{TFA}$ gave the best results, affording the desired tetrahydropyrans $\mathbf{2 7 0}$ in fair yields and with a complete cis stereoselectivity, as desired for the preparation of the target molecules.

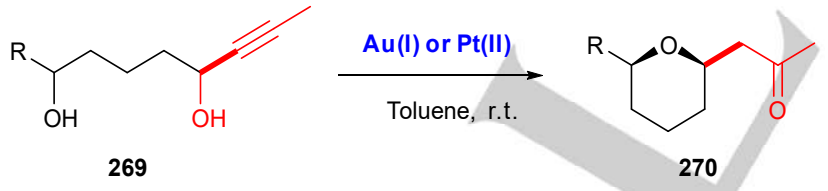

Scheme 67. MSR and oxa-Michael addition for the synthesis of cis 2,6-disubstituted tetrahydropyrans.

This method was ultimately employed for the preparation of the core structure of 15-epi-exiguolide (Scheme 68). ${ }^{[124]}$ Starting from the advanced propargylic intermediate $\mathbf{2 7 1}$, the crucial MSR step was successfully performed using catalyst $\mathbf{2 8 p}$ at $15 \mathrm{~mol} \%$ to obtain the enone intermediate 272. The TBS deprotection was followed immediately by the intramolecular oxa-Michael addition to give $\mathbf{2 7 3}$ and, after reprotection of the propargylic alcohol, the compound 274. This intermediate was ultimately transformed into $\mathbf{2 7 5}$, which is the core structure of the target macrolide.
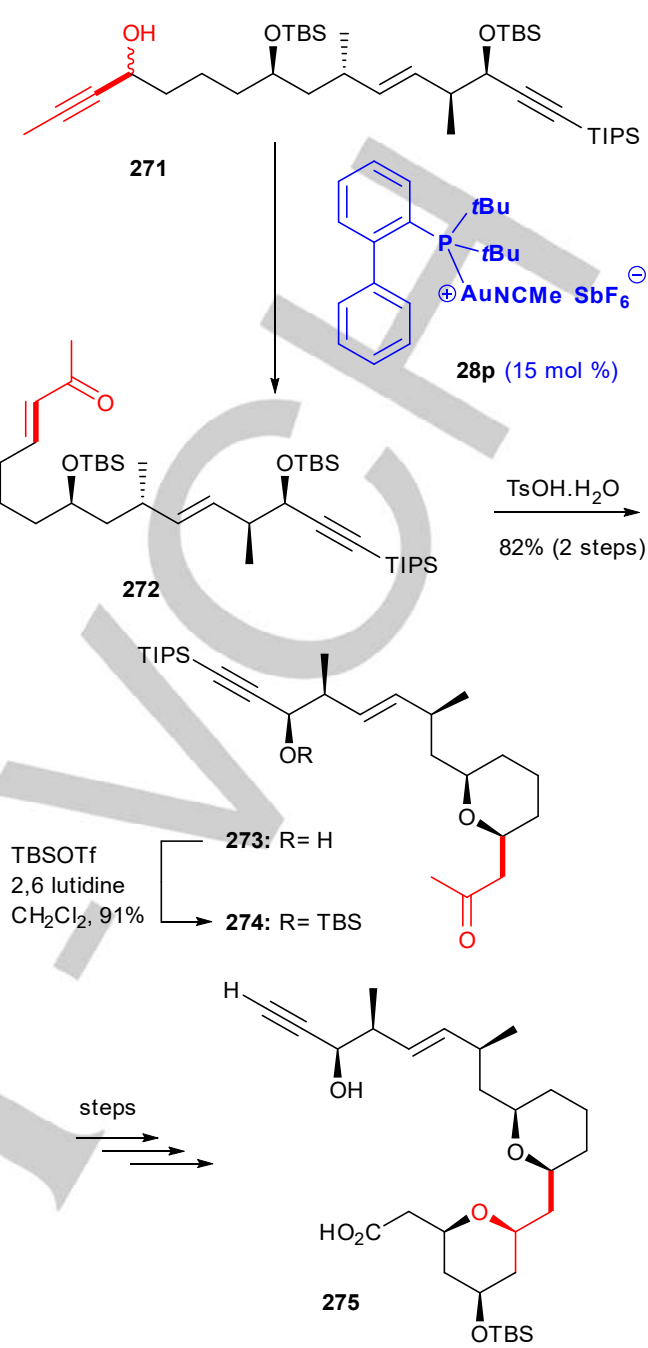

Scheme 68. MSR for the synthesis of the core structure of 15-epiexiguolide.

\section{The aza-Meyer-Schuster rearrangement}

In principle, the Meyer-Schuster rearrangement could be extended as well to propargyl amines such as $\mathbf{2 7 6}$ (Scheme 70) However, taking into account the presence of a basic amino group, even if this can be modulated by the nature of the $\mathrm{R}^{4}$ substituent, the development of efficient electrophilic catalysts (acidic or metallic) was a challenging task in that case. Furthermore, depending upon the nature of the substituents and the reaction conditions, various types of secondary processes can occur from the conjugated imines 277.

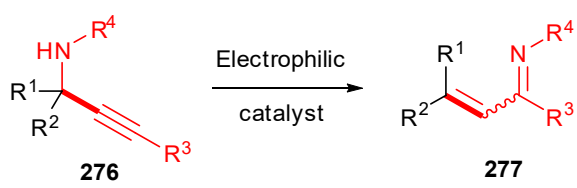

Scheme 69. The formal aza-analogue of the MSR.

\section{Accepted manuscript}


Hydrazine derivatives were a first solution to introduce the nitrogen atom and one example was reported in 2012, leading to $\alpha, \beta$-unsaturated nitriles as indicated in Scheme $70 .{ }^{[125]}$ Reaction of propargylic alcohols 278, bearing a TMS in terminal position, with tosylhydrazine afforded the conjugated nitriles 279. Extensive screening of the catalysts and reaction conditions indicated that $\mathrm{FeCl}_{3} \mathbf{1 0}$ (at $10 \mathrm{~mol} \%$ ) in nitromethane afforded the best yields in nitriles 279 . Similarly, tosyl hydrazine was the best nitrogen introducing reagent. Model studies were performed with $\mathbf{2 8 0}$, allowing the authors to propose a mechanism: the reaction with tosylhydrazine affords first the propargylic hydrazine 281, which could be isolated under slightly modified conditions.

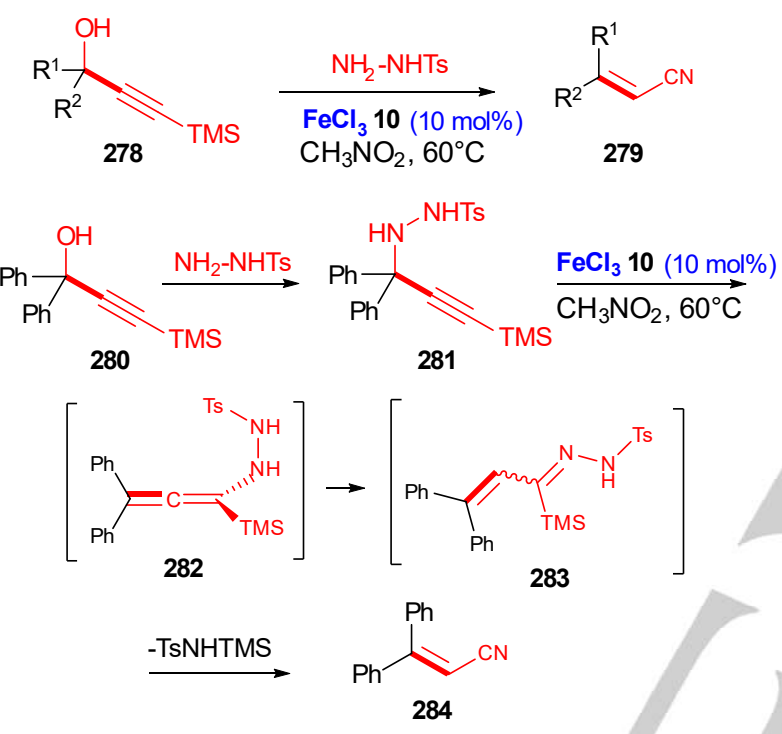

Scheme 70. Aza-MSR for the synthesis of $\alpha, \beta$-unsaturated nitriles.

On reaction with $\mathrm{FeCl}_{3} 10$, this intermediate was subjected to azaMeyer-Schuster to give allenyl intermediate 282, which tautomerized to conjugated hydrazone 283. After departure of Ts$\mathrm{NH}-\mathrm{TMS}$, the conjugated nitrile $\mathbf{2 8 4}$ was obtained as the final product.

Short time later, the same authors developed a synthesis of pyrazoles based on similar starting materials 285 (Scheme 71). ${ }^{[126]}$ The difference was that, immediately after the aza-MSR, they heated the reaction mixture with a base. Extensive screening showed that $\mathrm{Cs}_{2} \mathrm{CO}_{3}$, and also $\mathrm{K}_{2} \mathrm{CO}_{3}$, were the most efficient bases. Control experiments, combined with computational studies, allowed to propose a mechanism with an aza-MSR as a first step to give the conjugated imine $\mathbf{2 8 6}$ as an intermediate. After proton abstraction with the base and departure of $\mathrm{Ts}^{-}$, the conjugated diazo intermediate obtained (287) gave a first pyrazole intermediate 288 by electrocyclization. Then, sigmatropic shifts gave the $3,4,5$ pyrazoles 289 when $R^{1}, R^{2}$ were aryl groups and the $1,2,3$ pyrazoles 290 when $R^{1}, R^{2}$ were alkyl groups.
With slight changes, the same group established later a synthesis of similar iodo pyrazoles. ${ }^{[127]}$ The intermediate hydrazones 291 , prepared in the same way, were subjected to reaction with iodine in acetonitrile, in the presence of sodium bicarbonate as a base, affording in excellent yields the iodo pyrazoles 292. Latter compounds can be further employed in synthesis through classical Pd-catalyzed reactions of the carbon-iodine bond.
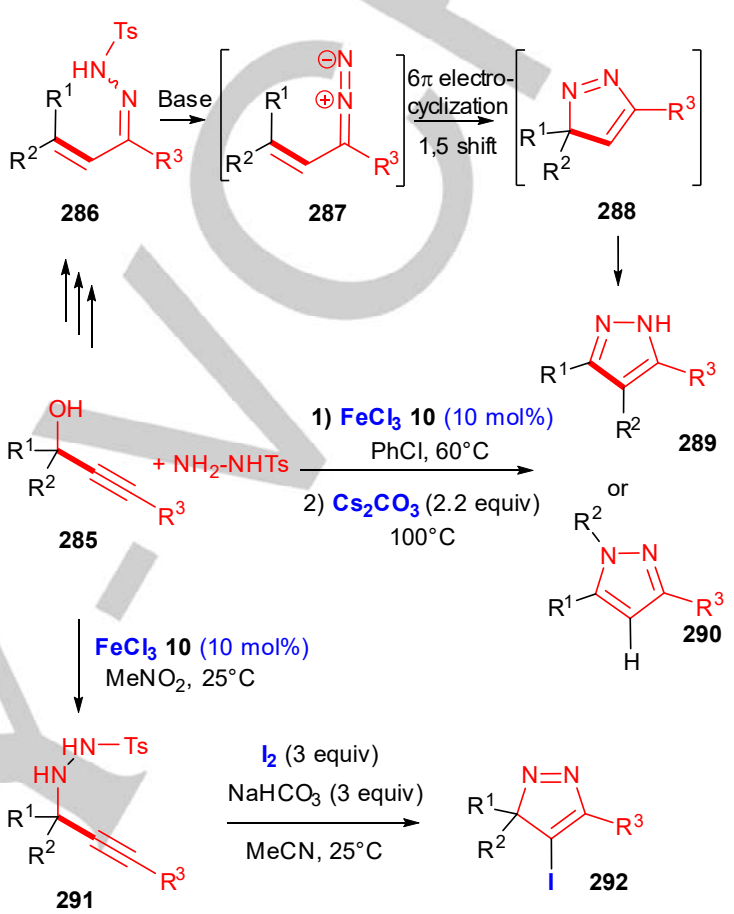

Scheme 71. Aza-MSR in the synthesis of various pyrazoles.

In parallel, another team has demonstrated that the use of $\mathrm{Yb}(\mathrm{OTf})_{3} 21$ in acetonitrile at $80^{\circ} \mathrm{C}$ allowed also the synthesis of the unsaturated hydrazones 286 . Then, reaction with $t$-BuOLi in toluene at $80^{\circ} \mathrm{C}$ gave the desired pyrazoles 293 or 294 depending upon the nature of the substituents $R^{1}$ and $R^{2}$ (Scheme 72). ${ }^{[128]} A$ one-pot transformation, starting from alkyne and aryl ketones, was also demonstrated.

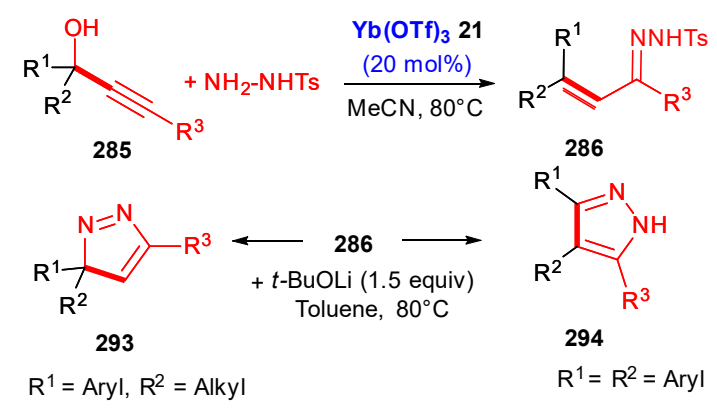

Scheme 72. Synthesis of hydrazones and pyrazoles using azaMSR mediated by $\mathrm{Yb}(\mathrm{OTf})_{3} 21$.

\section{Accepted manuscript}


The aza-MSR has been also performed with isatin hydrazones 296 (Scheme 73). ${ }^{[129]}$ In the presence of iodine in dichloroethane at room temperature, the propargylic alcohol 295 afforded in excellent yields the diazatrienes 297 through the aza-MSR followed by tautomerization. When the reaction was performed with an excess of iodine ( 2.5 equiv), the iodo derivatives 298 were obtained also in good yields. In latter case, the intermediate allenes were trapped by iodine. These reactions were extended to propargylic alcohols with various Ar groups, as well as to substituted isatins.

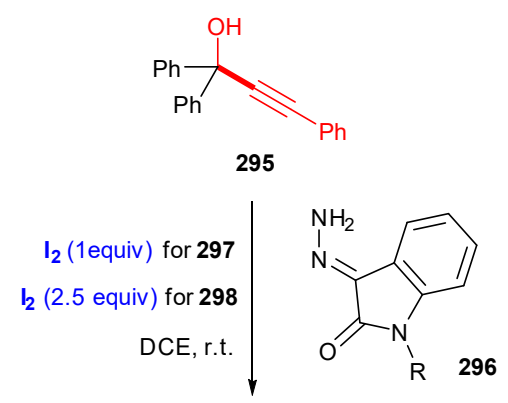<smiles>[R]N1C(=O)/C(=N/N=C/c2ccccc2)c2ccccc21</smiles><smiles>[R]N1C(=O)/C(=N/N=C(/I)C(I)=C(c2ccccc2)c2ccccc2)c2ccccc21</smiles>

Scheme 73. Synthesis of diazatrienes using aza-MSR

The aza-Meyer-Schuster has been performed also starting from $\gamma$-amino-ynamides 299 to afford azadienes 302 by reaction with $\mathrm{NHTf}_{2}$ (Scheme 74). ${ }^{[130]}$ In depth studies allowed the authors to propose a mechanism where a first step led to the keteneiminium $\mathbf{3 0 0}$ which cyclized to azetene $\mathbf{3 0 1}$ by intramolecular nucleophilic reaction. Then, a final electrocylic ring opening gave the amino azadiene 302 .

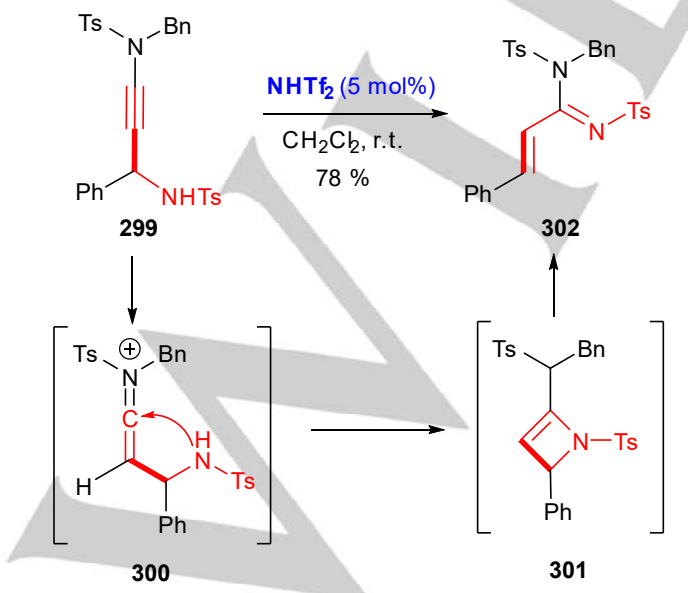

Scheme 74. Synthesis of azadienes through the aza-MSR.
Hydroxylamine has been also used to introduce nitrogen during aza-MSR (Scheme 75). ${ }^{[131]}$ Starting from arylpropynes 303, a $D D Q-m e d i a t e d$ single electron tranfer gave a propargylic cation, which reacted with hydroxylamine to give the propargylamine intermediate 304 through a cross dehydrogenative coupling reaction. Then, the aza-MSR promoted by polyphosphoric acid (PPA) gave the intermediate oxime $\mathbf{3 0 5}$ which, under the acidic reaction conditions, afforded the acrylamides 306 via a Beckman rearrangement.

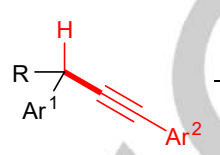

303

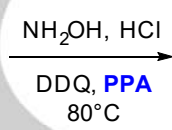

306
Beckmann Rearrangement

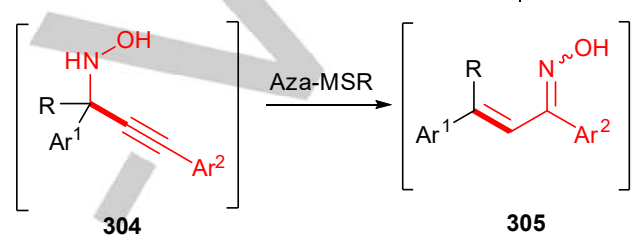

Scheme 75. Synthesis of $\alpha, \beta$-unsaturated amides in a one-pot process involving a cascade aza-MSR-Beckman rearrangement.

Another possibility has been described, starting from propargylic amines (Scheme 76). ${ }^{[132]}$ Oxidation of $\mathbf{3 0 7}$ by molecular oxygen in the presence of $\mathrm{Cu}(\mathrm{OAC})_{2}$ and $\mathrm{FeCl}_{3} 10$ at $100^{\circ} \mathrm{C}$ gave first a conjugated iminium ion $\mathbf{3 0 8}$ which was trapped by water to give intermediate 309. Then an aza-MSR occured to deliver the $\beta$ aminoacrylaldehyde $\mathbf{3 1 1}$, selectively as the $E$ isomers, after tautomerization of the allenol intermediate $\mathbf{3 1 0}$

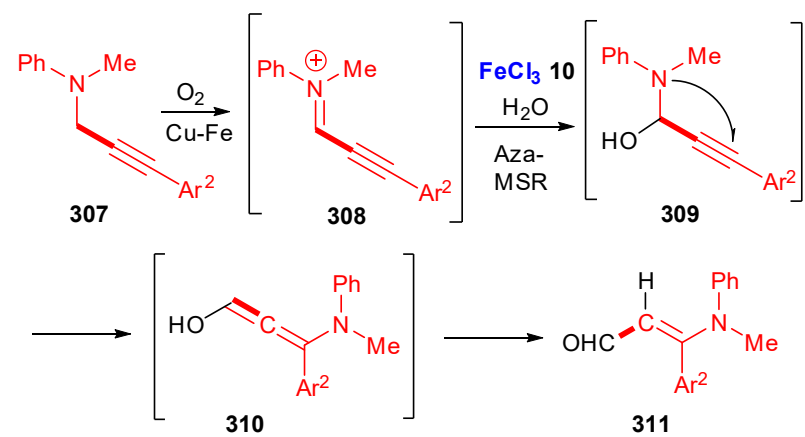

Scheme 76. Synthesis of $\beta$-aminoacrylaldehydes through azaMSR.

\section{Conclusions and Perspectives}

Almost a century after its discovery, it is clear that the MeyerSchuster Rearrangement has become a "classic reaction" in

\section{Accepted manuscript}


organic synthesis. It is particularly useful in the case where common olefination procedures are not working properly, or even not efficient at all. The last decade has shown significant development in MSR with the discovery and use of novel and very efficient catalysts, especially those based on gold and other metals. Further, it has been demonstrated that the intermediates of MSR, either the carbenium ions or the enol, offered many new opportunities in the synthetic applications, for instance in the "intercepted Meyer Schuster". On the other hand, the $\alpha, \beta$-unsaturated carbonyl derivatives obtained in the MSR proved to be highly versatile intermediates for the development of new cascade reactions. This aspect has been well explored during the last decade but it will very likely continue to develop in the future. Another key issue was the very significant extension of the use of MSR in the total synthesis of natural products and analogues. The MSR, as a key step in the preparation of highly complex and multifunctional molecules, demonstrated the high potentialities of the catalysts recently developed. Finally, this decade has seen the first papers appearing on the aza-Meyer-Schuster and this variant of MSR will probably continue to grow in the near future.

Among the possible future developments, some aspects can be anticipated. Taking into account its nature, it is clear that MSR has all potentialities to be employed in the context of flow chemistry and this should happen soon. On the other hand, it appears likely that the first examples of thia-MeyerSchuster could appear also in a near future. They could take advantage of the specific properties of the sulfur atom in order to generate carbenium intermediates under non usual reaction conditions and thus, contribute to develop new aspects in MSR.

Finally, more computational studies are required for an in depth understanding of some key mechanistic issues relevant from MSR. For instance, the use of aryl groups as substituents is very common, likely to facilitate the formation of the intermediate carbenium ions. However, even if the global mechanism of MSR is well understood, at the computational level, we don't have enough knowledge to date about the effect of the side chains substituents on the reactivity of the propargylic alcohols. How do these substituents effect the reactivity of the alkyne, the stability of the intermediate ions, and the reversibility of the ionisation and water re-addition steps? Further, how do they impact the reactivity and the regioselectivity of the additions of the various nucleophiles? At this level, detailed computational studies should contribute very much to a better understanding of these steps and this knowledge should transfer into improved synthetic uses of this superb reaction.

\section{Acknowledgements}

This research has been supported in Lebanon by the Research Grant program at Lebanese University. In France it has been supported by French CNRS and University of Rennes 1 (CNRS UMR 6226).

Keywords: Meyer-Schuster $•$ rearrangement $\bullet$ catalysis $•$ cascade reactions $\bullet$ total synthesis.

\section{References}

[1] K. H. Meyer and K. Schuster, Chem. Ber., 1922, 55, 819-823.

[2] S. Swaminathan and K. V. Naranayan, Chem. Rev., 1971, 71 429-438.

[3] D. A. Engel and G. B. Dudley, Org. Biomol. Chem., 2009, 7 4149-4158.

[4] D. Roy, P. Tharra and B. Baire, Asian J. Org. Chem., 2018, 7 1015-1032.

[5] (a) B. Zhang and T. Wang, Asian J. Org. Chem., 2018, 7, 17581783; (b) B. Alcaide and P. Almendros, Acc. Chem. Res. 2014, 47, 939-952; (c) S. Zhang, F. Wei, C. Song, J. Jia and Z. Xu, Chinese J. Chem., 2014, 32, 937-956.

[6] (a) V. Cadierno, P. Crochet, S. E. Garcia-Garrido and J. Gimeno, Dalton Trans., 2010, 39, 4015-4031; (b) V. Cadierno S. E. Garcia-Garrido, J. Gimeno and N. Nebra, Inorganica Chimica Acta., 2010, 363, 1912-1934; (c) E. B. Bauer, Synthesis, 2012, 44, 1131-1151.

[7] (a) Y. Zhu, L. Sun, P. Lu and Y. Wang, ACS Catal., 2014, 4 1911-1925; (b) S. Puri, ChemistrySelect, 2020, 5, 9866-9877.

[8] J. Park, J. Yun, D.-J. Jang, C. H. Park and K. Lee, Synth Commun., 2014, 44, 1924-1929.

[9] X. Gan, Z. Fu, L. Liu, Y. Yan, C. Chen, Y. Zhou and J. Dong Tetrahedron Lett., 2019, 60, 150906.

[10] H. Zheng, M. Lejowski and D. G. Hall, Chem. Sci., 2011, 2 1305-1310.

[11] (a) Y.-W. Kang, Y. J. Cho, S. J. Han and H.-Y. Jang, Org. Lett., 2016, 18, 272-275; (b) W. Shi, S. Sun, M. Wu, B. Catano, W. Li, J. Wang, H. Guo and Y. Xing, Tetrahedron Lett., 2015, 56, 468-471.

[12] M. Egi, M. Umemura, T. Kawai and S. Akai, Angew. Chem. Int Ed., 2011, 50, 12197-12200.

[13] N. Mameda, S. Peraka, M. R. Marri, S. Kodumuri, D. Chevella N. Gutta and N. Nama, Applied Catalysis A: General, 2015, 505, 213-216.

[14] A. J. Curtis, C. D. Gabbutt, B. M. Heron and C. Kilner Tetrahedron Lett., 2011, 52, 708-710.

[15] A. S. El Douhaibi, Z. M. A. Judeh, H. Basri, Z. Moussa, M Messali and G. Qi, Synth. Commun., 2011, 41, 533-540.

[16] S. Puri, M. H. Babu and M. S. Reddy, Org. Biomol. Chem. 2016, 14, 7001-7009.

[17] M. Ramasamy, H.-C. Lin, S.-C. Kuo and M.-T. Hsieh, Synlett, 2019, 30, 356-360.

[18] L. Yang and Q. Zeng, Synthesis, 2017, 49, 3149-3156.

[19] C. Du, X. Wang, S. Jin, H. Shi, Y. Li, Y. Pang, Y. Liu, M. Cheng, C. Guo and Y. Liu, Asian J. Org. Chem., 2016, 5, 755-762. 
[20] Z. Moussa and A. Aljuhani, Lett. Org. Chem., 2018, 15, 845853.

[21] B. Alcaide, P. Almendros, S. Cembellin and T. M. del Campo, Adv. Synth. Cat., 2015, 357, 1070-1078.

[22] (a) M. N. Pennell, M. G. Unthank, P. Turner and T. D. Sheppard, J. Org. Chem., 2011, 76, 1479-1482; (b) M. N. Pennell, P. G. Turner and T. D. Sheppard, Chem. Eur. J., 2012 $18,4748-4758$

[23] M. N. Pennell, M. P. Kyle, S. M. Gibson, L. Male, P. G. Turner R. S. Grainger and T. D. Sheppard, Adv. Synth. Cat., 2016 358, 1519-1525.

[24] G. V. Velegraki and M. Stratakis, J. Org. Chem., 2013, 78, 8080-8084.

[25] S. Gaillard, A. M. Z. Slavin and S. P. Nolan Chem. Commun., 2010, 46, 2742-2744.

[26] A. Gomez-Suarez, Y. Oonishi, S. Meiries and S. P. Nolan Organometallics, 2013, 32, 1106-1111.

[27] M. Brill, F. Nahra, A. Gomez-Suarez, C. Zinser, D. B. Cordes, A. M. Z. Slavin and S. P. Nolan ChemCatChem, 2017, 9, 117120.

[28] D. Wang, Y. Zhang, A. Harris, L. N. S. Gautam, Y. Chen and X. Shi, Adv. Synth. Cat., 2011, 353, 2584-2588.

[29] W. Yao, Y. Zhang, X. Xu, Y. Yang, W. Zeng and D. Wang, J. Organomet. Chem., 2019, 901, 120944

[30] Y. Yang, Y. Shen, X. Wang, Y. Zhang, D. Wang and X. Shi Tetrahedron Lett., 2016, 57, 2280-2282.

[31] (a) S. M. Kim, D. Lee and S. H. Hong, Org. Lett., 2014, 16 6168-6171; (b) D. Lee, S. M. Kim, H. Hirao and S. H. Hong, Org. Lett., 2017, 19, 4734-4737.

[32] W. Fang, M. Presset, A. Guerinot, C. Bour, S. BezzenineLafollée and V. Gandon, Chem. Eur. J., 2014, 20, 5439-5446.

[33] N. Naveen, G. Ramesh and R. Balamurugan, ChemistrySelect, 2019, 4, 13610-13614.

[34] J. Garcia-Alvarez, J. Diez, C. Vidal and C. Vicent, Inorg Chem., 2013, 52, 6533-6542.

[35] J. Garcia-Alvarez, S.E. Garcia-Garrido and V. Cadierno, J. Organomet. Chem., 2014, 751, 792-808.

[36] M. Talavera, J. Bravo, L. Consalvi, M. Peruzzini, C. Zuccaccia and S. Bolano, Eur. J. Inorg. Chem., 2014, 6268-6274.

[37] A. Antinolo, F. Carillo-Hermosilla, V. Cadierno, J. GarciaAlvarez and A. Otero, ChemCatchem, 2012, 4, 123-128.

[38] A. Nikolaev and A. Orellana, Org. Lett., 2015, 17, 5796-5799.

[39] (a) B. M. Trost, X. Luan and Y. Miller, J. Amer. Chem. Soc., 2011, 133, 12824-12833; (b) B. M. Trost and J. S. Tracy, Acc. Chem. Res., 2020, 53, 1568-1579.

[40] B. S. L. Collins, M. G. Suero and M. J. Gaunt, Angew. Chem Int. Ed., 2013, 52, 5799-5802.

[41] B. Alcaide, P. Almendros, E. Busto and A. Luna, Adv. Synth Cat., 2016, 358, 1526-1533.

[42] (a) J. Um, H. Yun and S. Shin, Org. Lett., 2016, 18, 484-487; (b) A. T.-Aca, M. N. Hopkinson, R. A. Garza-Sanchez and F. Glorius, Chem. Eur. J., 2016, 22, 5909-5913; (c) D. M. Knoll, C. Zippel, Z. Hassan, M. Nieger, P. Weiss, M. M. Kappes and S. Bräse Dalton Trans., 2019, 48, 17704-17708

[43] D. Kaiser, L. F. Veiros and N. Maulide, Adv. Synth. Cat., 2017 359, 64-77.

[44] S. Banerjee, S. B. Ambegave, R. D. Mule, B. Senthilkumar and N. T. Patil, Org. Lett., 2020, 22, 4792-4796.

[45] S. Puri, N. Thirupathi and M. S. Reddy, Org. Lett., 2014, 16, 5246-5249.

[46] H.-T. Zhu, M.-J. Fan, D.-S. Yang, X.-L. Wang, S. Ke, C.-Y Zhang and Z.-H. Guan, Org. Chem. Front., 2015, 2, 506-509.

[47] Y. Yang, W. Hu, X. Ye, D. Wang and X. Shi, Adv. Synth. Cat., 2016, 358, 2583-2588.

[48] M. Zao and J. T. Mohr, Tetrahedron, 2017, 73, 4115-4124

[49] (a) G. Zhang, Y. Peng, L. Cui and L. Zhang, Angew. Chem. Int Ed., 2009, 48, 3112-3115; (b) T. de Haro and C. Nevado Chem. Commun., 2011, 47, 248-249.
[50] (a) S. Sadhukhan and B. Baire, Chem. Eur. J., 2019, 25, 98169820; (b) J. M. D'Oyley, A. E. Aliev and T. D. Sheppard, Angew. Chem. Int. Ed., 2014, 53, 10747-10750.

[51] Y.-P. Xiong, M.-Y. Wu, X.-Y. Zhang, C.-L. Ma, L. Huang, L.-J Zhao, B. Tan and X.-Y. Liu, Org. Lett., 2014, 16, 1000-1003.

[52] Y. Lin, W. Kong and Q. Song, Org. Lett., 2016, 18, 3702-3705

[53] P. Tharra and B. Baire, Chem. Eur. J., 2017, 23, 2014-2017.

[54] P. Tharra and B. Baire, Org. Biomol. Chem., 2017, 15, 5579 5584

[55] P. Tharra and B. Baire, Chem. Commun., 2016, 52, 12147 12150.

[56] P. Tharra and B. Baire, Chem. Commun., 2016, 52, 14290 114293.

[57] P. Tharra and B. Baire, J. Org. Chem., 2015, 80, 8314-8328.

[58] M. M. Hansmann, A. S. K. Hashmi and M. Lautens, Org. Lett., 2013, 15, 3226-3229.

[59] S. Yaragorla, R. Dada, P. Rajesh and M. Sharma, ACS Omega, 2018, 3, 2934-2946.

[60] R. Tao, Y. Yin, Y. Duan, Y. Sun, Y. Sun, F. Cheng, J. Pan, C. Lu and $Y$. Wang, Tetrahedron, 2017, 73, 1762-1768.

[61] N. Okamoto, T. Sueda and R. Yanaka, J. Org. Chem., 2014 79, 9854-9859.

[62] A. E. Garst, A. D. Badiceanu and K. A. Nolin, Tetrahedron Lett. 2013, 54, 459-461

[63] Y. Wang, Y. Yin, Q. Zhang, W. Pan, H. Guo and K. Pei, Tetrahedron Lett., 2019, 60, 2030-2034.

[64] S. Sabater, J. A. Mata and E. Peris, Eur. J. Inorg. Chem., 2013, 4764-4769.

[65] C. Shan, F. Chen, J. Pan, Y. Gao, P. Xu and Y. Zhao J. Org. Chem., 2017, 82, 11659-11666

[66] (a) M. Presset, B. Michelet, R. Guillot, C. Bour, S. BezzenineLafollée and V. Gandon, Chem. Commun., 2015, 51, 5318 5321; (b) S. P. Morcillo, M. Presset, S. Floquet, V. Coeffard, C. Greck, C. Bour and V. Gandon, Eur. J. Org. Chem., 2016 2688-2694; (c) S. P. Morcillo, D. Leboeuf, C. Bour and V. Gandon, Chem. Eur. J., 2016, 22, 16974-16978.

[67] (a) N. Morita, T. Tsunokake, Y. Narikiyo, M. Harada, T. Tachibana, Y. Saito, S. Ban, Y. Hashimoto, I. Okamoto and O. Tamura, Tetrahedron Lett., 2015, 56, 6269-6272. (b) N. Morita, Y. Saito, A. Muraji, S. Ban, Y. Hashimoto, I. Okamoto and O. Tamura Synlett, 2016, 27, 1936-1940.

[68] (a) H.-D. Vu, J. Renault, T. Roisnel, N. Gouault and P. Uriac Eur. J. Org. Chem., 2014, 4506-4514; (b) H.-D. Vu, J. Renault, T. Roisnel, N. Gouault and P. Uriac, Tetrahedron Lett., 2016, 57, 3036-3038

[69] J. Guild, M. J. Morris, C. C. Robertson and A. W. H. Speed Tetrahedron Lett., 2019, 60, 151079.

[70] H. Minami, N. Okamoto, T. Sueda, T. Sakaguchi, M. Ishikura and R. Yanada, Tetrahedron Lett., 2017, 58, 4277-4280.

[71] G. Sun, F. Cheng, R. Tao, Y. Sun, J. Pan, Y. Zhu, Z. Wang, F. Wu and Y. Yin, Synth. Commun., 2016, 46, 1249-1256.

[72] C. Schwehm, M. Wohland and M. E. Maier, Synlett, 2010, 12 1789-1792

[73] N. Morita, A. Yasuda, M. Shibata, S. Ban, Y. Hashimoto, I. Okamoto and O. Tamura, Org. Lett., 2015, 17, 2668-2671.

[74] X.-S. Zhang, J.-Y. Jiao, X.-H. Zhang, B.-L. Hu and Z.-G. Zhang, J. Org. Chem., 2016, 81, 5710-5716.

[75] C. Liu, B. Wang, Z. Guo, J. Zhang and M. Xie, Org. Chem. Front., 2019, 6, 2796-2800.

[76] N.-N. Zhou, S;-S. Ning, X;-J. Tong, T;-T. Luo, J. Yang, L.-Q. Li M.-J. Fan, D.-S. Yang and H.-T. Zhu, J. Org. Chem., 2019, 84 8497-8508

[77] (a) S. Aiken, B. Armitage, C. D. Gabbutt and B. M. Heron Tetrahedron Lett., 2015, 56, 4840-4842; (b) C. D. Gabbutt, B. M. Heron, C. Kilner and S. B. Kolla, Org. Biomol. Chem., 2010 8, 4874-4883. 
[78] (a) H. Zhu and Z. Chen, Org. Lett., 2016, 18, 488-491; (b) B. Yan, Y. Fu, H. Zhu and Z. Chen, J. Org. Chem., 2019, 84 4246-4262.

[79] J.-H. An, H. Yun, S. Shin and S. Shin, Adv. Synth. Cat., 2014 356, 3748-3754.

[80] X.-Q. Mou, Z.-L. Xu, S.-H. Wang, D.-Y. Zhu, J. Wang, W. Bao S.-J. Zhou, C. Yang and D. Zhang, Chem. Commun., 2015, 51, 12064-12067.

[81] B. Alcaide, P. Almendros and M. T. Quiros, Adv. Synth. Cat. 2011, 353, 585-594.

[82] V. Kadiyala, P. B. Kumar, S. Balasubramanian and G. V. Karunakar J. Org. Chem., 2019, 84, 12228-12236.

[83] X.-S. Li, Y.-P. Han, X.-Y. Zhu, Y. Xia, W.-X. Wei, M. Li and Y. M. Liang, Adv. Synth. Cat., 2018, 360, 4441-4445.

[84] Y.-P. Han, X.-S. Li, Z. Sun, X.-Y. Zhu, M. Li, X.-R. Song and Y. M. Liang, Adv. Synth. Cat., 2017, 359, 2735-2740.

[85] Y.-F. Qiu, Y.-J. Niu, X.-R. Song, X. Wei, H. Chen, S.-X. Li, X.C. Wang, C. Huo, Z.-J. Quan and Y.-M. Liang, Chem. Commun., 2020, 56, 1421-1424.

[86] Y. Wu, M. Shao, Z. Feng, X. Gu, Y. Hong, Q. Cui, L. Ren and S. Wang, Asian J. Org. Chem., 2017, 6, 76-82.

[87] L. Sun, P. Liu, J. Wang, P. Lu and Y. Wang, J. Org. Chem., 2017, 82, 8407-8418

[88] Z. Sun, K. Xiang, H. Tao, L. Guo and Y. Li, Org. Biomol. Chem., 2018, 16, 6133-6139

[89] S. Yaragorla, R. Dada, G. Singh, A. Pareek, M. Rana and A. K. Sharma, ChemistrySelect, 2016, 1, 6902-6906

[90] X. Xu, Y. Lu, G. Hong, Z. Zhao and X. Li, Arkivoc, 2014, (v), 237-246.

[91] Y.-P. Han, X.-S. Li, X.-Y. Zhu, Z. Sun, M. Li, Y.-Z. Wang and Y.-M. Liang, Adv. Synth. Cat., 2018, 360, 870-874.

[92] Y.-F. Lin, C. Wang, B.-L. Hu, P.-C. Qian and X.-G. Zhang, Synlett, 2017, 28, 707-712.

[93] (a) J. Borge, V. Cadierno, J. Diez, S. E. Garcia-Garrido and J. Gimeno, Dyes and Pigments, 2010, 87, 209-217; (b) J. Francos, J. Borge, J. Diez, S. E. Garcia-Garrido and V. Cadierno, Catalysis Commun., 2015, 63, 10-14.

[94] C. J. Rieder, K. J. Winberg and F. G. West, J. Org. Chem., 2011, 76, 50-56.

[95] (a) E. Mattia, A. Porta, V. Merlini, G. Zanoni and G. Vidari, Chem. Eur. J., 2012, 18, 11894-11898; (b) E. Mattia, A. Porta, Z. Valiullina, G. Zanoni and G. Vidari, Eur. J. Org. Chem., 2016, 4900-4906.

[96] K. A. Nolin, R. W. Ahn, Y. Kobayashi, J. J. Kennedy-Smith and F. D. Toste, Chem. Eur. J., 2010, 16, 9555-9562.

[97] R. Dumeunier, S. Jaeckh and R. Goebel, Tetrahedron Lett., 2014, 55, 5801-5804

[98] R. S. Ramon, S. Gaillard, A. M. Z. Slawin, A. Porta, A. D'Alfonso, G. Zanoni and S. P. Nolan, Organometallics, 2010 29, 3665-3668

[99] G. Zanoni, A. D’Alfonso, A. Porta, L. Feliciani, S. P. Nolan and G. Vidari, Tetrahedron, 2010, 66, 7472-7478.

[100] R. Beretta, M. G. Gallotti, U. Pennè, A. Porta, J. F. Gil Romero, G. Zanoni and G. Vidari, J. Org. Chem., 2015, 80, 1601-1609.

[101] Y. Li, J. Huang, J. Liu, P. Yan, H. Liu, Q. Sun, X. Wang and C. Wang, Steroids, 2011, 76, 1615-1620.

[102] S. E. Kurhade, V. Siddaiah, D. Bhuniya and D. S. Reddy, Synthesis, 2013, 45, 1689-1692.

[103] V. Merlini, S. Gaillard, A. Porta, G. Zanoni, G. Vidari and S. P. Nolan, Tetrahedron Lett., 2011, 52, 1124-1127.

[104] S. Bugoni, V. Merlini, A. Porta, S. Gaillard, G. Zanoni, S P.Nolan and G. Vidari, Chem. Eur. J., 2015, 21,14068-14074.

[105] S. Bugoni, D. Boccato, A. Porta, G. Zanoni, and G. Vidari, Chem. Eur. J., 2015, 21, 791-799.

[106] J. Liu, J. Zhou, Y. Zou, Q. Wang and A. Goeke, Org. Biomol. Chem., 2020, 18, 7832-7836.

[107] S. S. Koval'skaya, N. G. Kozlov and E. A. Dikusar, Russ. J. Org. Chem., 2010, 46, 1493-1502.
[108] D. M. Hodgson, E. P. A. Talbot and B. P. Clark, Org. Lett. 2011, 13, 5751-5753

[109] (a) D. M. Hodgson, E. P. A. Talbot and B. P. Clark, Chem. Commun., 2012, 48, 6349-6350; (b) M. Egi, Y. Yamaguchi, N Fujiwara and S. Akai, Org. Lett., 2008, 10, 1867-1870.

[110] D. Oguro, N. Mori, H. Takikawa and H. Watanabe Tetrahedron, 2018, 74, 5745-5751.

[111] S. Parés, R. Alibés, M. Figueredo, J. Font and T. Parella, Eur J. Org. Chem., 2012, 1404-1417.

[112] J. Wang, W.-B. Sun, Yi.-Z. Li, X. Wang, B.-F. Sun, G.-Q. Lin and J.-P. Zou, Org. Chem. Front., 2015, 2, 674-676.

[113] W. C. Chan and K. Koide, Org. Lett., 2018, 20, 7798-7802.

[114] N. K. Swamy and S. G. Pyne, Synth. Commun., 2011, 41, 2435-2445.

[115] M. A. Arai, J. Seto, F. Ahmed, K. Uchiyama and M. Ishibashi, Synlett, 2010, 16, 2498-2502.

[116] N. Marsch, P. G. Jones and T. Lindel, Beilstein J. Org. Chem. 2015, 11, 1700-1706.

[117] N. Marsch, M. Kock and T. Lindel, Beilstein J. Org. Chem. 2016, 12, 334-342

[118] Y. Kitabayashi, T. Fukuyama and S. Yokoshima, Org. Biomol. Chem., 2018, 16, 3556-355.

[119] S. Arai, M. Nakajima, and A. Nishida, Angew. Chem. Int. Ed., 2014, 53, 5569-5572.

[120] T. Satoh, T. Adachi, K. Okano, J. Sakata and H. Tokuyama Heterocycles, 2019, 99, 310- 323.

[121] P. Persich, J. Llaveria, R.Lhermet, T. de Haro, R. Stade, A Kondoh and Alois Fürstner, Chem. Eur. J., 2013, 19, 1304713058

[122] K. Sakurai, M. Sasaki and H. Fuwa, Angew. Chem. Int. Ed. 2018, 57, 5143-5146.

[123] M. Wohland and M. E. Maier, Synlett, 2011, 11, 1523-1526.

[124] A. Riefert and M. E. Maier, Synthesis, 2018, 50, 3131-3145

[125] L. Hao, F. Wu, Z.-C. Ding, S.-X. Xu, Y.-L. Ma, L. Chen and Z. P. Zhan, Chem. Eur. J., 2012, 18, 6453-6456.

[126] L. Hao, J.-J. Hong, J. Zhu and Z.-P. Zhan, Chem. Eur. J., 2013 19, 5715-5720.

[127] X.-T Liu, Z.-C. Ding, L.-C. Ju, Z.-N. Tang, F. Wu and Z.-P Zhan, Synlett, 2017, 28, 620-624.

[128] W. Liu, H. Wang, H. Zhao, B. Li, and S. Chen, Synlett, 2015 26, 2170-2174.

[129] S. Muthusamy, K. Selvaraj and E. Suresh, Tetrahedron Lett., 2016, 57, 4829-4833.

[130] R. Qi, X.-N. Wang, K. A. DeKorver, Y. Tang, C.-C.Wang, Q. Li H. Li, M.-C. Lv, Q. Yu and R. P. Hsung, Synthesis, 2013, 45, 1749-1758.

[131] J. Qiu and R. Zhang, Org. Biomol. Chem., 2014, 12, 15561560.

[132] M. Chen, J. Peng, T. Mao and J. Huang, Org. Lett. 2014, 16 6286-6289.

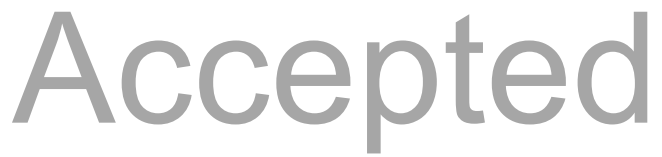




\section{Entry for the Table of Contents}

Insert graphic for Table of Contents here.

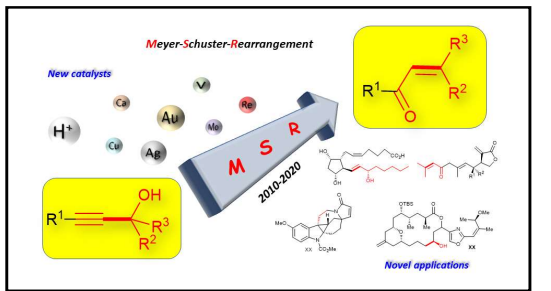

Insert text for Table of Contents here:

A century after its discovery, the Meyer-Schuster rearrangement appears as a very useful method to prepare $\alpha, \beta$-unsaturated carbonyl derivatives. This comprehensive review article highlights the progress of this reaction during the last decade focusing on the new catalysts, the novel cascade reactions, the brilliant applications in total synthesis of natural products and the first examples of azaMeyer-Schuster rearrangement. 